\title{
Desenvolvimento e Aplicação de uma Nova Fase para Extração por Sorção em Barra de Agitação (SBSE).
}

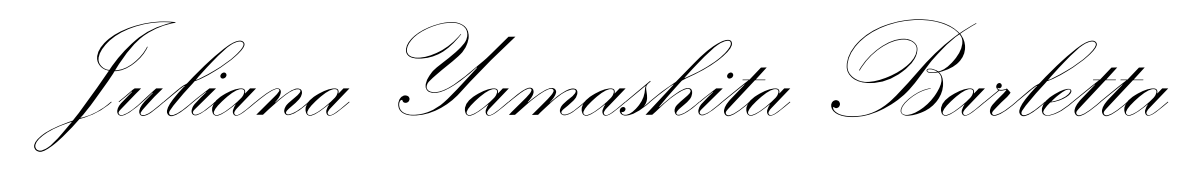

Dissertação apresentada ao Instituto de Química de São Carlos, da Universidade de São Paulo para obtenção do título de mestre em Ciências. Área de Concentração: Química Analítica

Orientador: Prof. Dr. Fernando M. Lanças

São Carlos

2010 
AUTORIZO A REPRODUÇÃo E DIVULGaÇÃO TOTAL OU PARCIAL DESTE TRABALHO, POR QUALQUER MEIO CONVENCIONAL OU ELETRÔNICO, PARA FINS DE ESTUDO E PESQUISA, DESDE QUE CITADA A FONTE. 
"Procure ser um homem de valor, em vez de ser um homem de sucesso." 


\section{AGRADECIMENTOS}

Ao Professor Dr. Fernando Mauro Lanças pela oportunidade e orientação;

Em especial, à dois grandes amigos, ao Paulo C. F. L. Gomes pela imensa colaboração no desenvolvimento deste trabalho e por toda dedicação concedida e ao Carlos E. D. Nazario pelas valiosas discussões que contribuiram neste trabalho;

À todos os colegas e funcionários do Laboratório de Cromatografia pela receptividade e auxílio. Em especial ao Prof. Dr. Álvaro J. Santos-Neto, Odete, Robson, Alcimar, Rogério, Lucas, Camila, Guilherme, Natália, Maraíssa e Meire pela amizade e ajuda;

Agradeço aos meus pais, José Antonio Barletta Júnior e Mamiko Yamashita Barletta, e ao meu irmão Fábio Yamashita Barletta pelo apoio durante toda a minha vida e principalmente com o que diz respeito à minha profissão;

Ao meu namorado Diego Ruiz de Freitas pela compreensão, apoio e paciência nas horas mais difíceis;

Aos meus amigos, que mesmo com a distância, sempre me apoiaram e me incentivaram, Ariane, Bárbara, Nathália, Vinícius e Aline;

Ao Níbio J. Mangerona pela ajuda no desenvolvimento do molde e além disso, ao longo destes anos em São Carlos tornou-se um grande amigo que terei comigo pra sempre; 
Às funcionárias da Biblioteca do IQSC e às funcionárias da Secretaria de PósGraduação, por serem sempre solícitas;

Ao CNPq pelo apoio financeiro, ao IQSC e à USP pelo apoio institucional. 


\section{RESUMO}

Uma fase polimérica inédita de polidimetilsiloxano/carvão ativado (PDMS-ACB) é proposta como fase extratora para extração por sorção em barras de agitação (SBSE). A barra de PDMS-ACB foi desenvolvida no laboratório usando um molde de teflon simples, demonstrando estabilidade e resistência aos solventes orgânicos. Utilizando uma única barra de PDMS-ACB mais de 150 extrações foram realizadas sem qualquer dano. A barra de SBSE contém aproximadamente $100 \mu \mathrm{L}$ de revestimento polimérico, 2,36 $\mathrm{mm}$ de diâmetro e 2,2 $\mathrm{cm}$ de comprimento. A barra PDMS-ACB foi aplicada na extração de seis pesticidas (ametrina, atrazina, bifentrina, carbofurano, metribuzim e tebutiurom), com propriedades predominantemente polares, comumente aplicados em plantações de cana-de-açúcar. A barra PDMS-ACB foi utilizada na determinação de pesticidas em garapa através de cromatografia gasosa hifenada à espectrometria de massa (GC-MS). O planejamento experimental foi empregado na etapa de otimização da extração SBSE, um planejamento fatorial fracionado avaliou a influência dos principais parâmetros envolvidos. Posteriormente, o planejamento composto central (CCD) com conformação estrela foi explorado para otimizar os fatores significativos na extração. Apenas $200 \mu \mathrm{L}$ de acetato de etila foram utilizados como solvente na dessorção líquida (LD). Para os compostos avaliados, o método apresentou limite de

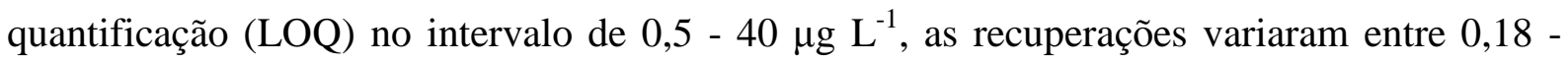
49,50 \% e a precisão intra-dia variou de 0,072 - 8,40 \% Concluída a etapa de validação, o método foi aplicado em amostras reais de garapa disponíveis comercialmente em São CarlosSP. 


\begin{abstract}
A novel polydimethylsiloxane/activated carbon (PDMS-ACB) is proposed as new polymeric phases for stir bar sorptive extraction (SBSE). The PDMS-ACB was developed in lab using simple teflon's mold, demonstrating remarkable stability and resistance to organic solvents, over 150 extractions without any damage. SBSE bar contained $100 \mu \mathrm{L}$ of polymeric coating, a diameter of $2.36 \mathrm{~mm}$ and a length of $2.2 \mathrm{~cm}$. It was applied to the determination of pesticides (ametryn, atrazine, bifenthrin, carbofuran, metribuzine and tebuthiuron) having predominantly polar properties, applied in sugarcane crops. PDMS-ACB was employed in the determination of pesticides in sugarcane juice using gas chromatography coupled to mass spectrometry (GC-MS). Experimental design was employed in the optimization step, a fractional factorial evaluated the main parameters involved in the extraction procedure. Afterwards, central composite design (CCD) was exploited to optimize the significant factors on the extraction. About $200 \mu \mathrm{L}$ of ethyl acetate were employed as solvent in the liquid desorption (LD). The method presented limit of quantification (LOQ) from 0.5 to $40 \mu \mathrm{g} \mathrm{L}^{-1}$, recoveries varied $0.18-49.50 \%$ and precision intra-day $0.072-8.40 \%$. Hence, the method was applied to the analysis of real sugarcane juice samples commercially available in São Carlos-SP.
\end{abstract}




\section{LISTA DE ILUSTRAÇÕES}

Figura 1. Gráfico da evolução da produção brasileira de cana-de-açúcar entre as safras de 1948/49 e 2008/09. Adaptado de [1].

Figura 2. Ilustração de um dispositivo utilizado em SPME.................................................. 20

Figura 3. Ilustração de uma barra de agitação para SBSE. ...................................................25

Figura 4. Comparação de eficiência de extração por SPME (PDMS: 0,5 $\mu \mathrm{L}$ ) e SBSE (PDMS:

$47 \mu \mathrm{L}$ ) em função do coeficiente de partição octanol/água, em mesmas condições

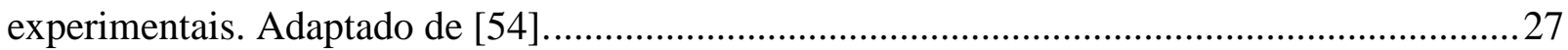

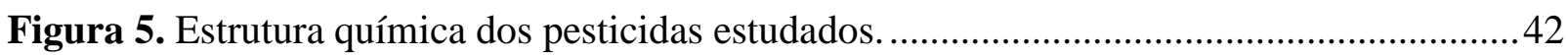

Figura 6. Molde desenvolvido anteriormente no Laboratório de Cromatografia por Nogueira [89].

Figura 7. Ilustração de um frasco utilizado na extração por SBSE

Figura 8. Cromatograma obtido através da injeção de $1 \mu \mathrm{L}$ de uma solução- padrão dos 6 analitos a $1 \mathrm{mg} \mathrm{L}^{-1}$

Figura 10. Comparação entre as barras de PDMS produzidas pelo molde antigo (à esquerda) e pelo molde novo (à direita).

Figura 11. Barra SBSE PDMS/ACB $18 \%$

Figura 12. Microscopia eletrônica de varredura da barra PDMS-ACB. (a) 100 x. (b) 500 x.

(c) $1000 \mathrm{x}$. (d) $5000 \mathrm{x}$.

Figura 13. Diagramas de Pareto mostrando os efeitos dos parâmetros avaliados para a extração por SBSE dos 6 pesticidas: (a) Ametrina, (b) Atrazina, (c) Bifentrina, (d) Carbofurano, (e) Metribuzim e (f) Tebutiruom. (continua)

Figura 14 . Superfície de resposta obtida a partir dos resultados do planejamento composto central.

Figura 15. Curva cinética da extração por SBSE dos 6 pesticidas estudados.

Figura 16. Curva de extração em relação à velocidade de agitação através da SBSE dos 6 pesticidas estudados

Figura 19. Cromatograma obtido através da injeção de uma extração no nível 3 de concentração.

Figura 20. Intervalos monitorados obtidos através da injeção de uma extração no nível 3 de concentração. (a) Tempo: 5,2 - 5,7 minutos; (b) Tempo: 5,8 - 6,5 minutos e (c) Tempo: 6,6 8,0 minutos. (continua) 


\section{LISTA DE TABELAS}

Tabela 1. Pesticidas estudados e sua classificação por ação e pela estrutura química.

Tabela 2. Valores dos LMRs dos pesticidas estudados para a cultura de cana-de-açúcar.

Tabela 3. Exemplos de revestimentos de fibra de SPME disponíveis comercialmente.

Disponível em [17]

Tabela 4. Algumas aplicações recentes de barras SBSE lab-made (continua). 29

Tabela 5. Pesticidas estudados, seus coeficientes de partição octanol-água e os íons monitorados durante as análises no modo SIM.

Tabela 6. Variáveis selecionadas para o planejamento fatorial fracionário $2^{4-1}$

Tabela 7. Variáveis avaliadas no planejamento fatorial fracionário $2^{4-1}$. 50

Tabela 8. Valores dos $\mathrm{pK}_{\mathrm{as}}$ dos pesticidas estudados. 51

Tabela 9. Variáveis avaliadas no planejamento composto central. 52

Tabela 10. Variáveis avaliadas na otimização univariada. 53

Tabela 11. Valores das variáveis utilizadas nos experimentos da validação.

Tabela 12. Valores de concentração utilizados na avaliação da linearidade. 54

Tabela 13. Valores de concentração usados para avaliação da precisão. 56

Tabela 14. Valores de concentração utilizados na avaliação da recuperação.

Figura 17. Cromatograma obtido através da injeção de uma extração de uma garapa livre de fortificação no modo SIM.

Tabela 15. Resultados da linearidade para os 6 pesticidas estudados. 73

Figura 18. Curvas de calibração e seus respectivos gráfico de resíduos para os 6 pesticidas estudados. (continua)

Figura 18. Curvas de calibração e seus respectivos gráfico de resíduos para os 6 pesticidas estudados. (continua)

Tabela 16. Dados obtidos da Precisão intra-ensaio para os 6 pesticidas estudados. 76 
Tabela 17. Dados obtidos da Recuperação para os 6 pesticidas estudados. 79

Tabela 18. Dados obtidos de Limites de Quantificação (LOQ) e Detecção (LOD) para os

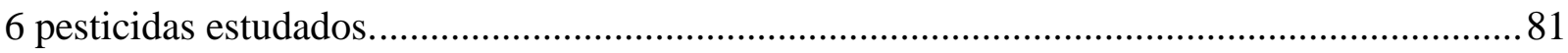

Tabela 19. Resíduos de pesticidas encontrados em garapas disponíveis comercialmente........82 


\section{SUMÁRIO}

\section{RESUMO}

\section{ABSTRACT}

LISTA DE FIGURAS

LISTA DE TABELAS

1. INTRODUÇÃO

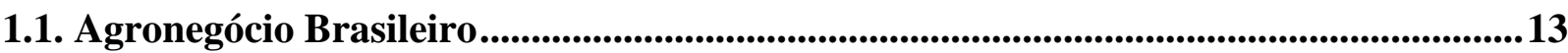

1.1.1. Cana-de-açúcar ...............................................................................................................................13

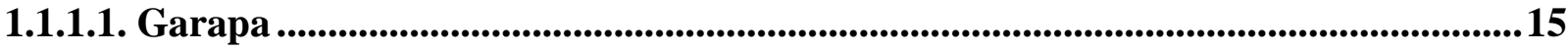

1.1.2. Pesticidas ............................................................................................................................................. 16

1.1.3. Limite Máximo de Resíduo (LMR) .......................................................................17

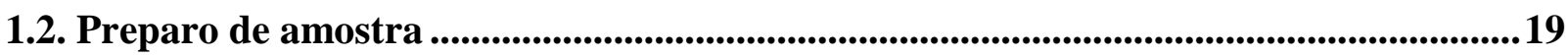

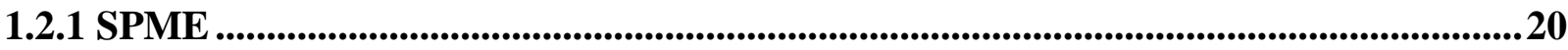

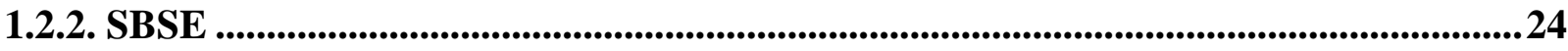

1.2.3. Novas fases para SBSE.......................................................................................................28

1.3. Planejamento e Otimização Experimental ..............................................................35

1.3.1. Planejamento Fatorial Fracionário......................................................................36

1.3.2. Planejamento Composto Central (CCD) .....................................................................37

1.3.3. Superfície de resposta....................................................................................................................38

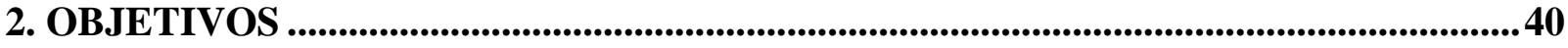

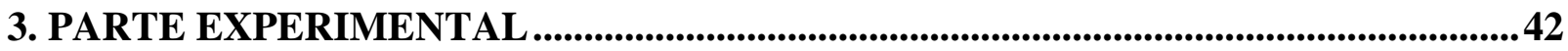

3.1. Padrões e Reagentes ...................................................................................................42

3.2. Equipamentos e Materiais ..................................................................................................................43

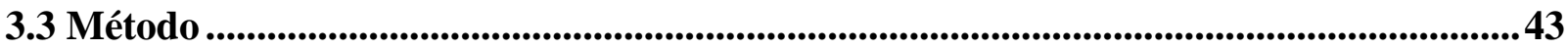


3.3.1. Condições Cromatográficas......................................................................................................43

3.3.2. Desenvolvimento do molde de Teflon ........................................................................44

3.3.3. Preparo da barra SBSE PDMS-ACB ....................................................................45

3.3.4. Amostras de garapa............................................................................................................46

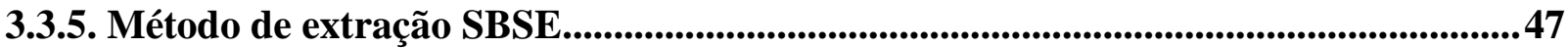

3.3.6. Planejamento e Otimização Experimental ..............................................................................48

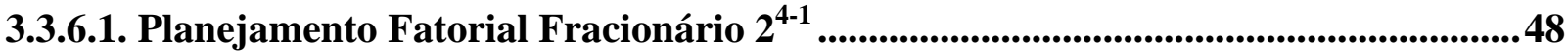

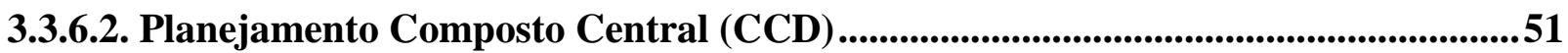

3.3.6.3. Otimização univariada ...........................................................................................................52

3.3.7. Validação ................................................................................................................................53

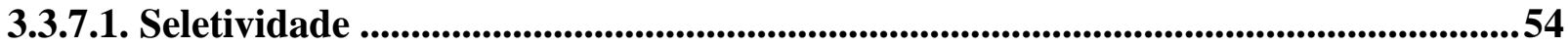

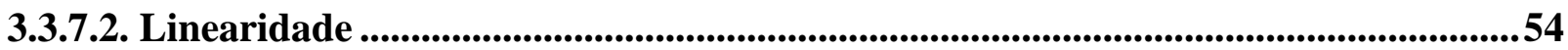

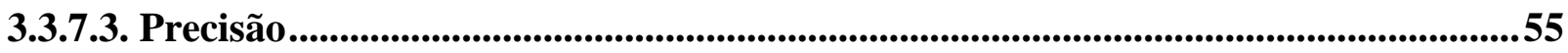

3.3.7.4. Recuperação/Exatidão ..............................................................................................................56

3.3.7.5. Limites de Detecção (LOD) e de Quantificação (LOQ) ...............................................57

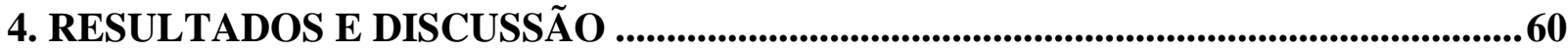

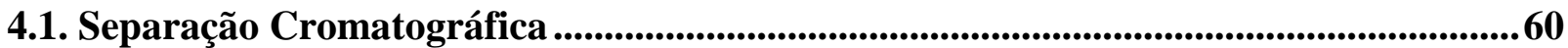

4.2. Desenvolvimento do molde de teflon..............................................................................61

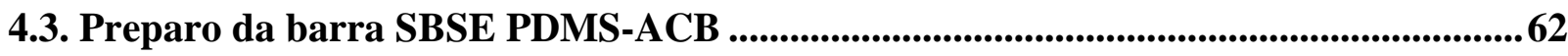

4.4. Caracterização da barra PDMS-ACB ........................................................................................63

4.5. Planejamento e Otimização Experimental ...........................................................................65

4.5.1. Planejamento Fatorial Fracionário $2^{4-1}$....................................................................65

4.5.2. Planejamento Composto Central (CCD) ..................................................................69

4.5.3. Otimização univariada ................................................................................................................70

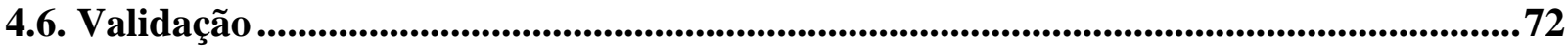


4.6.1. Seletividade 72

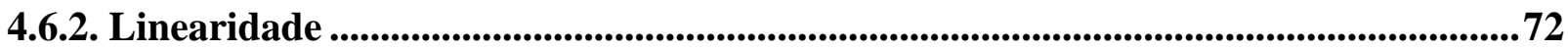

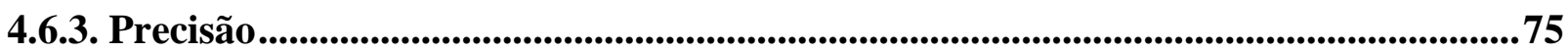

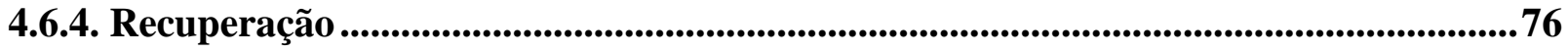

Acredita-se que a bifentrina apresentou valores baixos de recuperação devido a sua baixa polaridade $\left(\log K_{o / w}>6\right)$ [90] e sua estrutura química ser volumosa. Em processos adsorptivos é comum acontecer competição pelos sítios extrativos. Em virtude de possuir uma cadeia muito grande, a bifentrina, migrava lentamente para os poros em relação aos demais analitos, dessa maneira grande parte dos poros já continham os analitos o que causava a baixa eficiência na extração desse composto....................................................80

4.6.5. Limites de Detecção (LOD) e de Quantificação (LOQ) ..................................................80

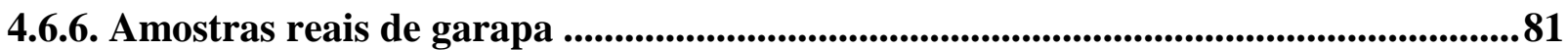

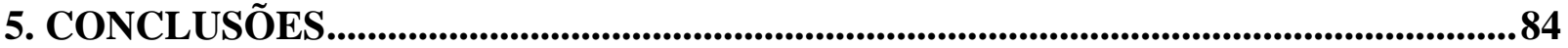

REFERÊNCIAS BIBLIOGRÁFICAS

PRODUÇÃO CIENTÍFICA 


\section{1}

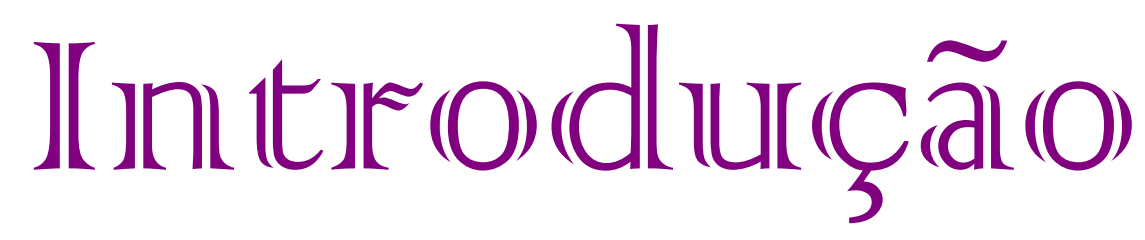




\section{INTRODUÇÃO}

\subsection{Agronegócio Brasileiro}

Desde 1970, a agricultura enfrenta o desafio de atender à crescente demanda por alimentos e energia renovável, entre outros produtos de origem agrícola. Devido ao crescimento da população mundial, à diminuição de áreas disponíveis para a agricultura, e ao aumento do número de pessoas que migram do campo para as regiões urbanas, surgiu a necessidade de desenvolver novas tecnologias e insumos que permitam aumentar a produtividade agrícola.

Atualmente, com a crescente industrialização da agricultura, produzir em grande quantidade já não é mais o principal objetivo. Além da quantidade, o mercado consumidor exige que se produza com qualidade, ou seja, o alimento não deve apresentar riscos à saúde humana na forma de resíduos de pesticidas e de contaminantes. Deste modo, é de suma importância que a produção dos alimentos seja realizada de forma correta, buscando garantir a máxima segurança dos alimentos ofertados para consumo.

\subsubsection{Cana-de-açúcar}

As primeiras mudas de cana-de-açúcar foram trazidas ao Brasil em 1532 na expedição de Martin Afonso de Souza. Devido ao clima tropical e ao solo fértil brasileiro, o cultivo da planta propagou-se rapidamente e hoje representa um dos principais produtos do agronegócio brasileiro. A Figura 1 ilustra um gráfico sobre o crescimento da produção brasileira de canade-açúcar, em milhões de toneladas, entre as safras 1948/49 até a de 2008/09. 


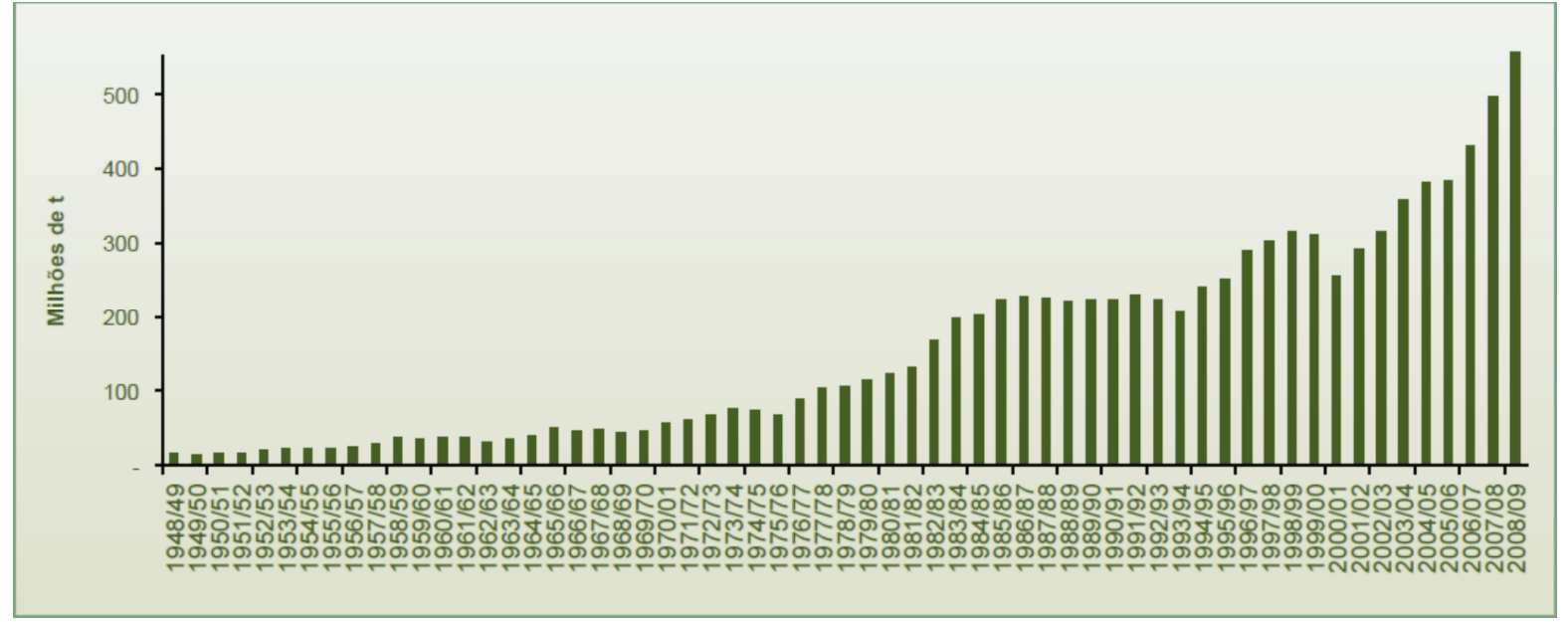

Figura 1. Gráfico da evolução da produção brasileira de cana-de-açúcar entre as safras de 1948/49 e 2008/09. Adaptado de [1].

Atualmente, o Brasil é o maior produtor mundial de cana-de-açúcar, seguido por Índia, Tailândia e Austrália, segundo a UNICA (União da Indústria da Cana-de-açúcar) [2]. A produção total de cana-de-açúcar moída, para a safra de 2010/11, está prevista em 664.333,4 mil toneladas, apresentando um aumento de 9,9 \% em relação a safra 2009/10. Deste total de cana-de-açúcar, 45,4 \% será destinada à produção de açúcar e 54,6 \% à produção de álcool anidro e hidratado [2]. De acordo com a Conab (Companhia Nacional de Abastecimento), a área colhida no Brasil, na primeira safra 2010/11, está estimada em 8.091,5 mil hectares. O estado de São Paulo é o maior produtor com 54,35 \% (4.397,5 mil hectares), seguido por Minas Gerais com 8 \% (647,7 mil hectares) e Paraná com 7,5 \% (607,9 mil hectares) [3]. Esta elevada produção deve-se, entre outros fatores, ao grande consumo de insumos agrícolas, como os pesticidas, nesta cultura. Segundo a Sindag, em 2009 somente cinco culturas foram responsáveis por $80 \%$ da demanda nacional de pesticidas, sendo que a cultura de cana-deaçúcar foi uma delas com $8 \%$ desse total [4].

A cana-de-açúcar é uma planta que pertence ao gênero Saccharum L., sendo composta por $65-75 \%$ de água, $11-18 \%$ de açúcares, 8 - $14 \%$ de fibras e 12 - $23 \%$ de sólidos solúveis. Do total de açúcares, a sacarose está presente numa faixa de concentração entre 70 a 
$91 \%$, seguida da glicose e da frutose (entre 2 a $4 \%$ cada uma) [5]. Assim, esta é empregada principalmente como matéria prima para a fabricação de açúcar e álcool, e também para a produção de aguardente, rapadura, caldo de cana (garapa) e melado.

\subsubsection{Garapa}

Garapa ou caldo de cana é o líquido extraído da moagem da cana-de-açúcar. A garapa é uma bebida típica do Brasil, geralmente presente em barracas de feira, podendo ser consumida in natura ou misturada com frutas cítricas, como, abacaxi ou limão. A garapa, devido a sua composição rica em carboidratos, é uma excelente fonte de energia [6]. A bebida conserva todos os nutrientes presentes na cana-de-açúcar, (como os minerais: ferro, cálcio, potássio, sódio, fósforo e magnésio) além do fato de ser uma fonte de antioxidantes como ácidos fenólicos e flavonóides [7].

Por esses motivos, em 2004 a garapa foi tema de uma pesquisa realizada no Laboratório de Bioquímica do Exercício, do Instituto de Biologia e do Departamento de Alimentos e Nutrição, da Faculdade de Engenharia de Alimentos da Unicamp. O objetivo da pesquisa foi comprovar a eficiência do consumo de garapa por atletas, jogadores de futebol das categorias de base da Associação Atlética Ponte Preta, em relação ao seu rendimento físico e a sua recuperação da massa muscular. Os resultados divulgados até o momento são positivos e o próximo passo da pesquisa é transformar a garapa em pó para que possa ser consumida não só no Brasil [6].

Somente outros dois trabalhos utilizando a garapa como amostra foram encontrados na literatura. Zuin et al. [8] em 2006, compararam dois métodos de extração: extração com solvente assistida por membrana (MASE) e extração por sorção em barras de agitação (SBSE) para a extração de 18 resíduos de contaminantes orgânico em garapa usando GC-MS. Para a técnica SBSE os valores de limite de deteção (LOD) foram de $0,002-0,71 \mu \mathrm{g} \mathrm{L}^{-1}$ enquanto 
que para MASE essa faixa variou entre 0,004 a $0,56 \mu \mathrm{g} \mathrm{L}{ }^{-1}$. Em 2009, Tfouni et al. [9] desenvolveram um método de extração líquido-líquido (LLE) de quatro PAHs (hidrocarbonetos policíclicos aromáticos) na garapa através da cromatografia líquida com detector de fluorescência (HPLC-FLU). Os valores de LOD determinados ficaram entre 0,004 - 0,009 $\mu \mathrm{g} \mathrm{kg}^{-1}$. Neste trabalho foram analisadas oitenta amostras garapa, provenientes de Ribeirão Preto e Campinas.

\subsubsection{Pesticidas}

Os pesticidas, (também chamados de: defensivos agrícolas, agrotóxicos, agroquímicos, defensivos químicos ou praguicidas) são substâncias químicas utilizadas na agricultura com a finalidade de controlar alguns fatores prejudiciais às culturas, como, ervas daninhas, ácaros, fungos, insetos, entre outros. Estes podem ser classificados de acordo com a sua ação; desta maneira são chamados de inseticidas, herbicidas, nematicidas, fungicidas e assim por diante. Outra maneira de classificá-los, quanto a sua estrutura química, é em clorados, fosforados, carbamatos, piretróides, entre outros. Os pesticidas estudados e sua classificação por ação e pela estrutura química são apresentados na Tabela 1 .

Tabela 1. Pesticidas estudados e sua classificação por ação e pela estrutura química.

\begin{tabular}{|c|c|c|}
\hline Pesticida & Classificação (ação) ${ }^{\mathrm{a}}$ & Classificação (estrutura química) \\
\hline Ametrina & Herbicida & Triazina \\
\hline Atrazina & Herbicida & Triazina \\
\hline Bifentrina & Inseticida, acaricida e formicida & Piretróide \\
\hline Carbofurano & $\begin{array}{c}\text { Acaricida, inseticida, nematicida e } \\
\text { cupinicida }\end{array}$ & Carbamato \\
\hline Metribuzim & Herbicida & Triazinona \\
\hline Tebutiurom & Herbicida & Uréia \\
\hline
\end{tabular}


O mercado de pesticidas no Brasil, em 2009, foi de US\$ 6,6 bilhões (R\$ 12,9 bilhões). Deste valor, o mercado de herbicidas representou 38\% (US\$ 2,5 bilhões), seguido por inseticidas e acaricidas, com $31 \%$ (US\$ 2,1 bilhões), fungicidas com $27 \%$ (US\$ 1,8 bilhões) e outros com 4\% (US\$ 0,3 bilhões), segundo o Sindicato Nacional de Indústria de Produtos para Defesa Agrícola (SINDAG) [11].

É incontestável que o mercado de pesticidas é importante para a economia brasileira, o que se torna preocupante é a aplicação indiscriminada desses podutos nas culturas dos alimentos. Se as Boas Práticas Agrícolas (BPA) forem seguidas corretamente, as contaminações pelos pesticidas podem ser evitadas. Deste modo, alguns cuidados devem ser tomados, como ler e atender as recomendações do rótulo e da bula, verificar o número correto de aplicações e quais as dosagens recomendadas para determinada cultura. É também importante cumprir o intervalo de confiança ou período de carência de cada pesticida, que é o intervalo de tempo adequado entre a última aplicação do pesticida e a colheita do alimento para a sua comercialização. Além disso, os agricultores que aplicam os pesticidas devem utilizar as roupas e acessórios adequados, para sua segurança. Porém, o uso incorreto ou indiscriminado de pesticidas na agricultura pode ocasionar a contaminação dos alimentos e do ambiente pela presença de seus resíduos, afetando à saúde humana direta ou indiretamente.

\subsubsection{Limite Máximo de Resíduo (LMR)}

O Limite Máximo de Resíduo (LMR) é a quantidade máxima de resíduos de pesticidas permitida legalmente no alimento, geralmente expresso em $\mathrm{mg}$ da substância por $\mathrm{kg}$ do alimento. Para o estabelecimento do LMR dois estudos devem ser avaliados. O primeiro é a Ingestão Diária Aceitável (IDA), que é a quantidade máxima de uma substância que uma pessoa pode ingerir por dia, durante toda a sua vida, sem que cause danos à saúde. 
A IDA depende da toxicidade do pesticida e da dieta da população em relação à este alimento e é representado por mg da substância por kg da pessoa que o ingere. Para maior segurança humana, dois indicadores de segurança são adicionados, um primeiro fator 10 que é para garantir que o ser humano não será afetado e um segundo fator 10 o qual considera que existam pessoas mais sensíveis do que outras. Então, a IDA é multiplicada 100 vezes e um valor de LMR é proposto. O segundo estudo consiste em verificar se os níveis de resíduos de pesticidas presentes nos alimentos quando as BPAs forem atendidas, estão abaixo do LMR proposto anteriormente. Caso positivo, o LMR é estabelecido.

Na Tabela 2, são apresentados os valores dos LMRs dos pesticidas estudados para a cultura de cana-de-açúcar, já que não existe uma norma regulamentadora com os LMRs para a garapa, assim como para suco de frutas.

\subsection{4. Órgãos Regulamentadores}

O Codex Alimentarius foi criado em 1963 pelas organizações Food and Agriculture Organization (FAO) e Word Health Organization (WHO) para elaborar normas e guias de segurança alimentar. As normas Codex foram criadas com o intuito de uniformizar as normas alimentares estabelecidas por vários países, promovendo o comércio justo de alimentos entre eles, e para proteger a saúde do consumidor.

Tabela 2. Valores dos LMRs dos pesticidas estudados para a cultura de cana-de-açúcar.

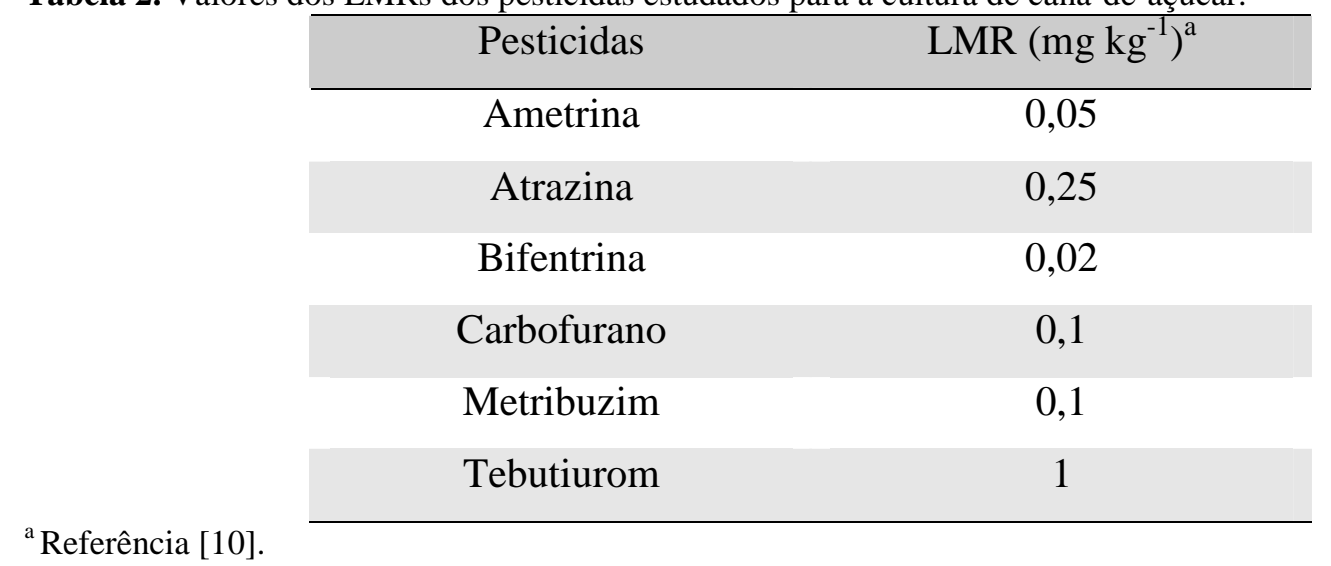


No Brasil, dois órgãos federais são responsáveis por fiscalizar e normatizar o processo produtivo dos alimentos: o Ministério da Agricultura, Pecuária e do Abastecimento (MAPA) e a Agência Nacional de Vigilância Sanitária (ANVISA). Em 2001, com intuito de monitorar a qualidade e segurança dos alimentos em relação aos resíduos de pesticidas, a ANVISA iniciou um projeto de análise de resíduos de agrotóxicos em alimentos, o qual se consolidou no Programa de Análise de Resíduos de Agrotóxicos em Alimentos (PARA), através da RDC 119 em 2003.

O monitoramento de resíduos de pesticidas tem como principais objetivos assegurar que a população consuma alimentos saudáveis e seguros, e favorecer a comercialização dos alimentos nacional ou internacionalmente. Por isso, o desenvolvimento de pesquisas para a determinação de resíduos de pesticidas nos alimentos é de máxima relevância.

\subsection{Preparo de amostra}

O preparo de amostras complexas envolve várias etapas como, extração, clean-up e ajuste de concentração.,Além de ser a etapa da análise que requer maior tempo, é também a parte mais susceptível à introdução de erros [12]. Em análises cromatográficas, a etapa de clean-up é importante pois elimina os compostos que fazem parte da amostra mas que não são de interesse e podem prejudicar o resultado. Além disso, evita o acúmulo de sujeiras no sistema de injeção e retira possíveis contaminantes que poderiam coeluir com o analito de interesse.

Para o preparo de amostras, técnicas clássicas de extração, como a extração líquidolíquido (LLE) e a extração com soxhlet, foram e ainda são utilizadas [13]. A LLE ocorre por partição e é baseada na solubilidade dos analitos no solvente de extração. A amostra complexa é colocada em um funil de separação, juntamente com um solvente orgânico no qual os analitos sejam solúveis. O funil de separação é agitado para que os analitos de interesse 
passem para a fase orgânica, que então é separada da amostra e concentrada para posterior análise. Porém, esta técnica requer grandes volumes de amostra e, consequentemente, de solvente, para ganho de sensibilidade.

Em busca da redução do tempo gasto no preparo de amostra e do consumo de amostra e de solventes orgânicos, a miniaturização das técnicas de extração tornou-se uma tendência na química analítica. Além disso, a miniaturização permite a automação da técnica e, assim, possibilita o acoplamento on-line com técnicas cromatográficas.

\subsubsection{SPME}

Em 1990 foi introduzida por Pawliszyn e colaboradores [14] , uma técnica de extração miniaturizada, denominada microextração em fase sólida (SPME). A SPME é baseada na sorção dos analitos presentes na amostra através de uma fibra de sílica fundida revestida externamente com uma fina camada polimérica. A fibra de SPME é fixa em um suporte, como mostra a Figura 2, a qual pode ser inserida diretamente na amostra (modo direto) ou utilizada no modo headspace.

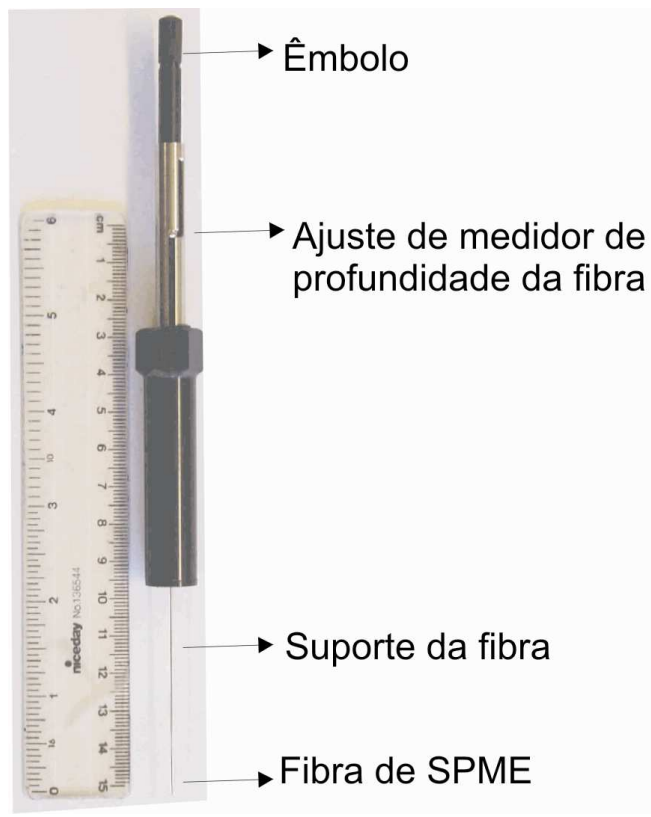

Figura 2. Ilustração de um dispositivo utilizado em SPME. 
No modo direto os analitos não voláteis ou semi-voláteis difundem-se diretamente da amostra para o revestimento da fibra, enquanto que no modo headspace os analitos voláteis presentes na fase gasosa difundem-se no revestimento da fibra, que se encontra fora da solução, ocorrendo então o fenômeno da partição. Este modo tem como principal vantagem a maior durabilidade da fibra, pois possíveis contaminantes presentes na amostra não entram em contato com a fibra. Há ainda um meio termo entre esses dois modos: a extração indireta. Nesse modo, a fibra é protegida por uma membrana, que tem como principal finalidade proteger a fibra do contato direto com amostras extremamente complexas [15].

A extração por SPME ocorre através da transferência de massa entre as fases, amostra, fibra e headspace até que o equilíbrio de partição seja atingido. Deste modo, sua teoria baseiase na cinética de transferência de massa entre as fases e na termodinâmica que descreve o equilíbrio de partição [16]. A quantidade de analito extraído no sistema em equilíbrio pode ser calculada de uma forma simplificada, como mostra a equação 1 , considerando um sistema constituído somente da amostra e da fase extratora da fibra:

$$
n_{0}=n_{a}^{e}+n_{f}^{e}
$$

em que:

$n_{o}$ é a quantidade total de analito extraído no sistema em equilíbrio;

$n_{a}{ }^{e}$ é a quantidade de analito presente na amostra no sistema em equilíbrio;

$n_{f}^{e}$ é a quantidade de analito presente na fase extratora da fibra no sistema em equilíbrio.

Como o particionamento é dependente do equilíbrio de concentração, deste modo a equação 1 pode ser modificada na equação 2 :

$$
C_{0} \cdot V_{a}=C_{a}^{e} \cdot V_{a}^{e}+C_{f}^{e} \cdot V_{f}^{e}
$$

onde:

$C_{o}$ é a concentração inicial da amostra; 
$V_{a}$ é o volume total da amostra;

$C_{a}$ é a concentração da amostra no sistema em equilíbrio;

$C_{f}$ é a concentração da fase extratora da fibra no sistema em equilíbrio;

$V_{f}$ é o volume da fase extratora.

Assim pode-se definir, através da equação 3, o coeficiente de partição da fase de extração e da amostra $\left(k_{f a}\right)$ como:

$$
k_{f a}=\frac{C_{f}^{d}}{C_{a}^{d}}
$$

Substituindo $C_{f}^{e}$ por $k_{f a} \cdot C_{a}{ }^{e}$ (equação 3 ) e rearranjando os termos da equação 2 podemos calcular a quantidade de analito extraído pela fibra no equilíbrio $\left(n_{0}{ }^{e}\right)$ com a equação 4:

$$
n_{0}^{*}=\frac{\left(k_{f a} \cdot V_{f} \cdot C_{0} \cdot V_{a}\right)}{\left(k_{f a} \cdot V_{f}+V_{a}\right)}
$$

Então, pode-se concluir que a quantidade extraída do analito no equilíbrio é independente do tempo de extração. Em outras palavras, uma vez atingido o equilíbrio a quantidade extraída será a mesma, dentro dos limites de erro experimental. Outro fato que também pode ser concluído através da equação 4 é que se $V_{a}>k_{f a .} V_{f}$, então temos que:

$$
n_{0}^{*}=k_{f a} \cdot V_{f} \cdot C_{0}
$$

Portanto, através da equação 5 pode-se realizar uma análise quantitativa, já que a quantidade de analito extraída pela fibra está linearmente relacionada com a concentração inicial do analito na amostra.

A eficiência da extração por SPME é influenciada por diversos fatores como o tipo da fase de revestimento da fibra, volume da amostra, força iônica, $\mathrm{pH}$, temperatura, velocidade de agitação, tempo de extração, além das condições da dessorção térmica ou liquida. Idealmente o tempo de extração deve ser suficiente para que o equilíbrio de distribuição dos 
analitos seja atingido. Porém esse tempo pode ser excessivamente longo e, neste caso, pode ser introduzida a agitação magnética para acelerar o processo de difusão dos analitos.

A SPME apresenta diversas vantagens como utilizar pouco ou nenhum solvente orgânico, simplicidade na sua utilização, possibilidade de total automação, rapidez, seletividade, sensibilidade e custo relativamente baixo. Dependendo da complexidade da amostra, das condições experimentais, e do cuidado no seu manuseio, as fibras podem ser reutilizada diversas vezes. Além disso, atualmente diversos tipos de revestimento de fibras para SPME são disponíveis comercialmente (Tabela 3).

Tabela 3. Exemplos de revestimentos de fibra de SPME disponíveis comercialmente. Disponível em [17].

\begin{tabular}{ccc}
\hline Revestimento & Espessura $(\mu \mathbf{L})$ & Aplicação \\
\hline Polidimetilsiloxano (PDMS) & 100 & Compostos apolares \\
& 30 & Compostos de média a alta polaridade \\
Poliacrilato (PA) & 7 & (fenóis, pesticidas organofosforados, \\
& 85 & cetonas, álcoois) \\
Polidimetilsiloxano/divinilben & 65 & Compostos de baixa a alta polaridade \\
zeno & 60 & (aminas e compostos nitroaromáticos) \\
(PDMS/DVB) & 75 & Hidrocarbonetos, Compostos \\
Carboxen/polidimetilsiloxano & & Orgânicos Voláteis (VOCs) \\
(CAR/PDMS) & 65 & Compostos de média a alta polaridade \\
(fenóis, pesticidas organofosforados, & \\
\hline $\begin{array}{c}\text { Carbowax/divinilbenzeno } \\
\text { (CW/DVB) }\end{array}$ & & cetonas, álcoois) \\
\hline $\begin{array}{l}\text { Divinilbenzeno/carboxen/ } \\
\text { (D) }\end{array}$ & $50 / 30$ & Compostos de Aromas \\
\hline
\end{tabular}


Atualmente, a SPME em conjunto com a cromatografia gasosa e líquida tem sido aplicada com êxito em diversas áreas, como a forense [18, 19], alimentícia [20-27], farmacêutica [28, 29] e ambiental [30-34]. Entretanto, a principal limitação da técnica SPME é a pequena quantidade de fase polimérica presente no revestimento da fibra. Como exemplo, a fibra mais comumente utilizada de PDMS $(100 \mu \mathrm{m})$ possui um volume polimérico de 0,5 $\mu L$. Então, com o intuito de aumentar a quantidade de fase extratora e, consequentemente, a quantidade dos analitos extraída, foi desenvolvida a extração por sorção em barra de agitação (SBSE).

\subsubsection{SBSE}

A extração por sorção em barra de agitação (SBSE) foi desenvolvida por Baltussen e colaboradores em 1999 [35]. A SBSE é uma técnica similar a SPME, porém ao invés de fibras revestidas utiliza-se uma barra de agitação magnética recoberta com uma fase extratora, originalmente, o polidimetilsiloxano (PDMS). Este é o polímero mais utilizado em técnicas de extração por sorção porque apresenta diversas vantagens, como, ser inerte e possuir estabilidade térmica $\left(-100^{\circ} \mathrm{C}-350^{\circ} \mathrm{C}\right)$ e mecânica [35].

A barra SBSE é constituída por um magneto envolvido por uma camada de vidro que é revestida por um filme polimérico, como mostra a seguir a Figura 3. Assim como a SPME, são possíveis dois modos de extração: modo direto e no modo headspace. Após atingir o equilíbrio de partição dos analitos de interesse entre a fase extratora e a amostra, a barra SBSE é retirada do frasco com ajuda de uma haste metálica, no caso do modo direto, enxaguada cuidadosamente com água deionizada e enxugada delicadamente com um papel absorvente macio a fim de remover moléculas de água e outros componentes da amostra não voláteis. 


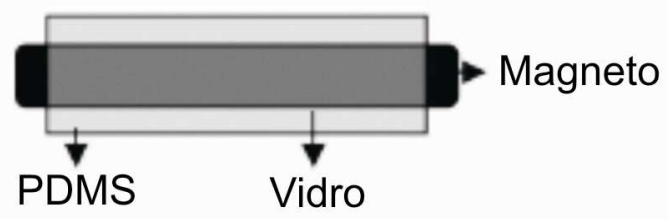

Figura 3. Ilustração de uma barra de agitação para SBSE.

A dessorção dos analitos pode ser térmica (TD) ou através de um líquido (LD). Na TD, a barra é colocada dentro de um tubo de vidro o qual é inserido na unidade de dessorção térmica para que os analitos sejam dessorvidos, criofocados e analisados por cromatografia gasosa. No processo LD a barra SBSE é colocada em um pequeno tubo contendo alguns $\mu \mathrm{L}$ de solvente orgânico adequado para a dessorção dos analitos e assim podem ser analisados por cromatografia líquida. As condições experimentais da SBSE podem ser otimizadas de forma análoga as da SPME.

Assim como a SPME, a SBSE apresenta diversas vantagens como utilizar um pequeno volume de amostra, facilidade de sua aplicação, utilização de pouco ou nenhuma quantidade de solvente orgânico, possibilidade de automação. Por isso, tem sido aplicada com sucesso em diversas matrizes e em diferentes classes de compostos, incluindo alimentos [36-40], amostras ambientais [41-50] e na área farmacêutica [51, 52].

A SBSE baseia-se nos mesmos princípios de equilíbrio da SPME. Utilizando o PDMS como fase extratora pode-se relacionar o coeficiente de distribuição octanol/água $\left(\mathrm{K}_{\mathrm{o} / \mathrm{w}}\right)$ com o coeficiente de partição da barra SBSE. Portanto, a eficiência da extração em PDMS diminui com o aumento da polaridade do analito. De uma forma generalizada os compostos que apresentam $\log \mathrm{K}_{\mathrm{o} / \mathrm{w}}>3$ são considerados apolares e com $\log \mathrm{K}_{\mathrm{o} / \mathrm{w}}<3$ são polares. $\mathrm{O}$ equilíbrio de sorção é diretamente proporcional a quantidade de PDMS na fase extratora, como se pode observar na equação 6 [53]:

$$
K_{o / w} \approx K_{P D M S / w}=\frac{C_{P D M S}}{C_{w}}=\frac{V_{w} \cdot m_{P D M S}}{V_{P D M S} \cdot m_{w}}=\frac{\beta \cdot m_{P D M S}}{m_{w}}
$$


em que:

$K_{P D M S / w}$ é o coeficiente de partição do analito entre as fases PDMS e aquosa;

$C_{P D M S}$ é a concentração do analito na fase PDMS no equilíbrio;

$C_{w}$ é a concentração do analito na fase aquosa no equilíbrio;

$m_{P D M S}$ é a massa do analito na fase PDMS;

$V_{w}$ é o volume da amostra;

$m_{w}$ é a massa do analito na fase aquosa;

$V_{P D M S}$ é o volume da fase extratora;

$\beta$ é a razão entre $V_{w} / V_{P D M S}$.

A massa inicial do analito presente na amostra $\left(m_{o}\right)$ pode ser descrita pela equação 7:

$$
m_{0}=m_{\text {PDMS }}+m_{\mathrm{w}}
$$

Rearranjando as equações 6 e 7, pode-se dizer que:

$$
m_{w}=\frac{\beta . m_{P D M S}}{K_{P D M S}}
$$

Deste modo, se os valores de $K_{o / w}$ e de $\beta$ são conhecidos, pode-se estimar o fator de recuperação através da equação 9:

$$
\frac{m_{P D M S}}{m_{0}}=\frac{\frac{K_{P D M S / w}}{\beta}}{\left[1+\left(\frac{K_{P D M S}}{\beta}\right)\right]}
$$

De acordo com a equação 9, quanto maior a quantidade de fase extratora $\left(V_{P D M S}\right)$, menor será o $\beta$ e assim maior será a eficiência da extração. Então, a SBSE apresenta uma maior eficiência de extração do que a SPME já que uma barra de PDMS apresenta um volume de 24 e $219 \mu \mathrm{L}$ enquanto que a fibra mais comumente utilizada apresenta $0,5 \mu \mathrm{L}$. A Figura 4 ilustra a comparação da eficiência das técnicas SBSE (PDMS: $47 \mu \mathrm{L}$ ) e SPME (PDMS: 0,5 $\mu \mathrm{L}$ ) em função dos $\log \mathrm{K}_{\mathrm{o} / \mathrm{w}}$, nas mesmas condições experimentais [54]. 


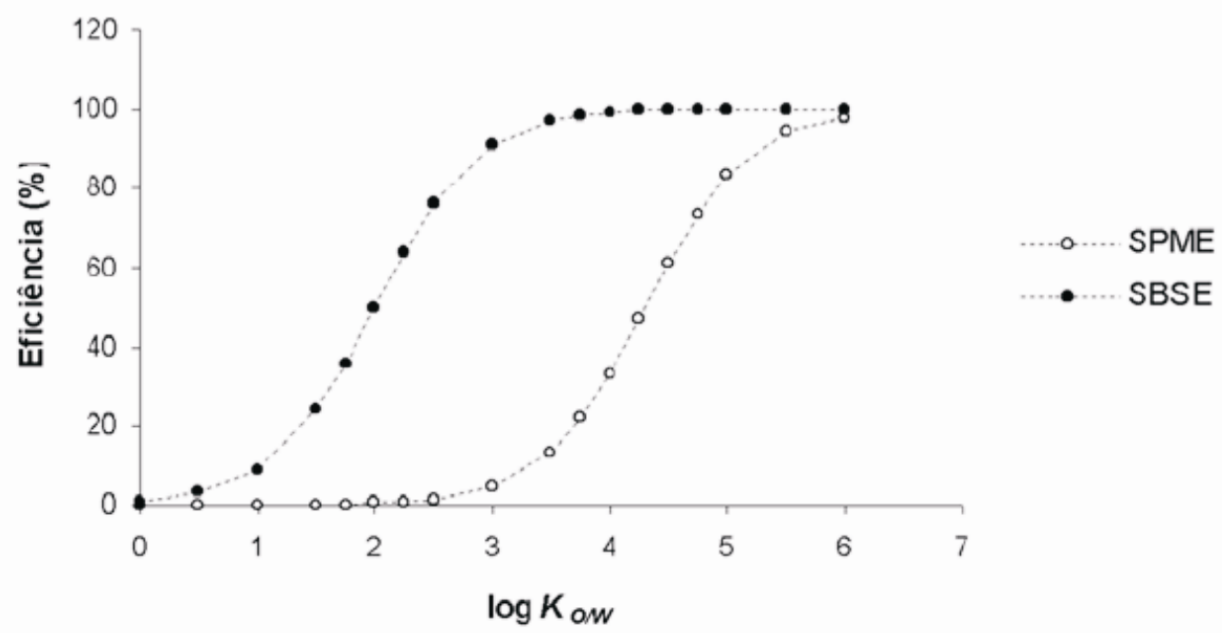

Figura 4. Comparação de eficiência de extração por SPME (PDMS: 0,5 $\mu \mathrm{L}$ ) e SBSE (PDMS: $47 \mu \mathrm{L}$ ) em função do coeficiente de partição octanol/água, em mesmas condições experimentais. Adaptado de [54].

$\mathrm{Na}$ literatura diversos estudos relatam a comparação entre a SPME e SBSE e alguns deles mostram que a SBSE é uma técnica de extração mais sensível do que a SPME. Blasco et al. [55] mostraram resultados que para análise de seis inseticidas organofosforados em mel utilizando LC-MS, a SBSE apresenta maior sensibilidade e exatidão do que a SPME. De Jager et al. [56] apresentaram resultados que mostram que a SBSE é uma técnica de extração mais sensível do que a SPME na análise de tetrametileno de dissulfotetramina em diferentes matrizes (água, suco, molho de maçã, iogurte, manteiga de amendoim, ervilhas, atum e batata frita) usando GC-MS. Maggi et al. [57] estudaram a eficiência da extração de halofenóis e haloanisóis em matrizes aquosas (vinho, suco de limão e água) comparando SBSE e SPME como técnica de extração e determinação e quantificação por GC-MS/MS e verificaram que SBSE é a técnica mais sensível.

Porém, a SBSE apresenta uma limitação em relação à SPME: somente barras de PDMS são disponíveis comercialmente. Deste modo, para a extração eficiente de compostos com características polares é necessário realizar derivatização. Contudo, isto não é desejável, pois aumenta uma etapa no processo de extração. A fim de contornar essa limitação, desde 
2004, diversos trabalhos na literatura apresentam o desenvolvimento de novas fases poliméricas com características polares para SBSE.

\subsubsection{Novas fases para SBSE}

Atualmente diversas fases extratoras mais seletivas têm sido desenvolvidas com o intuito de tornar a SBSE mais abrangente e versátil, chamadas de barras SBSE lab-made, as quais apresentam eficiência na extração de compostos polares sem o uso da derivatização in situ. Os recobrimentos das barras SBSE lab-made podem ser feitos utilizando diversas técnicas. A Tabela 4 apresenta uma visão geral de trabalhos atuais encontrados na literatura. 
Tabela 4. Algumas aplicações recentes de barras SBSE lab-made (continua).

\begin{tabular}{|c|c|c|c|c|c|}
\hline Ano & Analito(s) & $\operatorname{Amostra}(\mathbf{s})$ & Barra SBSE lab-made & LOQ ou LOD & Referência \\
\hline 2004 & $\begin{array}{l}8 \text { n-alcanos } \\
16 \text { PAHs } \\
14 \text { OPPs }\end{array}$ & Amostras aquosas & $\begin{array}{c}\text { Sol-gel } \\
\text { hydroxy-terminated PDMS }\end{array}$ & $\begin{array}{c}\text { GC-FID } \\
\text { LOD: } 0,74-7,44 n g \mathrm{~L}^{-1}\end{array}$ & [58] \\
\hline 2005 & $\begin{array}{c}\text { Cafeína } \\
3 \text { Metabólitos }\end{array}$ & Plasma de rato & $\begin{array}{c}\text { RAM } \\
\mathrm{C}_{18^{-}} \text {alkyl-diol-silica (ADS) }\end{array}$ & $\begin{array}{c}\text { HPLC-UV } \\
\text { LOD: } 75 \mathrm{ng} \mathrm{mL}^{-1} \\
\text { LOQ: } 75 \mathrm{~g} \mathrm{ng} \mathrm{mL}^{-1}\end{array}$ & [59] \\
\hline 2005 & $\begin{array}{l}15 \text { Compostos polares e } \\
\text { voláteis (Café) } \\
13 \text { Compostos polares e } \\
\text { voláteis (Sálvia) }\end{array}$ & $\begin{array}{l}\text { Café } \\
\text { Sálvia }\end{array}$ & $\begin{array}{c}\text { Fase dupla } \\
\text { PDMS/materiais adsorventes } \\
\text { (Carbopack B, Carbopack C, } \\
\text { Carbosieve e Carboxen) }\end{array}$ & $\begin{array}{c}\text { GC-MS } \\
\text { (Não apresentou) }\end{array}$ & [60] \\
\hline 2006 & 10 OPPs & Solo & $\begin{array}{c}\text { MIP } \\
\text { Nylon-6 }\end{array}$ & $\begin{array}{c}\text { GC-NPD } \\
\text { LOD: } 12-24 \mu \mathrm{g} \mathrm{kg}^{-1}\end{array}$ & [61] \\
\hline 2007 & $\begin{array}{c}8 \text { PAHs (Água do mar): } \\
4 \text { anabolizantes - esteróides } \\
\text { (Urina) }\end{array}$ & $\begin{array}{c}\text { Água do mar } \\
\text { Urina Poly } \\
\text { (vinylpyridine- } \\
\text { ethylene } \\
\text { dimethacrylate) }\end{array}$ & $\begin{array}{l}\text { Material monolítico } \\
\text { Poly (methacrylic acid } \\
\text { stearyl ester-ethylene } \\
\text { dimethacrylate) }\end{array}$ & $\begin{array}{c}\text { HPLC-DAD } \\
\text { LOD: } 1,86-6,61 \mathrm{pg} \mathrm{mL}^{-1} \\
\text { (Água do mar) } \\
\text { LOD: } 62,3-212 \mathrm{pg} \mathrm{mL}^{-1} \text { (Urina) }\end{array}$ & {$[62]$} \\
\hline
\end{tabular}


Tabela 4. Algumas aplicações recentes de barras SBSE lab-made (continuação).

\begin{tabular}{|c|c|c|c|c|c|}
\hline Ano & Analito(s) & Amostra(s) & Barra SBSE lab-made & LOQ ou LOD & Referência \\
\hline 2007 & $\begin{array}{c}4 \text { Estrógenos } \\
\text { (Água de rio e lago) } \\
\text { Bisfenol A (Água para } \\
\text { consumo humano) }\end{array}$ & $\begin{array}{l}\text { Água de rio e lago } \\
\text { Água para consumo } \\
\text { humano }\end{array}$ & $\begin{array}{c}\text { Sol-gel } \\
\text { PDMS- } \beta-C D \text { (ciclodextrina) }\end{array}$ & $\begin{array}{l}\text { HPLC-UV (Estrógenos) } \\
\text { LOD: } 0,04-0,11 \mu g \mathrm{~L}^{-1} \\
\text { HPLC-FLU (Bisfenol A) } \\
\text { LOD: } 8 \mathrm{ng} \mathrm{L}^{-1}\end{array}$ & {$[63]$} \\
\hline 2007 & $\begin{array}{c}7 \text { Retardadores de chama } \\
\text { bromados }\end{array}$ & $\begin{array}{l}\text { Solo } \\
\text { Poeira }\end{array}$ & $\begin{array}{c}\text { Sol-gel } \\
\text { PDMS- } \beta-C D\end{array}$ & $\begin{array}{c}\text { HPLC-UV } \\
\text { LOD: } 2,9-4,2 \mu \mathrm{g} \mathrm{L}^{-1}\end{array}$ & [64] \\
\hline 2007 & $\begin{array}{c}\text { Atrazina } \\
\text { 2,3,4,5-tetraclorofenol } \\
\text { fluoreno }\end{array}$ & Amostras aquosas & $\begin{array}{l}\text { Polimerização } \\
\text { Poliuretana }\end{array}$ & $\begin{array}{c}\text { HPLC-DAD } \\
\text { GC-MS } \\
\text { (Não apresentou) }\end{array}$ & {$[65]$} \\
\hline 2007 & $\begin{array}{l}\text { Mistura de (13 - café, } 19 \text { - } \\
\text { sálvia e } 11 \text { - água) } \\
\text { compostos com diferentes } \\
\text { solubilidade em água, } \\
\text { acidez, polaridade e } \\
\text { volatilidade }\end{array}$ & $\begin{array}{c}\text { Café arábica torrado } \\
\text { Sálvia seca } \\
\text { Água }\end{array}$ & $\begin{array}{l}\text { Fase dupla PDMS/materiais } \\
\text { adsorventes (Tenax GC, } \\
\text { copolímero bisfenol-PDMS, } \\
\text { Carbopack com } 5 \% \text { de } \\
\text { Carbowax e } \beta-C D \text { ) }\end{array}$ & $\begin{array}{c}\text { GC-MS } \\
\text { (Não apresentou) }\end{array}$ & [66] \\
\hline
\end{tabular}

\section{HPLC-DAD}

20087 Herbicidas (triazinas)

Água

Polimerização

Poliuretana

LOD: $0,1-0,5 \mu \mathrm{g} \mathrm{L}{ }^{-1}$

LOQ: $0,5-1,7 \mu \mathrm{g} \mathrm{L}^{-1}$ 
Tabela 4. Algumas aplicações recentes de barras SBSE lab-made (continuação).

\begin{tabular}{|c|c|c|c|c|c|}
\hline Ano & Analito(s) & Amostra(s) & Barra SBSE lab-made & LOQ ou LOD & Referência \\
\hline 2008 & $\begin{array}{l}6 \text { Fármacos ácidos } \\
\text { (reguladores de lipídeo e } \\
\text { antiinflamatórios não } \\
\text { esteróides) }\end{array}$ & $\begin{array}{c}\text { Água de rio, mar e } \\
\text { resíduais }\end{array}$ & $\begin{array}{l}\text { Polimerização } \\
\text { Poliuretana }\end{array}$ & $\begin{array}{c}\text { HPLC-DAD } \\
\text { LOD: } 0,4-1,3 \mu \mathrm{g} \mathrm{L}^{-1} \\
\text { LOQ: } 1,5-4,2 \mu \mathrm{g} \mathrm{L} \mathrm{L}^{-1}\end{array}$ & {$[68]$} \\
\hline 2008 & 6 Fenóis polares & Água de lago e mar & $\begin{array}{c}\text { Material monolítico } \\
\text { Poly (vinylpyridine-ethylene } \\
\text { dimethacrylate) }\end{array}$ & $\begin{array}{c}\text { HPLC-DAD } \\
\text { LOD: } 0,98-2,57 \mu g \mathrm{~L}^{-1} \\
\text { LOQ: } 3,28-8,5 \mu \mathrm{g} \mathrm{L}^{-1}\end{array}$ & [69] \\
\hline 2008 & 6 Hormônios sexuais & Urina & $\begin{array}{l}\text { Material monolítico } \\
\text { Poly (methacrylic acid stearyl } \\
\text { ester-ethylene dimethacrylate) }\end{array}$ & $\begin{array}{c}\text { HPLC-DAD } \\
\text { LOD: } 0,062-0,38 \mu \mathrm{g} \mathrm{L}^{-1} \\
\text { LOQ: } 0,2-1,2 \mu \mathrm{g} \mathrm{L}^{-1}\end{array}$ & {$[70]$} \\
\hline 2008 & $\begin{array}{c}4 \text { Organoclorados } \\
\text { (Água do mar) } \\
4 \text { OPPs (Sucos de uva e } \\
\text { pêssego) }\end{array}$ & $\begin{array}{l}\text { Água do mar } \\
\text { Sucos de uva e } \\
\text { pêssego }\end{array}$ & $\begin{array}{c}\text { Precipitação por imersão } \\
\text { Poly(phthalazine ether sulfone } \\
\text { ketone) }\end{array}$ & $\begin{array}{c}\text { GC-ECD } \\
\text { LOD: } 0,05-2,53 \mathrm{ng} \mathrm{L^{-1 }} \\
\text { (Água do mar) } \\
\text { GC-TSD } \\
\text { LOD: } 0,17-2,25 \mathrm{ng} \mathrm{L^{-1 }} \\
\text { (Suco de uva) } \\
\text { LOD: } 2,47-10,3 \text { ng.L }{ }^{-1} \\
\text { (Suco de pêssego) }\end{array}$ & [71] \\
\hline
\end{tabular}


Tabela 4. Algumas aplicações recentes de barras SBSE lab-made (continuação).

\begin{tabular}{|c|c|c|c|c|c|}
\hline Ano & Analito(s) & $\operatorname{Amostra}(s)$ & Barra SBSE lab-made & LOQ ou LOD & Referência \\
\hline 2009 & 6 Antidepressivos & Plasma humano & $\begin{array}{c}\text { Polimerização } \\
\text { PDMS/Polipirrol }\end{array}$ & $\begin{array}{c}\text { HPLC-UV } \\
\text { LOD: } 5-20 \mathrm{ng} \mathrm{mL}^{-1} \\
\text { LOQ: } 20-50 \mathrm{ng} \mathrm{mL}^{-1}\end{array}$ & {$[72]$} \\
\hline 2009 & 5 OPPs & Mel & $\begin{array}{c}\text { Sol-gel } \\
\text { PDMS/Poly(vinylalcohol) }\end{array}$ & $\begin{array}{c}\text { GC-FPD } \\
\text { LOD: } 0,013-0,081 \mu \mathrm{g} \mathrm{L}^{-1}\end{array}$ & [73] \\
\hline 2009 & $\begin{array}{c}3 \text { PAHs (Água de lago) } \\
4 \text { PASHs (Solo) }\end{array}$ & $\begin{array}{l}\text { Água de lago } \\
\text { Solo }\end{array}$ & $\begin{array}{c}\text { Dumbbell-shaped } \\
\text { PDMS/ } \beta-C D \\
\text { PDMS/DVB (divinilbenzeno) } \\
\text { PDMS/ } \beta-C D / D V B\end{array}$ & $\begin{array}{c}\text { HPLC-UV } \\
\text { LOD: } 0,007-0,103 \mu \mathrm{g} \mathrm{L}^{-1}\end{array}$ & {$[74]$} \\
\hline 2009 & 8 Fenóis polares & $\begin{array}{c}\text { Água de torneira, mar } \\
\text { e residual }\end{array}$ & $\begin{array}{c}\text { Material monolítico } \\
\text { Poly(vinylpyrrolididone-DVB) }\end{array}$ & $\begin{array}{c}\text { HPLC-DAD } \\
\text { LOD: } 0,72-1,37 \mathrm{ng} \mathrm{mL}{ }^{-1} \\
\text { LOQ: } 2,40-4,27 \mathrm{ng} \mathrm{mL} \mathrm{mL}^{-1}\end{array}$ & {$[75]$} \\
\hline 2009 & $\begin{array}{l}7 \text { Hormônios, } 5 \text { aminas } \\
\text { aromáticas e } 9 \text { fenóis }\end{array}$ & Amostras aquosas & $\begin{array}{c}\text { Material monolítico } \\
\text { Poly(vinylpyrrolididone-DVB) }\end{array}$ & $\begin{array}{c}\text { HPLC-DAD } \\
\text { LOD: } 0,036-0,24 \mathrm{ng} \mathrm{mL}^{-1}\end{array}$ & {$[76]$} \\
\hline 2009 & $\begin{array}{l}5 \text { Antibactericida - } \\
\text { sulfonamidas }\end{array}$ & Leite & $\begin{array}{c}\text { Material monolítico } \\
\text { Poly (vinylimidazole-DVB) }\end{array}$ & $\begin{array}{c}\text { HPLC-DAD } \\
\text { LOD: } 1,30-7,90 \mathrm{ng} \mathrm{mL} \mathrm{m}^{-1} \\
\text { LOQ: } 4,29-26,3 \mathrm{ng} \mathrm{mL}^{-1}\end{array}$ & {$[77]$} \\
\hline 2009 & 7 Hormônios sexuais & Água residual & $\begin{array}{c}\text { Material monolítico } \\
\text { Poly(vinylpyridine-ethylene } \\
\text { dimethacrylate) }\end{array}$ & $\begin{array}{c}\text { HPLC-DAD } \\
\text { LOD: } 0,061-0,41 \mathrm{ng} \mathrm{mL}^{-1} \\
\text { LOQ: } 0,20-1,37 \mathrm{ng} \mathrm{mL}^{-1}\end{array}$ & {$[78]$} \\
\hline
\end{tabular}


Tabela 4. Algumas aplicações recentes de barras SBSE lab-made (continuação)

\begin{tabular}{|c|c|c|c|c|c|}
\hline Ano & Analito(s) & Amostra(s) & Barra SBSE lab-made & LOQ ou LOD & Referência \\
\hline 2009 & 5 PAAs & Água de lago e mar & $\begin{array}{c}\text { Material monolítico } \\
\text { Poly (vinylimidazole-DVB) }\end{array}$ & $\begin{array}{c}\text { HPLC-DAD } \\
\text { LOD: } 0,09-0,28 \mu g \mathrm{~L}^{-1} \\
\text { LOQ: } 0,37-1,15 \mu \mathrm{g} \mathrm{L} \mathrm{L}^{-1}\end{array}$ & [79] \\
\hline 2010 & 4 Quinolonas & Amostras aquosas & $\begin{array}{c}\text { Material monolítico } \\
\text { Poly(methacrylic acid-3- } \\
\text { sulfopropyl ester potassium } \\
\text { salt-DVB) }\end{array}$ & $\begin{array}{c}\text { HPLC-DAD } \\
\text { LOD: } 0,37-0,56 \mu g \mathrm{~L}^{-1} \\
\text { LOQ: } 1,22-1,86 \mu g \mathrm{~L}^{-1}\end{array}$ & {$[80]$} \\
\hline 2010 & 4 Ânions inorgânicos & Água purificada & $\begin{array}{l}\text { Material monolítico } \\
\text { Poly(2-methacryloyloxy)ethyl } \\
\text { trimelammonium chloride-co- } \\
\text { DVB) }\end{array}$ & $\begin{array}{c}\text { IC-CD } \\
\text { LOD: } 0,92-2,62 \mu \mathrm{g} \mathrm{L}^{-1} \\
\text { LOQ: } 3,03-9,25 \mu \mathrm{g} \mathrm{L}{ }^{-1}\end{array}$ & {$[81]$} \\
\hline 2010 & 9 Herbicidas - triazinas & $\begin{array}{c}\text { Arroz, maçã, alface e } \\
\text { solo }\end{array}$ & $\begin{array}{c}\text { MIP } \\
\text { Terbutilazina }\end{array}$ & $\begin{array}{c}\text { HPLC-UV } \\
\text { LOD: } 0,04-0,12 \mu g \mathrm{~L}^{-1}\end{array}$ & {$[82]$} \\
\hline 2010 & 6 Sulfoniluréias & $\begin{array}{l}\text { Água de torneira } \\
\text { Solo }\end{array}$ & $\begin{array}{c}\text { MIP } \\
\text { Nicosulfuron }\end{array}$ & $\begin{array}{c}\text { HPLC-UV } \\
\text { LOD: } 0,04-0,12 \mu \mathrm{g} \mathrm{L}^{-1} \text { (Água de } \\
\text { torneira) } \\
\text { LOD: } 0,04-0,12 \mu \mathrm{g} \mathrm{L}^{-1} \text { (Solo) }\end{array}$ & [83] \\
\hline 2010 & $\begin{array}{c}\text { Isoxsuprina, clenbuterol e } \\
\text { ractopamina }\end{array}$ & $\begin{array}{c}\text { Carne suína, fígado e } \\
\text { ração }\end{array}$ & $\begin{array}{c}\text { MIP } \\
\text { Ractopamina }\end{array}$ & $\begin{array}{l}\text { HPLC-UV e HPLC-FLU } \\
\text { LOD: } 0,1-0,21 \mu g \mathrm{~L}^{-1}\end{array}$ & [84] \\
\hline
\end{tabular}


Tabela 4. Algumas aplicações recentes de barras SBSE lab-made (conclusão).

$\begin{array}{ccccc}\text { Ano } & \text { Analito(s) } & \text { Amostra(s) } & \text { Barra SBSE } \text { lab-made } & \text { LOQ ou LOD } \\ & & \text { Água de torneira, rio e } & \text { Polimerização } & \text { HPLC-DAD } \\ 2010 & 5 \text { Metabólitos triazínicos } & \text { subterrânea } & \text { Poliuretana } & \text { LOD: } 0,4-1,3 \mu g L^{-1} \\ & & & & \text { LOQ: } 1,3-4,4 \mu g L^{-1}\end{array}$

Referência

por ionização de chama, RAM: material de acesso restrito, $\mathrm{C}_{18}$ : octadecil silano, HPLC UV: cromatografia líquida de alta eficiência com detector ultravioleta, GC-MS cromatografia gasosa com detector de espectrometria de massas, MIP: polímero molecularmente impresso, GC-NPD: cromatografia gasosa com detector de nitrogênio fósforo, HPLC-FLU: cromatografia líquida de alta eficiência com detector por fluorescência, HPLC-DAD: cromatografia líquida de alta eficiência com detector de díodos, GC-ECD: cromatografia gasosa com detecção por captura de elétrons, GC-TSD: cromatografia gasosa com detector termoiônico específico, GC-FPD: cromatografia gasosa com detecção fotométrica de chama, PASHs: heterociclos aromáticos policíclicos de enxofre , PAA: amina aromática polar, IC-CD: cromatografia iônica com detector de condutividade. 


\subsection{Planejamento e Otimização Experimental}

A otimização de um método analítico, geralmente requer o ajuste de um número elevado de variáveis. Isto pode ser feito através de dois modos: univariado e multivariado. O modo univariado é quando somente uma variável é modificada até que se encontre a sua melhor resposta, enquanto que as demais são mantidas fixas. Este procedimento é feito até que todos os fatores forneçam a melhor resposta. Porém, este modo apresenta as seguintes desvantagens: é necessário um elevado número de experimentos, consumindo assim muitos materiais, reagentes e tempo. Além disso, o modo univariado não investiga as interações entre as variáveis.

Em contrapartida, no modo multivariado todas as variáveis de interesse são variadas ao mesmo tempo. Deste modo, é possível avaliar efeitos de dois tipos: principais e de interação. O efeito principal é causado por uma das variáveis quando seus níveis variam de um valor para outro, enquanto que o efeito de interação é causado pela interação das variáveis, que pode ser de segunda, terceira ou de ordem superior, dependendo do número de fatores selecionados. É de extrema importância estudar o efeito de interação porque em alguns casos o valor ideal de uma variável pode depender do valor de outra [86].

Recentemente, o planejamento experimental tem sido muito utilizado na otimização de um procedimento analítico pois permite que os experimentos sejam realizados e analisados de uma forma econômica e eficaz. Utilizando-o, é possível extrair o máximo de informações realizando um número mínimo de experimentos.

Inicialmente deve-se selecionar as variáveis importantes para o sistema estudado para assim avaliar quantitativamente como elas e suas interações influenciam a resposta. Os valores dos fatores, ou seja, os níveis que cada fator será estudado nos experimentos devem ser especificados. Os experimentos devem ser executados de forma a efetuar todas as 
possíveis combinações dos níveis das variáveis, onde cada experimento é um ensaio experimental. Os ensaios são realizados variando-se pelo menos dois níveis de cada fator.

É chamado de planejamento fatorial $2^{\mathrm{k}}$, se houver $\mathrm{k}$ fatores sendo investigados em dois níveis. Para realizar um planejamento fatorial de dois níveis serão necessários, no mínimo, $2^{\mathrm{k}}$ ensaios distintos. Em geral, os níveis superior e inferior são representados por (+) e (-), respectivamente. A fim de estimar o erro experimental sem realizar todo o planejamento em replicata, e verificar se há falta de ajuste, pode-se incluir experimentos no ponto central (nível zero) no qual todas as variáveis se encontram em seu valor médio. Os ensaios devem ser realizados em ordem aleatória, para evitar que os erros incomuns sejam associados às combinações de níveis.

No entanto, o número de ensaios necessários para a execução de um planejamento fatorial completo aumenta rapidamente com k. Desta forma, por um planejamento fatorial completo de dois níveis com $\mathrm{k} \geq 4$ serão necessários $2^{\geq 4}$ ensaios, um número bastante elevado. Neste caso, é realizado um planejamento fatorial fracionário, em que um número menor de ensaios é necessário e, geralmente, pode-se determinar os efeitos principais e de interações mais importantes [86].

\subsubsection{Planejamento Fatorial Fracionário}

O planejamento fatorial fracionário permite que somente uma parte dos ensaios de um planejamento fatorial completo seja realizada, diminuindo o número de experimentos. Isto é possível porque mesmo que o número de efeitos de interações aumente com o número de fatores, esses efeitos apresentam valores baixos e podem ser desconsiderados. Além disso, conforme aumenta o número de variáveis a possibilidade de que uma ou mais variáveis não afetem significativamente a resposta também cresce. 
O planejamento fatorial fracionário é utilizado para determinar quais as variáveis que afetam significativamente a resposta. Através deste, é possível verificar a necessidade ou não de realizar mais experimentos e completar o planejamento. Caso os resultados iniciais indiquem que poucas variáveis estudadas são significativas, pode-se mudar os níveis estudados ou acrescentar novas variáveis ao planejamento [86].

Após essa etapa, as variáveis que afetam significativamente a resposta são selecionadas e uma metodologia de análise de superfície de respostas é executada para a otimização do experimento. Um dos planejamentos mais utilizados para ajustar modelos quadráticos é o Planejamento Composto Central (CCD - Central Composite Design)

\subsubsection{Planejamento Composto Central (CCD)}

O planejamento composto central é uma ampliação do planejamento fatorial. Isto pode ser feito através de uma rotação de $45^{\circ}$ em relação à orientação de partida do planejamento inicial. Então, os novos pontos terão uma distância de $2^{1 / 2}$ do ponto central. Os valores desses fatores são calculados segundo a equação 10 [87]:

$$
x_{i}=\frac{\left(z_{i}-\bar{z}\right)}{\frac{\Delta z}{2}}
$$

em que:

$x_{i}$ é o valor do planejamento CCD,

$z_{i}$ é o valor experimental do nível,

$\bar{z}$ é o valor médio entre os níveis superior (+) e inferior (-), que é exatamente o valor do nível zero (0);

$\Delta z$ é a diferença entre os níveis mais (+) e menos (-).

As superfícies de resposta são utilizadas para ilustrar graficamente a relação entre as variáveis e as respostas encontradas após a aplicação do planejamento CCD. 


\subsubsection{Superfície de resposta}

Na década de 1950, G. E. P. Box introduziu a metodologia de superfície de resposta (RSM - Response Surface Methodology) como uma técnica de otimização baseada no uso de planejamento fatorial [86]. A superfície de resposta é a função que descreve como as variáveis influenciam a resposta, mostrando informações a respeito do comportamento das variáveis na região estudada. Esta metodologia pode ser realizada em duas etapas, modelagem e deslocamento as quais podem realizadas quantas vezes se achar necessário até atingir uma região ótima (máxima ou mínima) da superfície [88]. 
2

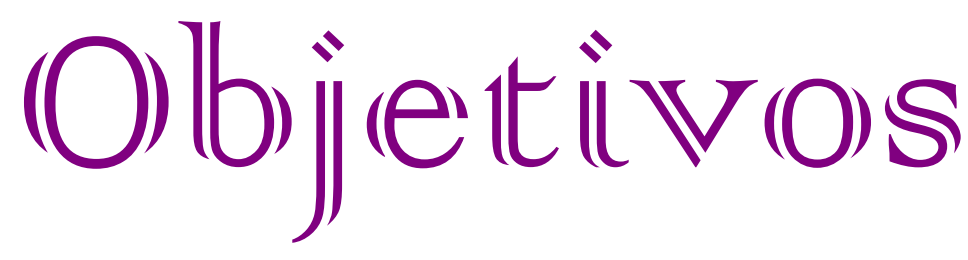




\section{OBJETIVOS}

ثै Aprimorar a confecção de um molde simples de teflon para o desenvolvimento de barras SBSE com diversos recobrimentos.

¿ Desenvolver um novo recobrimento para barra SBSE com características polares já que somente PDMS, fase apolar, é disponível comercialmente.

is Desenvolver e otimizar um método, utilizando planejamento fatorial fracionado e planejamento composto central, para extração de resíduos de pesticidas (ametrina, atrazina, bifentrina, carbofurano, metribuzim e tebutiurom) em garapa através de SBSE e GC-MS.

is Validar o método desenvolvido segundo critérios aceitos internacionalmente avaliando os parâmetros: linearidade, precisão, recuperação, limite de detecção e limite de quantificação.

¿ Aplicar o método em amostras reais de garapa disponíveis comercialmente em São Carlos - SP. 


$$
\text { 了) }
$$

\section{P'alletie}

Exprereiunnernitall 


\section{PARTE EXPERIMENTAL}

\subsection{Padrões e Reagentes}

Os padrões analíticos dos pesticidas ametrina, atrazina, bifentrina, carbofurano, metribuzim e tebutiurom, foram obitidos da Sigma-Aldrich (Steinheim, Alemanha). As estruturas dos analitos estão representadas na Figura 5.

As soluções estoque foram preparadas em acetonitrila em uma concentração de $100 \mu \mathrm{g}$ $\mathrm{mL}^{-1}$. As soluções de trabalho foram preparadas semanalmente, a partir de diluições das soluções estoque, em acetonitrila. Estas foram armazenadas a $4{ }^{\circ} \mathrm{C}$, em frasco âmbar e utilizadas no processo de fortificação das amostras de garapa.

O metanol e a acetonitrila, grau HPLC, foram adquiridos da Tedia (Fairfield, USA). O cloreto de sódio, acetato de sódio trihidratado, acetato de etila, ácido acético e ácido clorídrico foram obtidos da J.T. Baker (Phillipsbourg, USA). O carbono ativado e o carbonato de sódio foram adquiridos da Synth (Diadema, Brazil). O bicarbonato de sódio foi obtido da Merck (Darmstadt, Germany).

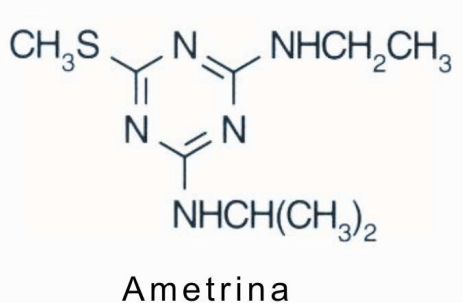

Ametrina<smiles>CCNc1nc(Cl)nc(NC(C)C)n1</smiles>

Atrazina

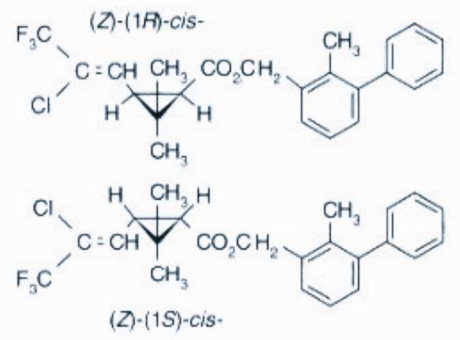

Bifentrina<smiles>CC(=O)Oc1cccc2c1OC(C)(C)C2</smiles>

Carbofurano<smiles>CCCCSc1nnc(C)c(=O)n1N</smiles>

Metribuzim<smiles>CNC(=O)N(C)c1nnc(C(C)(C)C)s1</smiles>

Tebutiurom

Figura 5. Estrutura química dos pesticidas estudados. 
O PDMS Sylgard 184 e seu agente de cura foram obtidos da Dow Corning Corporation (Midland, USA).

A água ultrapura foi obtida do sistema Elga Ultra OS purification (High Wycombe, UK).

\subsection{Equipamentos e Materiais}

is Sistema GC-MS QP5000, Shimadzu

is $\mathrm{pH}$-metro, Micronal

\& Centrífuga LS-3 plus, Celm

is Agitador magnético, Corning

is Lavadora Ultra-sônica Ultra Clear, Unique

¿t Balança analítica AG285, Mettler Toledo

is Banho termostático, Quimis

is Filtro de papel, F.Maia

\subsection{Método}

\subsubsection{Condições Cromatográficas}

As análises foram realizadas utilizando-se uma coluna de sílica fundida RTX-5MS (5 $\%$ difenil / $95 \%$ dimetil polisiloxano, $15 \mathrm{~m} \times 0.25 \mathrm{~mm} \times 0.25 \mu \mathrm{m}$ ) da Restek (Bellefonte, USA). A programação de temperatura utilizada iniciou-se em $120^{\circ} \mathrm{C}$, que foi mantida por 2 minutos, aumentada a uma taxa de $30^{\circ} \mathrm{C} \min ^{-1}$ até $210^{\circ} \mathrm{C}$ e aumento com taxa de $55^{\circ} \mathrm{C} \min ^{-1}$ até $280^{\circ} \mathrm{C}$, permanecendo nesta temperatura por 2 minutos, resultando em um tempo total de análise de 8 minutos. 
Como gás de arraste utilizou-se hélio a um fluxo de $0,7 \mathrm{~mL} \min ^{-1}$. A temperatura da interface foi de $300^{\circ} \mathrm{C}$ e do injetor de $265^{\circ} \mathrm{C}$. As injeções foram realizadas no modo splitless, com volume injetado de $1 \mu \mathrm{L}$. O espectrômetro de massas foi operado no modo de impacto de elétrons a $70 \mathrm{eV}$. As análises foram realizadas no modo SIM, sendo que os tempos de retenção, os coeficientes de partição octanol-água $\left(\log \mathrm{K}_{\mathrm{o} / \mathrm{w}}\right)$ e os íons monitorados de cada analitos estão apresentados na Tabela 5.

\subsubsection{Desenvolvimento do molde de Teflon}

Anteriormente, no Grupo de Cromatografia, um molde de teflon foi desenvolvido por Nogueira et al. [89] cujo desenho é mostrado na Figura 6. A fim de dar continuidade à este estudo, foram feitos alguns testes com novas fases poliméricas utilizando esse mesmo molde. Porém, alguns problemas foram observados, como a baixa reprodutibilidade na confecção de barras e baixo volume polimérico, cerca de $22 \mu \mathrm{L}$. Além disso, como o molde apresenta uma grande quantidade de teflon o qual é um bom isolante térmico, o interior do molde não atingia a temperatura programada no forno. Desta forma, não foi possível a síntese de algumas fases poliméricas que exigem alta temperatura para a polimerização.

Tabela 5. Pesticidas estudados, seus coeficientes de partição octanol-água e os íons monitorados durante as análises no modo SIM.

\begin{tabular}{cccc}
\hline Compostos & $\begin{array}{c}\text { Tempo de retenção } \\
(\min )\end{array}$ & $\log \mathrm{K}_{\mathrm{o} / \mathrm{w}}{ }^{\mathrm{a}}$ & Ílons monitorados $^{\mathrm{b}}$ \\
\hline Carbofurano & 5,40 & 1,52 & $164,149,131$ \\
Atrazina & 5,42 & 2,5 & $200,173,215$ \\
Metribuzim & 5,92 & 1,6 & $212,170,227$ \\
Ametrina & 6,00 & 2,5 & $198,144,103$ \\
Tebutiurom & 5,99 & 1,82 & $156,171,158$ \\
Bifentrina & 7,67 & $>6$ & $181,166,165$ \\
\hline
\end{tabular}




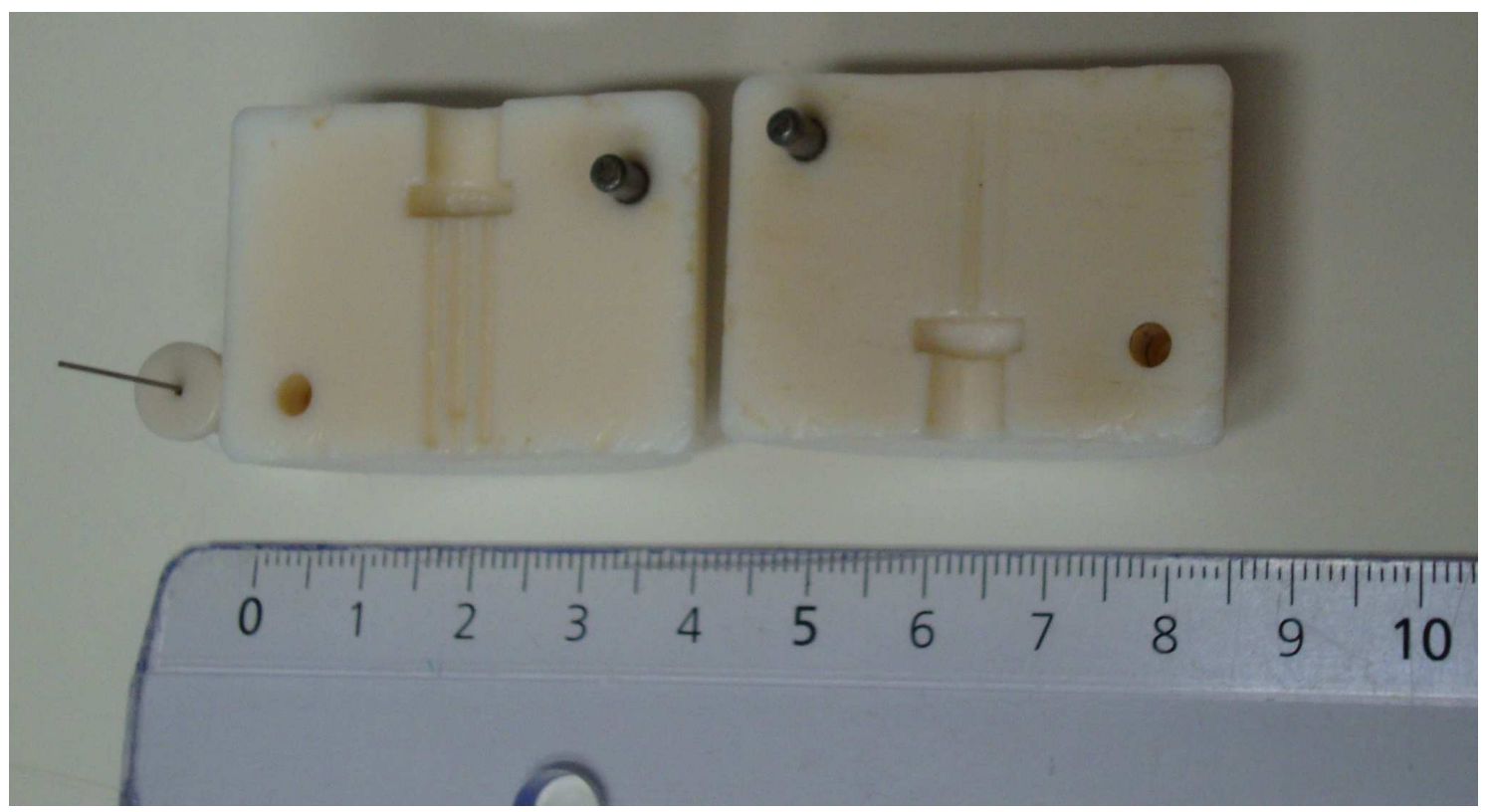

Figura 6. Molde desenvolvido anteriormente no Laboratório de Cromatografia por Nogueira [89].

Deste modo, em parceria com o Grupo de Polímeros "Prof. Bernhard Gross" do Instituto de Física de São Carlos (IFSC), um novo molde foi desenvolvido a fim de superar esses problemas. O teflon foi utilizado somente como suporte para o capilar de vidro e para a barra magnética pois, diferentemente do teflon, o vidro apresenta boa condutividade térmica, o que permite a síntese de diversas fases poliméricas que precisem de uma temperatura mais elevada para a sua síntese.

\subsubsection{Preparo da barra SBSE PDMS-ACB}

O desenvolvimento de barras SBSE de PDMS modificado com carvão ativado teve como base o sucesso do emprego da fibra mista PDMS/Carboxen de SPME comercializada pela Supelco em diversos trabalhos [23, 91-93]. Adicionalmente, somente barra SBSE de PDMS são disponíveis comercialmentes. Então, essa modificação foi feita para se obter barras com recobrimentos polares e possibilitar a extração de compostos com características polares.

Primeiramente, uma mistura do PDMS Sylgard 184, do agente de cura na proporção 10:1 (m/m) e $18 \%(\mathrm{~m} / \mathrm{m})$ de carvão ativado foi preparada em um frasco de vidro. Então, esta 
foi colocada cuidadosamente no interior do capilar de vidro utilizando-se uma pipeta volumétrica, e o capilar foi inserido no molde de teflon. Posteriormente, a barra magnética de aço inox $(2,5 \mathrm{~cm})$ foi colocada no centro do capilar, diretamente em contato com a fase polimérica. O fato não compromete a fase polimérica uma vez que a etapa de dessorção foi feita em solvente. Então, o conjunto foi levado ao forno a $65^{\circ} \mathrm{C}$ por 60 minutos.

Após o resfriamento, o capilar de vidro foi quebrado tomando-se o máximo de cuidado para não causar danos na superfície polimérica. Assim, a barra foi condicionada termicamente em um forno na seguinte condição: iniciou-se em $60^{\circ} \mathrm{C}$, aumentou-se a temperatura com uma taxa de $30{ }^{\circ} \mathrm{C} \min ^{-1}$ até $120^{\circ} \mathrm{C}$, a qual foi mantida por 120 minutos.

A barra SBSE PDMS-ACB apresentou um volume polimérico de aproximadamente 92 $\mu \mathrm{L}, 2,36 \mathrm{~mm}$ de diâmetro e 2,2 $\mathrm{cm}$ de comprimento.

Barras de PDMS-ACB foram preparadas com diferentes quantidades de carvão ativado $(4,5,9,13$ e $18 \%$ m/m). A eficiência da extração destas barras SBSE foi testada, verificando que a barra PDMS-ACB $18 \%$ apresentou melhores resultados para os compostos estudados. Portanto, a barra PDMS-ACB $18 \%$ foi selecionada para a extração SBSE.

\subsubsection{Amostras de garapa}

Para o desenvolvimento, otimização e validação do método de extração SBSE foram utilizadas amostras de garapa livres de pesticidas (branco), que posteriormente foram fortificadas.

As amostras de garapa passaram por um procedimento de pré-tratamento antes de realizar a extração. Nesta etapa, a garapa foi filtrada à vacuo, centrifugada a 3400 rpm por 20 minutos e armazenada a $-20^{\circ} \mathrm{C}$ em frasco fechado. Antes de cada análise as amostras de garapa foram descongeladas. 
De acordo com o Codex Alimentarius, as amostras reais devem ser coletadas no último ponto antes do consumidor para que se verifique os níveis de resíduos de pesticidas e contaminantes nos alimentos que serão consumidos pela população [94]. Deste modo, as amostras reais de garapa foram adquiridas de 3 diferentes fornecedores em São Carlos-SP. Estas foram transportadas a $8{ }^{\circ} \mathrm{C}$ e pré-tratadas como descrito anteriormente. As amostras foram analisadas no dia seguinte.

\subsubsection{Método de extração SBSE}

A extração SBSE foi realizada em um frasco de vidro $(22 \mathrm{~mL})$ adicionando-se 7,75 $\mathrm{mL}$ de garapa que foi fortificada com quantidades adequadas das soluções de trabalho e foi homogeinizada por 15 segundos. Posteriormente, adicionou-se 7,75 mL de tampão acetato de sódio $0,5 \mathrm{~mol} \mathrm{~L}^{-1}(\mathrm{pH}=6,5)$ e $1,55 \mathrm{~g}$ de $\mathrm{NaCl}$.

Posteriormente, a barra SBSE foi inserida no frasco de vidro, o qual foi lacrado com septo de PTFE e lacre de alumínio. A barra SBSE foi mantida sob agitação magnética de 450 rpm por 45 minutos a $70{ }^{\circ} \mathrm{C}$. Após o tempo de extração, a barra foi removida da amostra de garapa e cuidadosamente lavada com água destilada e secada com lenços de papel. O frasco utilizado na extração está ilustrado na Figura 7.

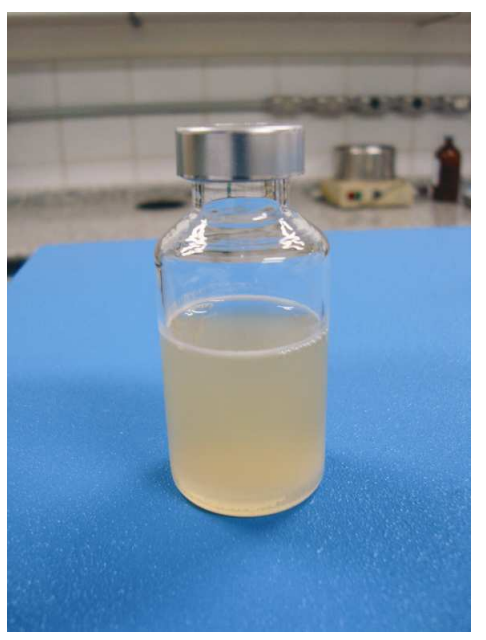

Figura 7. Ilustração de um frasco utilizado na extração por SBSE. 
A dessorção dos analitos foi realizada em um "insert" preenchido com $200 \mu \mathrm{L}$ de acetato de etila, no banho de ultra-som a $65^{\circ} \mathrm{C}$ por 20 minutos. Após essa etapa, uma alíquota de $1 \mu \mathrm{L}$ foi injetada no GC-MS.

Depois de cada extração um procedimento de cleanup da barra SBSE foi realizado para evitar o efeito carryover. Nesta etapa, a barra é colocada dentro de um vial contendo 1,5 $\mathrm{mL}$ de metanol que é colocado no ultra-som por 10 minutos. Este procedimento é realizado duas vezes. A fim de garantir o sucesso do cleanup, $1 \mu \mathrm{L}$ do metanol foi injetado no GC-MS e nenhum pico cromatográfico foi detectado.

\subsubsection{Planejamento e Otimização Experimental}

SBSE é uma técnica de extração miniaturizada na qual muitas variáveis influenciam a sua eficiência. Deste modo, um planejamento experimental foi aplicado para reduzir o número de experimentos necessários para a sua otimização.

Inicialmente, um planejamento fatorial fracionário $2^{4-1}$ foi realizado para determinar as variáveis e as interações entre as variáveis que apresentam influência significativa sobre a resposta de interesse. Após selecionar as variáveis, foi realizada a etapa de otimização utilizando o planejamento composto central e a metodologia de superfície de resposta. As variáveis que não foram escolhidas foram fixadas durante todo o experimento. A estimativa de erros foi avaliada através de experimentos no ponto central, em três réplicas.

\subsubsection{Planejamento Fatorial Fracionário $2^{4-1}$}

Para construir o planejamento fatorial fracionário $2^{4-1}$ primeiramente as 4 variáveis, que possivelmente influenciam o rendimento da extração, foram selecionadas com base em trabalhos descritos na literatura e são apresentadas na Tabela 6. 
Tabela 6. Variáveis selecionadas para o planejamento fatorial fracionário $2^{4-1}$.

\begin{tabular}{cc}
\hline Número & Variáveis \\
\hline 1 & Temperatura $\left({ }^{\circ} \mathrm{C}\right)$ \\
2 & Volume da amostra $(\mathrm{mL})$ \\
3 & $\mathrm{pH}$ \\
4 & Força iônica $(\% \mathrm{NaCl})$ \\
\hline
\end{tabular}

Então, um planejamento completo $2^{3}$ foi construído utilizando as variáveis 1,2 e 3 e para a variável 4 foram atribuídos os valores dos produtos das variáveis 1, 2 e 3 . Deste modo foi possível, com um total de 11 experimentos, analisar três níveis de cada variável e verificar se existia falta de ajuste para o modelo.

O planejamento fatorial fracionário $2^{4-1}$ foi utilizado para avaliar o efeito das principais variáveis e de suas interações na extração SBSE (temperatura, volume da amostra, força iônica e pH), de acordo com os níveis apresentados na Tabela 7. Os valores dos níveis superior e inferior de cada variável foram escolhidos de acordo com experimentos prévios.

A temperatura influencia na extração aumentando a difusão dos compostos e, portanto, aumentando a quantidade de analito extraída. Por outro lado, com o seu aumento, o coeficiente de partição entre o analito e o polímero de extração diminui, ocasionando uma menor eficiência de extração.

A adição de sais inorgânicos em uma solução causa o efeito salting out, ou seja, a solubidade do soluto na solução diminui devido ao aumento da força iônica da solução, facilitando que os analitos migrem da solução para a fase extratora da barra SBSE.

O volume de amostra é um fator fundamental pois envolve a distrubuição dos analitos entre a fase de extração e a solução, de modo que um maior volume de amostra deve resultar em uma maior massa extraída. 
Tabela 7. Variáveis avaliadas no planejamento fatorial fracionário $2^{4-1}$.

\begin{tabular}{|c|c|c|c|c|}
\hline Variáveis & Baixo (-) & Ponto central (0) & & Alto (+) \\
\hline Temperatura $\left({ }^{\circ} \mathrm{C}\right)$ & 30 & 50 & & 70 \\
\hline $\begin{array}{c}\text { Volume da } \\
\text { amostra (mL) }\end{array}$ & 6 & 13 & & 20 \\
\hline $\mathrm{pH}$ & 3 & 6,5 & & 10 \\
\hline Força iônica (\% $\mathrm{NaCl}$ & 10 & 20 & & 30 \\
\hline Experimento & Temperatura $\left({ }^{\circ} \mathrm{C}\right)$ & $\begin{array}{c}\text { Volume da } \\
\text { amostra }(\mathrm{mL})\end{array}$ & pH & $\begin{array}{c}\text { Força iônica } \\
(\% \mathrm{NaCl})\end{array}$ \\
\hline 1 & - & - & - & - \\
\hline 2 & - & - & - & + \\
\hline 3 & - & - & + & + \\
\hline 4 & - & + & + & + \\
\hline 5 & + & + & + & + \\
\hline 6 & + & + & + & - \\
\hline 7 & + & + & - & - \\
\hline 8 & + & - & - & - \\
\hline 9 & 0 & 0 & 0 & 0 \\
\hline 10 & 0 & 0 & 0 & 0 \\
\hline 11 & 0 & 0 & 0 & 0 \\
\hline
\end{tabular}

$\mathrm{O}$ pH atua diretamente na eficiência da extração, possibilitando ou não a ionização dos analitos, a qual é diretamente dependente dos valores de $\mathrm{pK}_{\mathrm{a}}$ dos mesmos (Tabela 8). Como são possíveis dois mecanismos diferentes de extração, a absorção e a adsorção, a influência do $\mathrm{pH}$ foi avaliada para cada analito.

Os dados experimentais obtidos foram utilizados na construção do modelo através do programa Statistica 6.0, o qual foi avaliado por ANOVA (Análise de variância). 
Tabela 8. Valores dos $\mathrm{pK}_{\mathrm{as}}$ dos pesticidas estudados.

\begin{tabular}{cc}
\hline Composto & $\mathbf{p K}_{\mathbf{a}}{ }^{\mathrm{a}}$ \\
\hline Carbofurano & $12,28 /-1,49$ \\
\hline Atrazina & 2,35 \\
Metribuzim & $-0,58$ \\
\hline Ametrina & 3,82 \\
\hline Tebutiurom & $13,36 / 1,95$ \\
\hline Bifentrina & - \\
\hline
\end{tabular}

${ }^{a}$ Referência [90].

Inicialmente os parâmetros tempo de extração e velocidade de rotação na agitação foram fixados em 60 minutos e $450 \mathrm{rpm}$, respectivamente, e posteriormente a otimização univariada dessas variáveis foi realizada. Como um dos objetivos deste trabalho é diminuir o consumo de solvente, a dessorção líquida foi feita em um insert de $500 \mu \mathrm{L}$ utilizando apenas $200 \mu \mathrm{L}$ de acetato de etila durante 20 minutos sob ultrasson a $65^{\circ} \mathrm{C}$.

\subsubsection{Planejamento Composto Central (CCD)}

Como as variáveis $\mathrm{pH}$ e volume de amostra apresentaram um efeito significativo ( $\mathrm{p}>$ 0,05) estas foram avaliadas em 5 níveis na otimização empregando-se planejamento composto central (CCD), nos intervalos apresentados na Tabela 9. O ponto central foi avaliado em três réplicas, a fim de estimar o erro e verificar se houve ou não falta de ajuste ao modelo.

Neste planejamento os parâmetros tempo de extração e velocidade de rotação na agitação também foram fixados em 60 minutos e $450 \mathrm{rpm}$, respectivamente. A dessorção líquida foi realizada em um insert de $500 \mu \mathrm{L}$ utilizando-se $200 \mu \mathrm{L}$ de acetato de etila durante 20 minutos sob ultrasson a $65^{\circ} \mathrm{C}$.

Os dados experimentais obtidos foram utilizados na construção do modelo através do programa Statistica 6.0, o qual foi avaliado por ANOVA (Análise de variância). 
Tabela 9. Variáveis avaliadas no planejamento composto central.

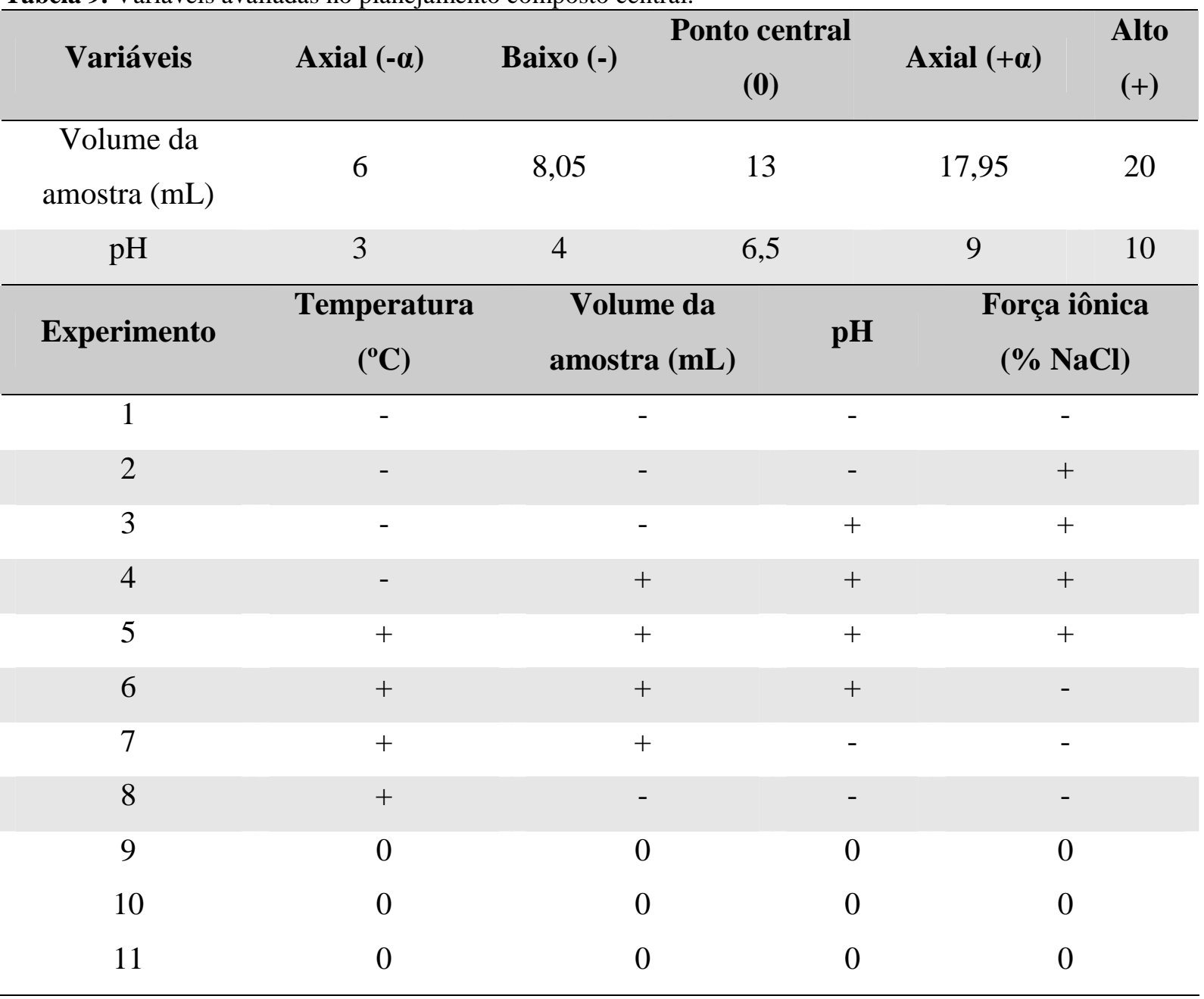

\subsubsection{Otimização univariada}

A otimização univariada das variáveis tempo de extração e velocidade de agitação foi realizada após os experimentos dos planejamento fatorial fracionário e composto central. Os valores utilizados para avaliar o efeito do tempo de extração e velocidade de agitação sobre o processo de extração por SBSE são apresentados na Tabela 10. Para a otimização univariada os valores das variáveis temperatura de extração, $\mathrm{pH}$, quantidade de amostra e quantidade de $\mathrm{NaCl}$ foram fixadas em $70{ }^{\circ} \mathrm{C} ; 6,5 ; 15,5 \mathrm{~mL}$ e $10 \%$, respectivamente. Em um insert de $500 \mu \mathrm{L}$ foi realizada a dessorção líquida utilizando-se $200 \mu \mathrm{L}$ de acetato de etila a $65^{\circ} \mathrm{C}$ durante 20 minutos sob ultrasson. 
Tabela 10. Variáveis avaliadas na otimização univariada.

\begin{tabular}{cc}
\hline Tempo de extração $(\mathbf{m i n})$ & Velocidade de agitação $(\mathbf{r p m})$ \\
\hline 30 & 210 \\
45 & 450 \\
60 & 620 \\
90 & - \\
\hline
\end{tabular}

\subsubsection{Validação}

A metodologia para análise de seis pesticidas em garapa através de SBSE e GC-MS foi validada segundo critérios aceitos internacionalmente [95]. Os parâmetros de validação selecionados foram: seletividade, linearidade, recuperação (exatidão), limite de detecção (LOD), limite de quantificação (LOQ) e precisão (DPR).

A Tabela 11 apresenta os valores das variáveis utilizadas na validação do método SBSE. A dessorção líquida foi realizada em um insert de $500 \mu \mathrm{L}$ utilizando-se $200 \mu \mathrm{L}$ de acetato de etila durante 20 minutos sob ultrasson a $65^{\circ} \mathrm{C}$.

Nas análises do GC-MS foram monitorados três íons para cada composto, sendo um íon utilizado para a quantificação e os demais para confirmação do analito.

Tabela 11. Valores das variáveis utilizadas nos experimentos da validação.

\begin{tabular}{cc}
\hline Variável & Valor \\
\hline Temperatura $\left({ }^{\circ} \mathrm{C}\right)$ & 70 \\
Volume da amostra $(\mathrm{mL})$ & 15,5 \\
$\mathrm{pH}$ & 6,5 \\
\hline Força iônica $(\% \mathrm{NaCl})$ & 10 \\
Tempo de extração $(\mathrm{min})$ & 45 \\
Velocidade de agitação $(\mathrm{rpm})$ & 450 \\
\hline
\end{tabular}




\subsubsection{Seletividade}

A especificidade do método foi verificada através da análise da amostra de garapa livre de fortificação (branco), em três réplicas, observando a presença ou não de interferentes nos tempos de retenção dos analitos de interesse.

\subsubsection{Linearidade}

A linearidade foi verificada analisando-se amostras de garapa (branco) fortificadas em cinco níveis de concentração (Tabela 12), com três replicatas em cada nível. Os valores de LMRs para a cana-de-açúcar apresentados pela ANVISA foram levados e consideração na escolha do intervalo de linearidade [10].

As curvas de calibração foram feitas por padronização externa e foram construídas plotando-se os valores das áreas obtidas em função da concentração. O coeficiente de determinação $\left(r^{2}\right)$ e a equação linear de regressão foram calculados pelo método dos mínimos quadrados. O coeficiente angular (b) e linear (a) foram obtidos em função da equação da reta $(y=a x+b)$. Para se obter o coeficiente de correlação (r), a equação 11 foi utilizada:

$$
r^{2}=\sqrt{r}
$$

Tabela 12. Valores de concentração utilizados na avaliação da linearidade.

\begin{tabular}{cccccc}
\hline Compostos & \multicolumn{5}{c}{ Nível $\left(\mu \mathrm{g} \mathrm{L}^{-1}\right)$} \\
\cline { 2 - 6 } & 1 & 2 & 3 & 4 & 5 \\
\hline Carbofurano & 0,5 & 5,0 & 50,0 & 100,0 & 150,0 \\
Atrazina & 0,5 & 5,0 & 100,0 & 150,0 & 200,0 \\
Metribuzim & 1,0 & 10,0 & 50,0 & 75,0 & 100,0 \\
Ametrina & 1,0 & 10,0 & 25,0 & 37,5 & 50,0 \\
Tebutiurom & 40,0 & 450,0 & 675,0 & 900,0 & 1375,0 \\
Bifentrina & 20,0 & 200,0 & 250,0 & 500,0 & 750,0 \\
\hline
\end{tabular}




\subsubsection{Precisão}

A precisão intra-dia foi avaliada em três níveis de concentração (Tabela 13), com três replicatas e foi expressa como Desvio Padrão Relativo (DPR, \%). O DPR (\%) foi calculado utilizadando as equações 12, 13 e 14 .

$$
D P R(\%)=\frac{S}{100 \cdot \bar{x}}
$$

em que:

$\bar{x}$ é a média aritmética dos valores;

S é a estimativa do desvio padrão.

A média aritmética $(\bar{x})$ foi calculada através da equação 13:

$$
\bar{x}=\frac{x_{1}+x_{2}+\cdots+x_{n n}}{n}=\sum x_{i}
$$

onde:

$x_{i}$ são os valores obtidos;

$n$ é o número de resultados obtidos.

A estimativa do desvio padrão (S) foi calculada pela equação 14:

$$
S=\sqrt{\frac{\sum\left(x_{i}-\bar{x}\right)^{2}}{n}}
$$


Tabela 13. Valores de concentração usados para avaliação da precisão.

\begin{tabular}{cccc}
\hline \multirow{2}{*}{ Compostos } & \multicolumn{3}{c}{ Nível $\left(\mu \mathrm{g} \mathrm{L}^{-1}\right)$} \\
\cline { 2 - 4 } & 1 & 2 & 3 \\
\hline Carbofurano & 5,0 & 50,0 & 100,0 \\
\hline Atrazina & 5,0 & 100,0 & 150,0 \\
Metribuzim & 10,0 & 50,0 & 75,0 \\
Ametrina & 10,0 & 25,0 & 37,5 \\
\hline Tebutiurom & 450,0 & 675,0 & 900,0 \\
Bifentrina & 200,0 & 250,0 & 500,0 \\
\hline
\end{tabular}

\subsubsection{Recuperação/Exatidão}

A exatidão de um método expressa a concordância entre o valor medido e o verdadeiro ou de referência. A exatidão é determinada, quando possível, utilizando uma amostra certificada cuja concentração é conhecida. No entanto, quando a amostra certificada não está disponível, pode-se adicionar (fortificar) a matriz com uma quantidade conhecida do padrão analítico de interesse. Assim, também chamada de recuperação, é calculada através dos valores determinados pelo método e pelos valores reais de concentração, conforme a equação 15:

$$
\operatorname{Rec}(\%)=\frac{X_{\mathrm{m}} \cdot 100}{X_{\mathrm{w}}}
$$

em que:

$X_{m}$ é o valor determinado pelo método;

$X_{r}$ é o valor real;

$\operatorname{Rec}(\%)$ é a recuperação. 
A recuperação foi avaliada em três níveis de concentração (baixa, média e alta), em três replicatas, conforme apresentadas na Tabela 14. Os valores reais foram determinados preparando-se soluções-padrões dos pesticidas em solvente, nas concentrações expressas na Tabela 14 e injetando-as no sistema cromatográfico (valor correspondente a 100\%).

\subsubsection{Limites de Detecção (LOD) e de Quantificação (LOQ)}

O limite de detecção (LOD) foi estimado considerando a menor concentração em que o pico relativo aos analitos fosse cerca de três vezes maior que o ruído da linha de base. Para o cálculo do limite de detecção foi utilizado a equação16:

$$
L O D=3,3, \frac{s}{a}
$$

onde:

$S$ é o desvio padrão de acordo com a concentração do analito capaz de gerar um sinal três vezes maior que a amplitude do ruído;

$a$ é a inclinação da curva de calibração.

Tabela 14. Valores de concentração utilizados na avaliação da recuperação.

\begin{tabular}{|cccc|}
\hline \multirow{2}{*}{ Compostos } & \multicolumn{3}{c}{ Nível $\left(\mu \mathrm{g} \mathrm{L}^{-1}\right)$} \\
\cline { 2 - 4 } & 1 & 2 & 3 \\
\hline Carbofurano & 5,0 & 50,0 & 100,0 \\
\hline Atrazina & 5,0 & 100,0 & 150,0 \\
\hline Metribuzim & 10,0 & 50,0 & 75,0 \\
\hline Ametrina & 10,0 & 25,0 & 37,5 \\
\hline Tebutiurom & 450,0 & 675,0 & 900,0 \\
\hline Bifentrina & 200,0 & 250,0 & 500,0 \\
\hline
\end{tabular}


O Limite de Quantificação (LOQ) foi considerado como a menor quantidade do analito em que o pico fosse cerca de dez vezes maior do que o ruído da linha de base além de apresentar um desvio padrão relativo menor do que $15 \%$. 


\section{4}

Rersurlltaldilloss e

D) ìs(culssãa (O) 


\section{RESULTADOS E DISCUSSÃO}

\subsection{Separação Cromatográfica}

As análises foram realizadas utilizando as condições cromatográficas descritas anteriormente no item 3.3.1. O cromatograma do íon extraído de uma injeção de $1 \mu \mathrm{L}$ da solução-padrão dos analitos a $1 \mathrm{mg} \mathrm{L}^{-1}$ está ilustrado na Figura 8 , onde pode ser observado que os picos apresentaram um pouco de cauda. Houve a coeluição de dois compostos em diferentes regiões do cromatograma, porém isso não foi um problema já que é possível separar, identificar e quantificar através dos íons monitorados no espectrômetro de massas (modo SIM). Devido à ausência de picos de produtos de degradação pode-se verificar que os compostos são termicamente estáveis.

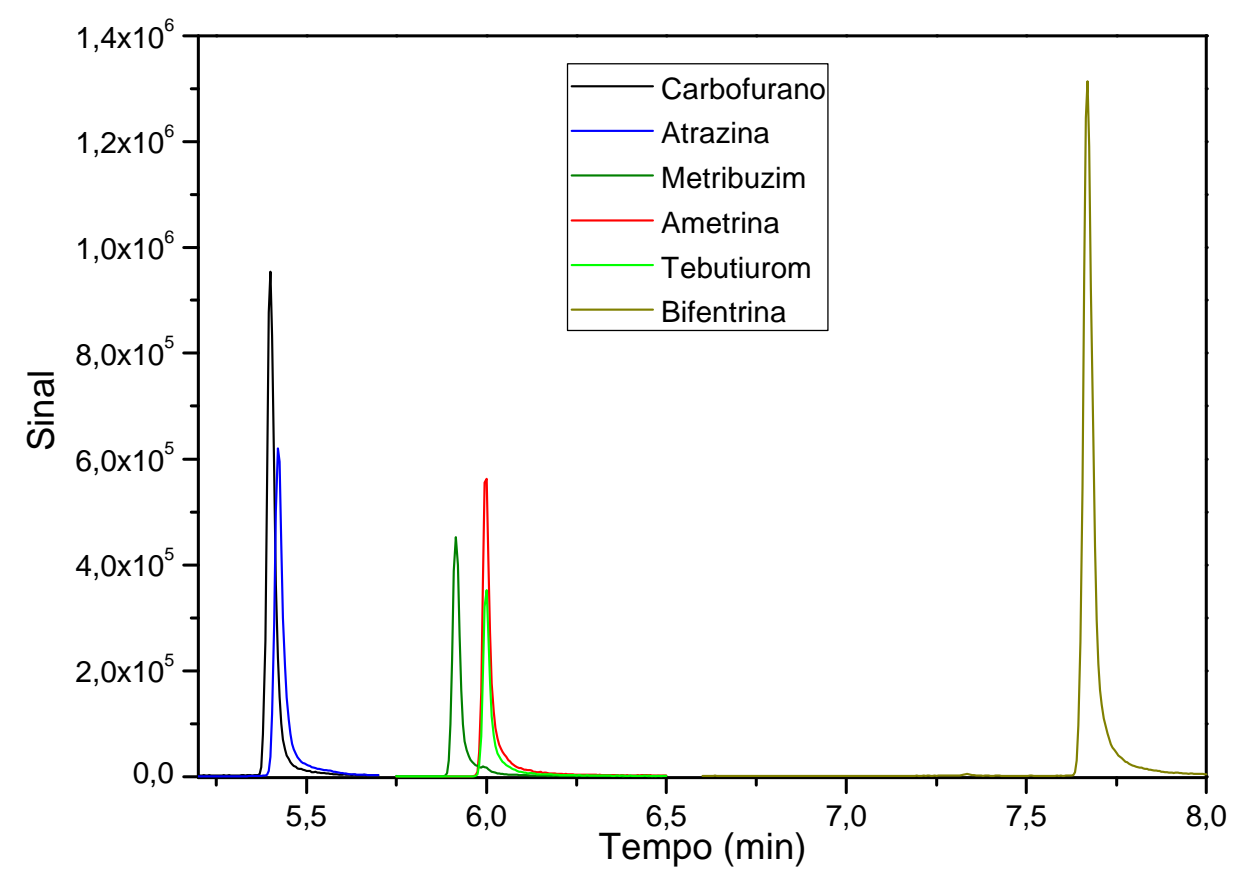

Figura 8. Cromatograma obtido através da injeção de $1 \mu \mathrm{L}$ de uma solução- padrão dos 6 analitos a $1 \mathrm{mg} \mathrm{L} \mathrm{L}^{-1}$. 


\subsection{Desenvolvimento do molde de teflon}

O novo molde foi desenvolvido conforme descrito no item 3.3.2. e está ilustrado na Figura 9. O uso deste proporcionou um aumento de 4 vezes no volume do recobrimento das barras em comparação com o molde anterior, já que uma barra produzida no molde anterior apresentava $22 \mu \mathrm{L}$ e a produzida no molde novo apresentou cerca de $92 \mu \mathrm{L}$. Deste modo, o esperado pelos cálculo é que a performance da extração dos compostos também aumente.

A Figura 10 ilustra a comparação entre as barras de PDMS produzidas pelo molde anterior e pelo molde novo, demonstrando a melhoria na produção das barras de SBSE com respeito a quantidade de fase e imperfeições causadas pelo molde.

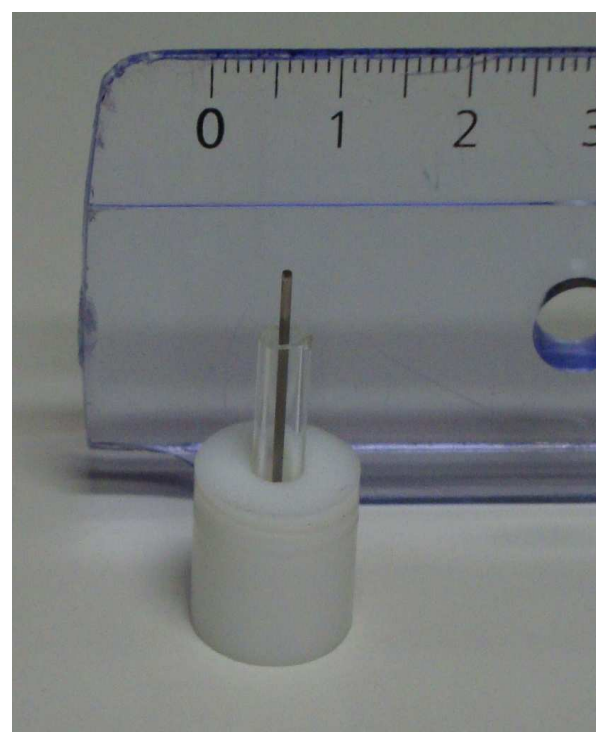

Figura 9. Novo molde desenvolvido, composto por um suporte de teflon, um capilar de vidro e um magneto. 


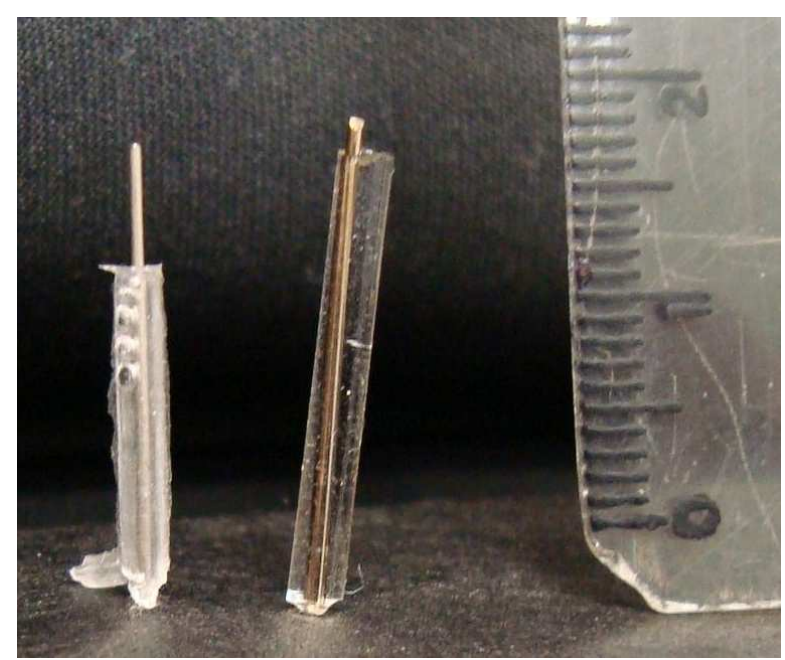

Figura 10. Comparação entre as barras de PDMS produzidas pelo molde antigo (à esquerda) e pelo molde novo (à direita).

\subsection{Preparo da barra SBSE PDMS-ACB}

A barra SBSE PDMS-ACB foi preparada conforme o item 3.3.3., e está ilustrada na Figura 11. Suas dimensões são: volume polimérico de aproximadamente $100 \mu \mathrm{L}, 2,36 \mathrm{~mm}$ de diâmetro e 2,2 cm de comprimento. As barras SBSE lab-made desenvolvidas com a utilização do novo molde apresentaram um recobrimento maior do que os apresentados na literatura [42, 72]. O método de preparo da barra SBSE PDMS-ACB 18\% mostrou-se reprodutível. A barra apresentou estabilidade mecânica e química. O recobrimento polimérico mostrou-se fortemente ligado à barra magnética o que previniu danos causados por impactos físicos.

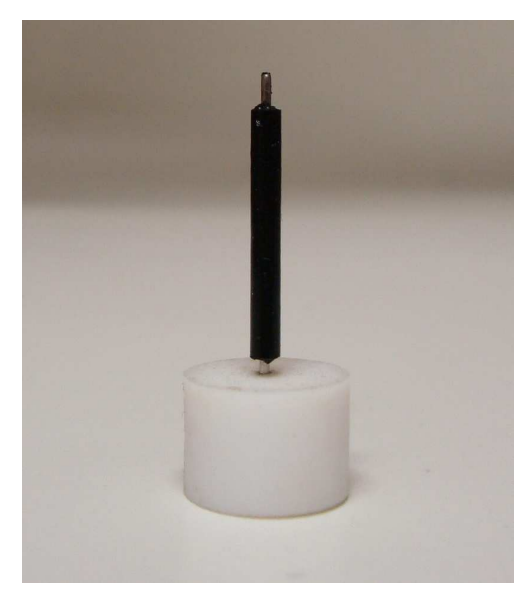

Figura 11. Barra SBSE PDMS/ACB $18 \%$. 
Além disso, diversos solventes orgânicos foram testados na dessorção líquida (LD) como, metanol, tolueno, acetonitrila e acetato de etila. Apenas quando utilizado acetato de etila e tolueno foi observado um certo inchamento do polímero, porém o mesmo volta a sua forma original logo após mergulhar a barra em metanol, não sendo observado nenhum dano na superfície da barra SBSE após mais de 150 ciclos de dessorção utilizando acetato de etila. Esta estabilidade do polímero pode ser atribuída a uma polimerização completa, o que foi corroborado pela ausência de picos de siloxanos nos cromatogramas obtidos com injeção dos solventes no modo de SCAN.

\subsection{Caracterização da barra PDMS-ACB}

A caracterização da barra SBSE PDMS-ACB foi feita por microscopia eletrônica de varredura. Os aumentos mostrados na Figura 12 são de (a) 100, (b) 500, (c) 1000 e (d) 5000 vezes. A imagem obtida da barra PDMS-ACB apresentou superfície relativamente homogênea e sem bolhas.

A SBSE pode envolver dois mecanismos de extração, a absorção e adsorção. No caso da barra SBSE PDMS-ACB, provavelmente, o PDMS é responsável pela extração por absorção enquanto que o ACB é pela adsorção. Deste modo, é esperado que ocorram os dois mecanismos de extração pela barra desenvolvida. Nas imagens obtidas por MEV não é possível observar a presença de poros pois, o diâmentro dos poros geralmente é cerca de 13 nm e nestas imagens chegou-se a $1 \mu \mathrm{m}$ [96].

O carvão ativado cria pequenos poros dentro da estrutura do PDMS, os quais produzem caminhos que permitem a entrada de compostos polares de acordo com o tamanho dos poros [60]. Como a adsorção é competitiva, pode ocorrer o efeito de deslocamento limitando a faixa linear [97]. 


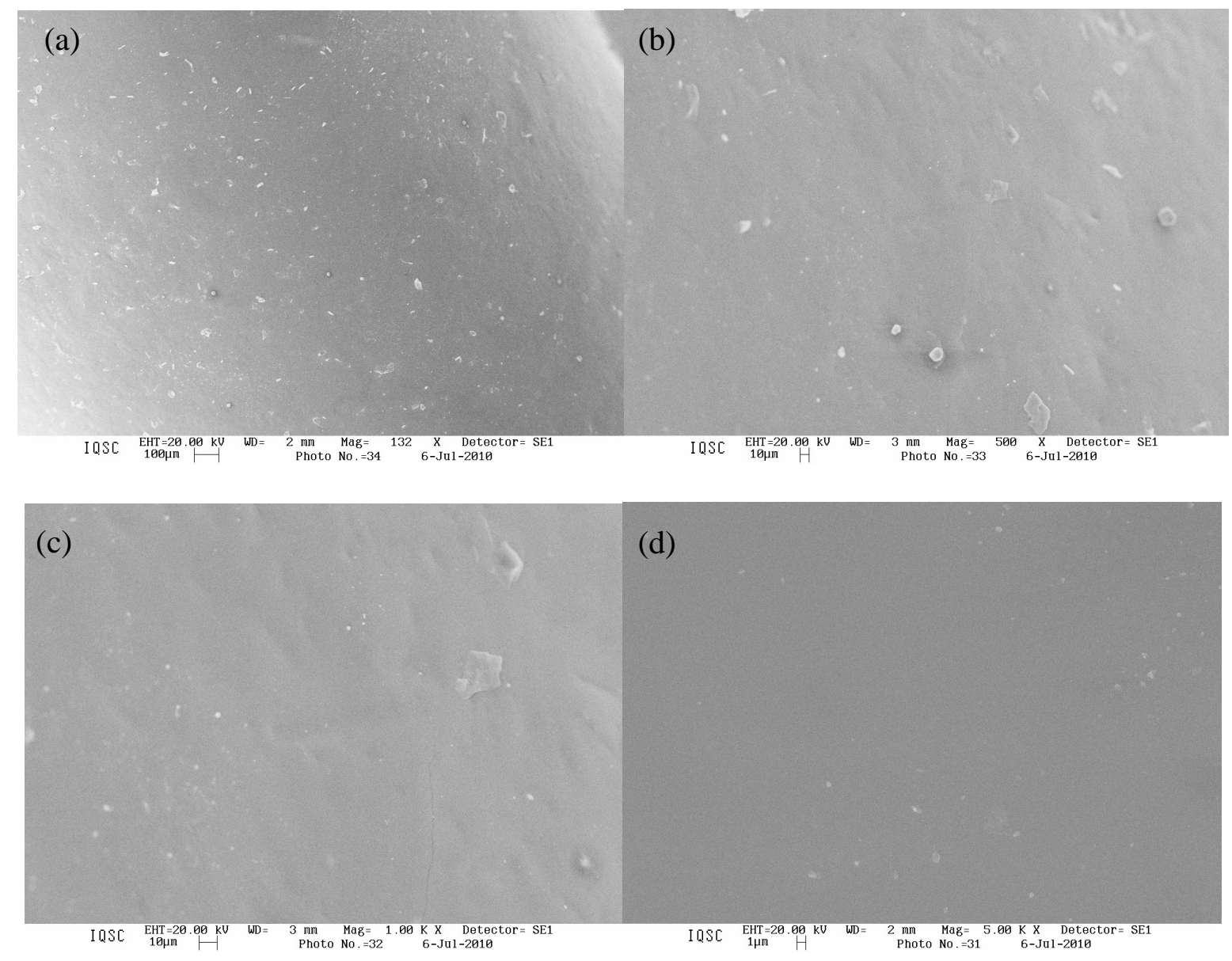

Figura 12. Microscopia eletrônica de varredura da barra PDMS-ACB. (a) 100 x. (b) 500 x. (c) 1000 x. (d) 5000 $\mathrm{x}$.

Outra forma de caracterizar as barras SBSE lab-made é através de espectros vibracionais na região do infravermelho. Neste caso, as medidas no infravermelho seriam realizadas para a confirmação da polimerização por completo do PDMS, já que adição do carvão ativado não muda a estrutura do polímero. Porém, não foi possível realizar essa caracterização devida a elevada quantidade de carvão ativo e consequente aspecto escuro da fase de recobrimento da barra SBSE.

Foram utilizados diversos solventes (metanol, tolueno, acetonitrila, acetato de etila) na dessorção dos analitos, em testes preliminares utilizando a barra PDMS-ACB e não foi observado nenhum dano a barra e nem a presença picos cromatográficos que não fossem referentes aos compostos estudados. Desta forma, pode-se afirmar que provavelmente a reação de polimerização ocorreu por completo. 


\subsection{Planejamento e Otimização Experimental}

$\mathrm{Na}$ otimização da extração por SBSE, com o intuito de reduzir o número de experimentos necessários, foi realizado um planejamento experimental já que a eficiência da SBSE pode ser influenciada por diversas variáveis.

\subsubsection{Planejamento Fatorial Fracionário $2^{4-1}$}

No planejamento fatorial fracionário $2^{4-1}$ foram avaliados os fatores: temperatura, $\mathrm{pH}$, força iônica e do volume da amostra que mais influenciam a extração SBSE, como foi descrito no item 3.3.6.1.

A Figura 13 ilustra os diagramas de Pareto nos quais pode ser observado as variáveis significativas para cada pesticida estudado: (a) Ametrina, (b) Atrazina, (c) Bifentrina, (d) Carbofurano, (e) Metribuzim e (f) Tebutiruom. A linha pontilhada indica a região acima da qual os efeitos foram significativos (com limite de confiança de 95\%).

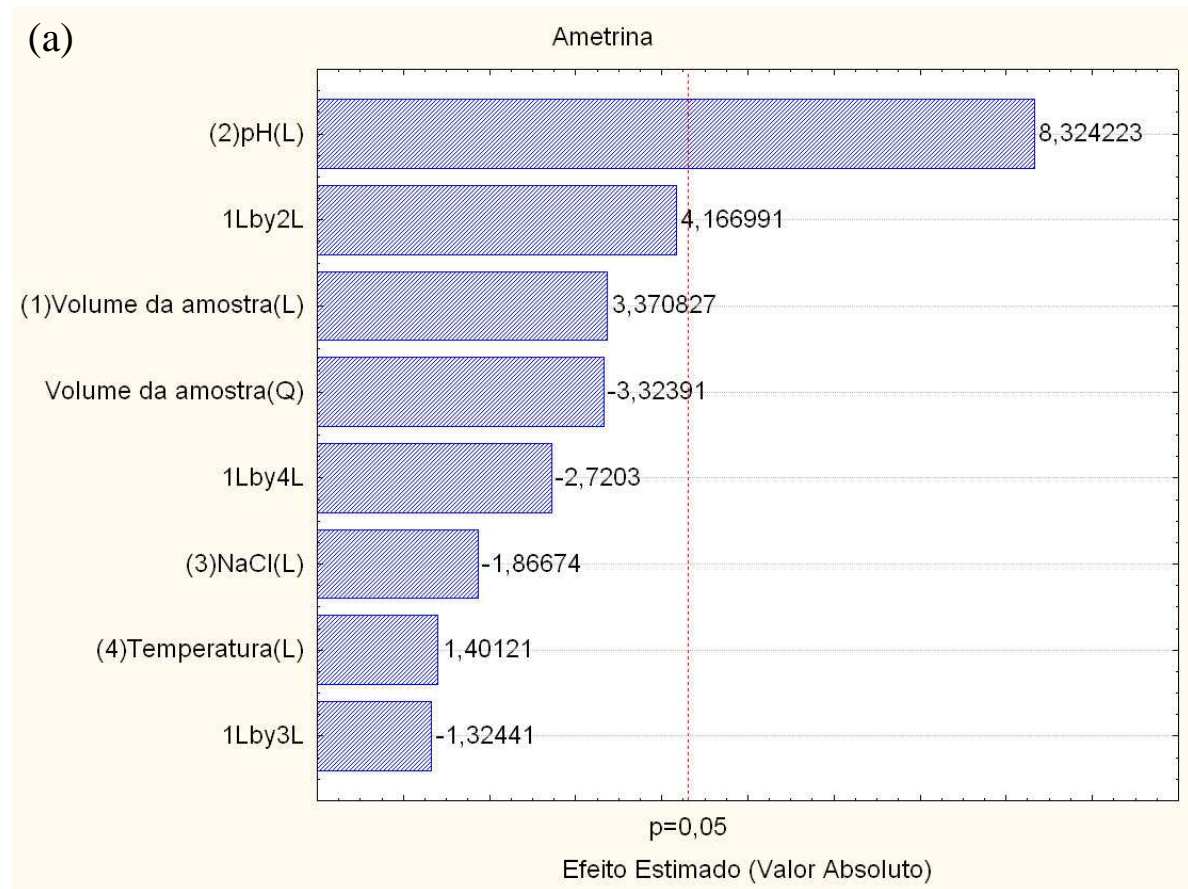

Figura 13. Diagramas de Pareto mostrando os efeitos dos parâmetros avaliados para a extração por SBSE dos 6 pesticidas: (a) Ametrina, (b) Atrazina, (c) Bifentrina, (d) Carbofurano, (e) Metribuzim e (f) Tebutiruom. (continua) 
(b)

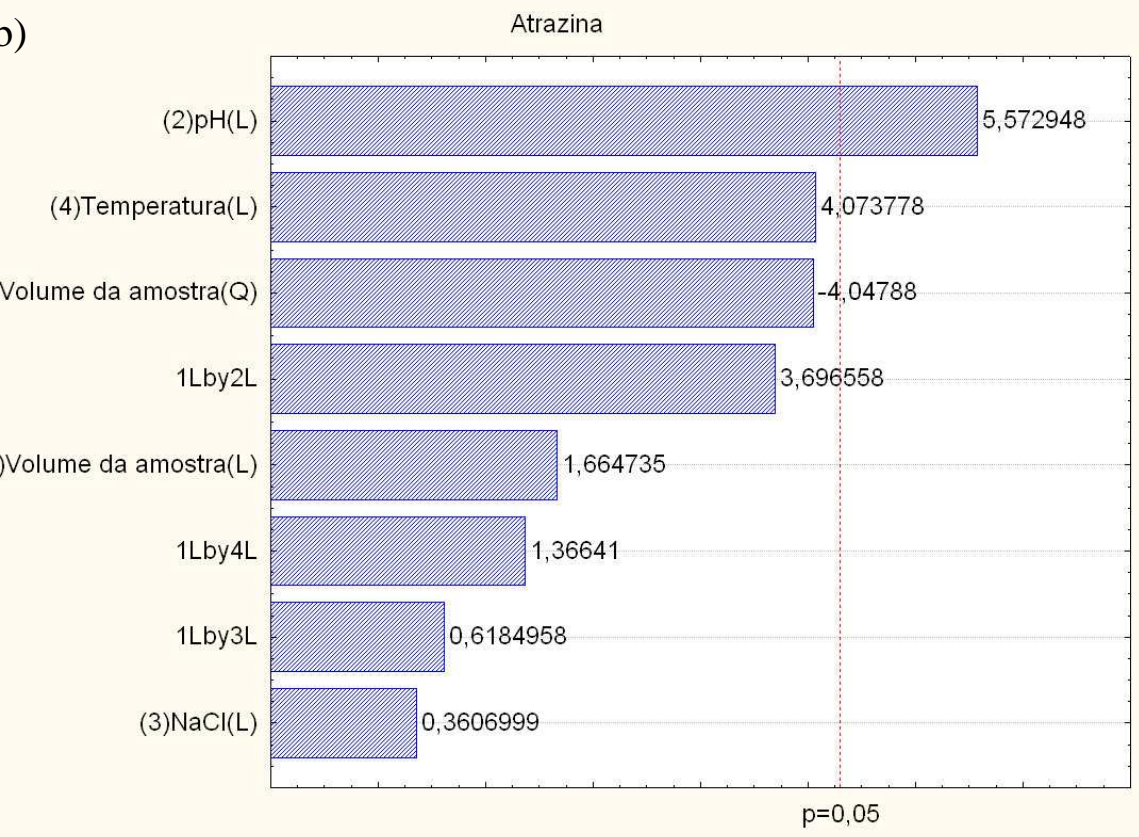

(c)

Efeito Estimado (Valor Absoluto)

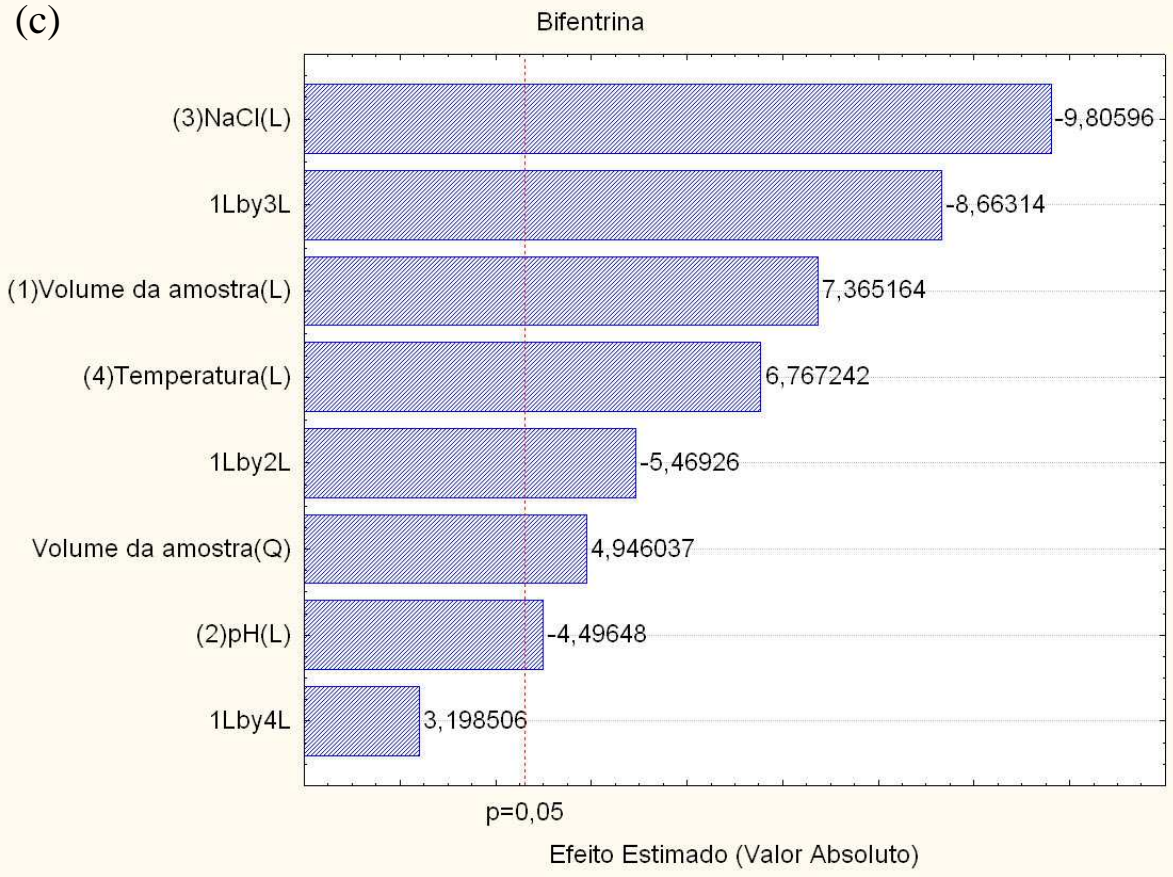

Figura 13. Diagramas de Pareto mostrando os efeitos dos parâmetros avaliados para a extração por SBSE dos 6 pesticidas: (a) Ametrina, (b) Atrazina, (c) Bifentrina, (d) Carbofurano, (e) Metribuzim e (f) Tebutiruom. (continua) 


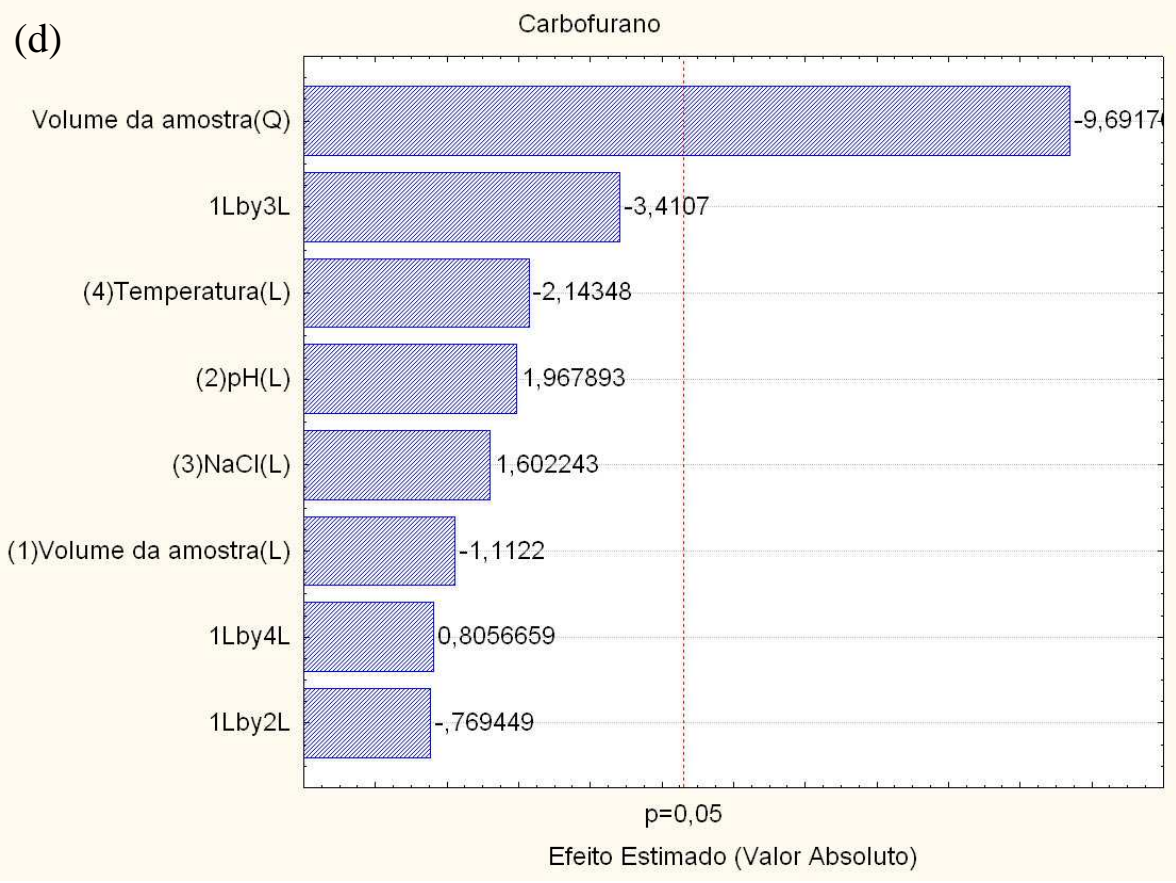

(e)

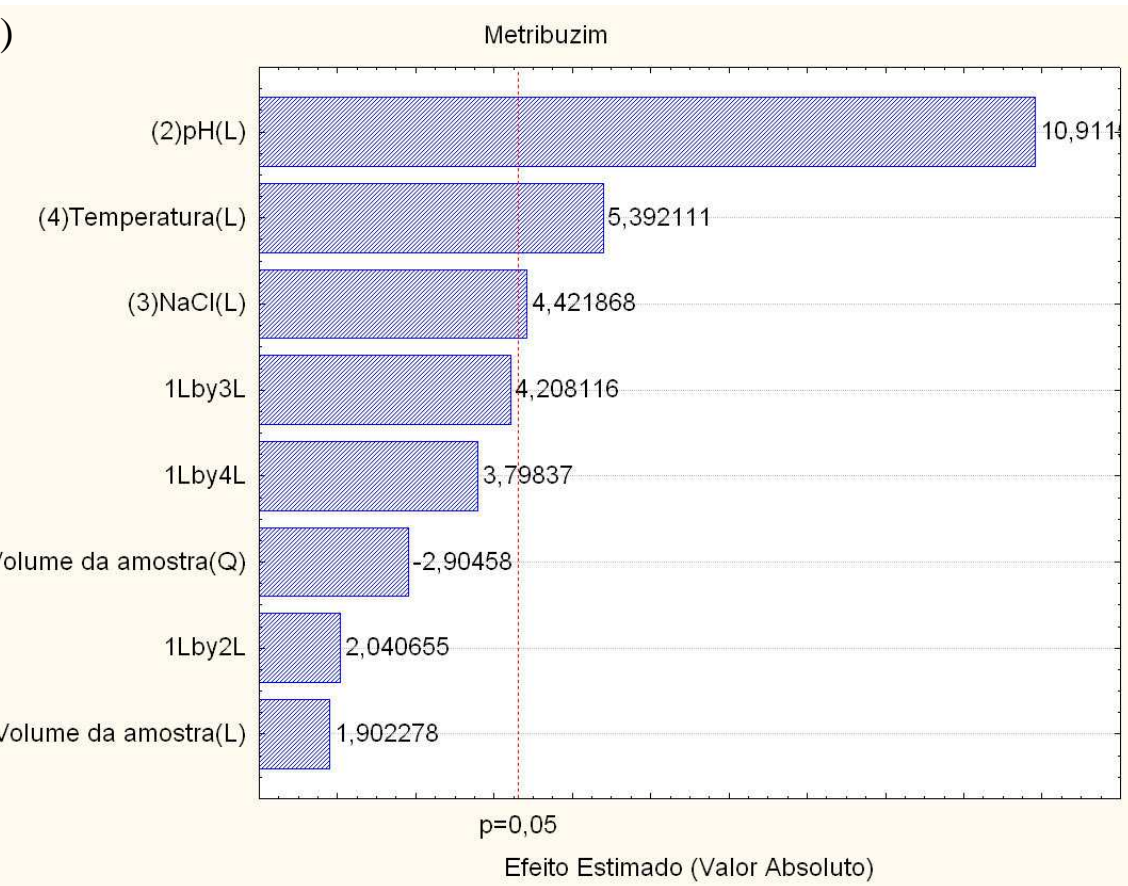

Figura 13. Diagramas de Pareto mostrando os efeitos dos parâmetros avaliados para a extração por SBSE dos 6 pesticidas: (a) Ametrina, (b) Atrazina, (c) Bifentrina, (d) Carbofurano, (e) Metribuzim e (f) Tebutiruom. (continua) 


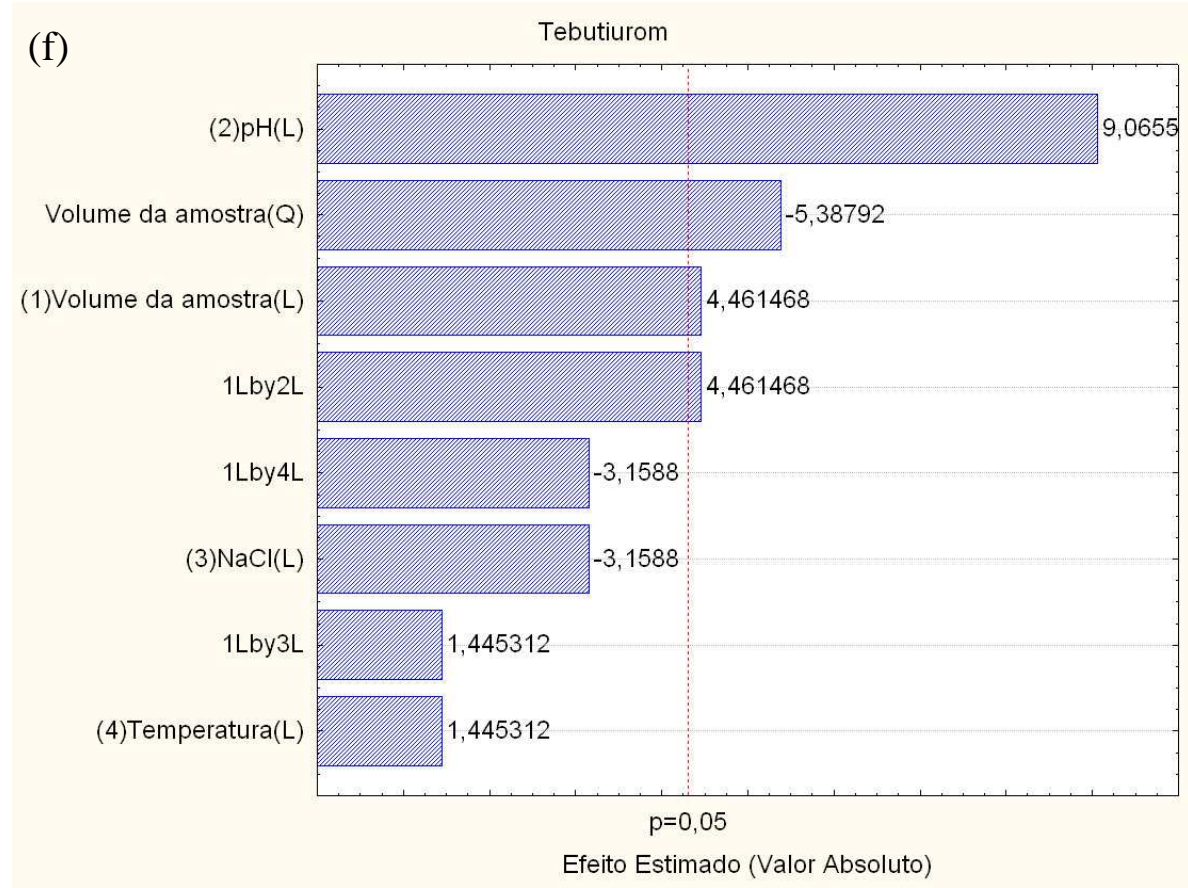

Figura 13. Diagramas de Pareto mostrando os efeitos dos parâmetros avaliados para a extração por SBSE dos 6 pesticidas: (a) Ametrina, (b) Atrazina, (c) Bifentrina, (d) Carbofurano, (e) Metribuzim e (f) Tebutiruom. (conclusão)

O planejamento fatorial fracionário mostrou resultados diferentes para cada composto estudado. Como pode ser observado dos diagramas de Pareto, o pH foi a variável que mais influenciou de forma positiva no processo de extração, apenas apresentando efeito negativo para a bifentrina. Então, com bases nos resultados apresentados, o valor de $\mathrm{pH}$ escolhido foi de 6,5 .

A temperatura apresentou resultados semelhantes para todos os compostos, exceto para o carbufurano. No entanto, o efeito positivo foi significativo apenas para a bifentrina e para o metribuzim. Deste modo, a temperatura de extração definida foi de $70{ }^{\circ} \mathrm{C}$. Acredita-se que os resultados apresentados para o carbofurano com respeito a temperatura de extração sejam devido à sua alta volatilidade, sendo ele o primeiro composto a ser eluído na coluna do GC, mas este não foi significativo estatisticamente.

A força iônica, avaliada por meio da adição de $\mathrm{NaCl}$, apresentou efeito positivo significativo somente para o metribuzim e um efeito negativo significativo para a bifentrina. 
Com base nessa observação, a quantidade de $\mathrm{NaCl}$ foi fixada em $10 \%(\mathrm{~m} / \mathrm{v})$, valor que apresentou o melhor resultado considerando todos os compostos estudados.

O volume de amostra apresentou efeito significativo positivo para a bifentrina e negativo para o carbofurano e o tebutiurom. Além disso, o volume de amostra apresentou efeito de interação positivo com o pH para o tebutiurom e negativo para a bifentrina.

Os modelos obtidos para os seis compostos não estavam de acordo entre si, porém apresentaram coeficientes de correlação adequados e falta de ajuste não significativo, com exceção da bifentrina. A bifentrina apresentou uma tendência oposta em relação aos outros compostos. Então, frente aos resultados obtidos através do planejamento fatorial fracionário $2^{4-1}$, as variáveis $p H$ e quantidade de amostra foram selecionadas para o planejamento compostos central, que é a segunda etapa de otimização.

\subsubsection{Planejamento Composto Central (CCD)}

As variáveis de maior influencia na extração, $\mathrm{pH}$ e volume de amostra, foram otimizados por um planejamento composto central (CCD), de acordo com o item 3.3.6.1. A metodologia de superfície de resposta fornece o ponto ótimo em torno da região experimental disponível. Considerando os resultados obtidos no planejamento fatorial, a temperatura de extração foi fixada a $70{ }^{\circ} \mathrm{C}$ e a força iônica em $10 \% \mathrm{de} \mathrm{NaCl}(\mathrm{m} / \mathrm{v})$.

A Figura 14 mostra a média dos resultados para a superfície de resposta, levando em conta os modelos dos seis analitos. Todos os pesticidas apresentaram um coeficiente de correlação adequado e falta de ajuste não-significativo, com exceção da bifentrina. 


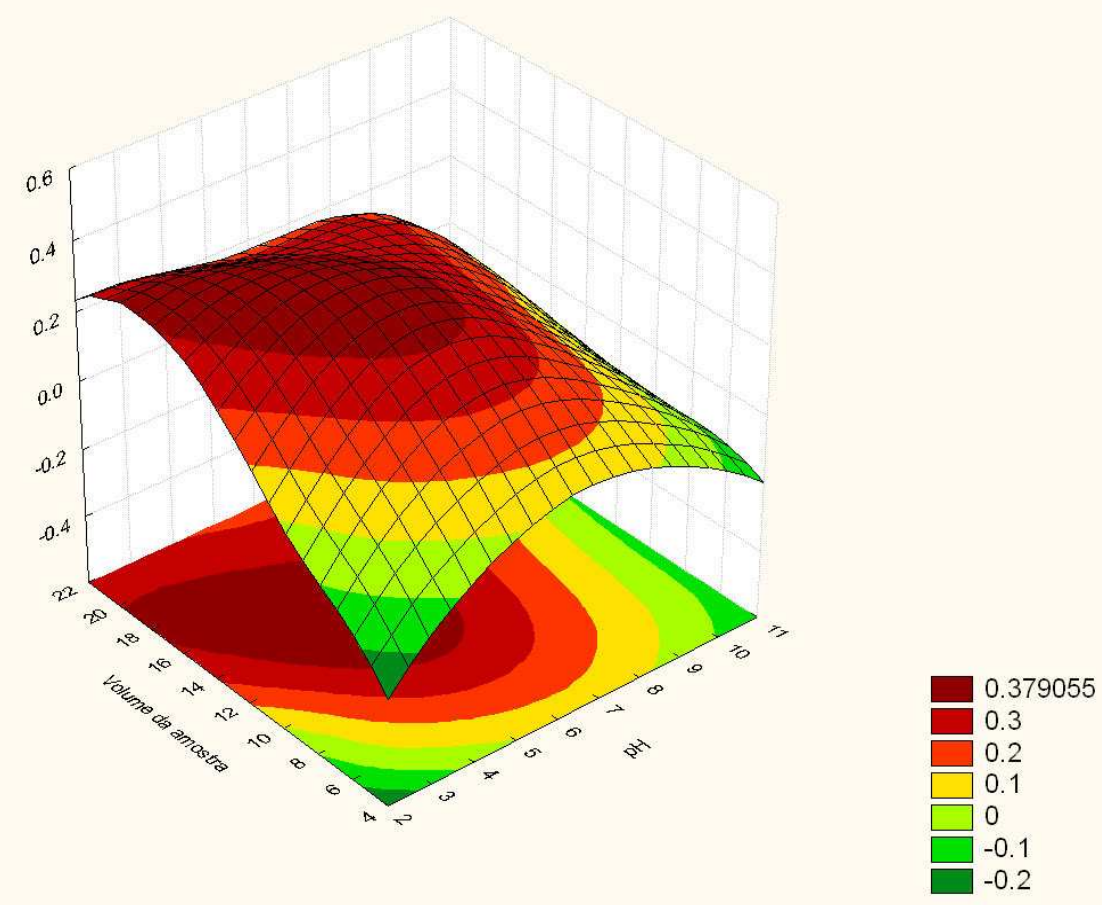

Figura 14 . Superfície de resposta obtida a partir dos resultados do planejamento composto central.

Dessa forma, as condições otimizadas pelo planejamento fatorial para a extração por SBSE dos 6 pesticidas estudados foram: volume de amostra $15,5 \mathrm{~mL}, 70{ }^{\circ} \mathrm{C}, 10 \%$ de $\mathrm{NaCl}$ e pH 6,5. O volume de amostra de $15,5 \mathrm{~mL}$ continha $7,75 \mathrm{ml}$ de garapa e 7,75 mL de solução tampão de acetato de sódio $0,5 \mathrm{~mol} \mathrm{~L}^{-1}$ a $\mathrm{pH}=6,5$. O tempo de extração e a velocidade de agitação foram estudados separadamente.

\subsubsection{Otimização univariada}

A otimização univariada foi realizada conforme o item 3.3.6.3. para a otimização das variáveis: tempo de extração e velocidade de agitação. A Figura 15 mostra a curva cinética, em relação ao tempo de extração, para a extração dos 6 pesticidas estudados nas condições otimizadas. É possível perceber que no tempo de 60 minutos, o equilíbrio foi atingido para a maioria dos compostos. Porém, o tempo de 45 minutos foi escolhido já que houve um bom resultado para a quantidade extraída e também um número maior de ensaios pode ser realizado em um dia. 


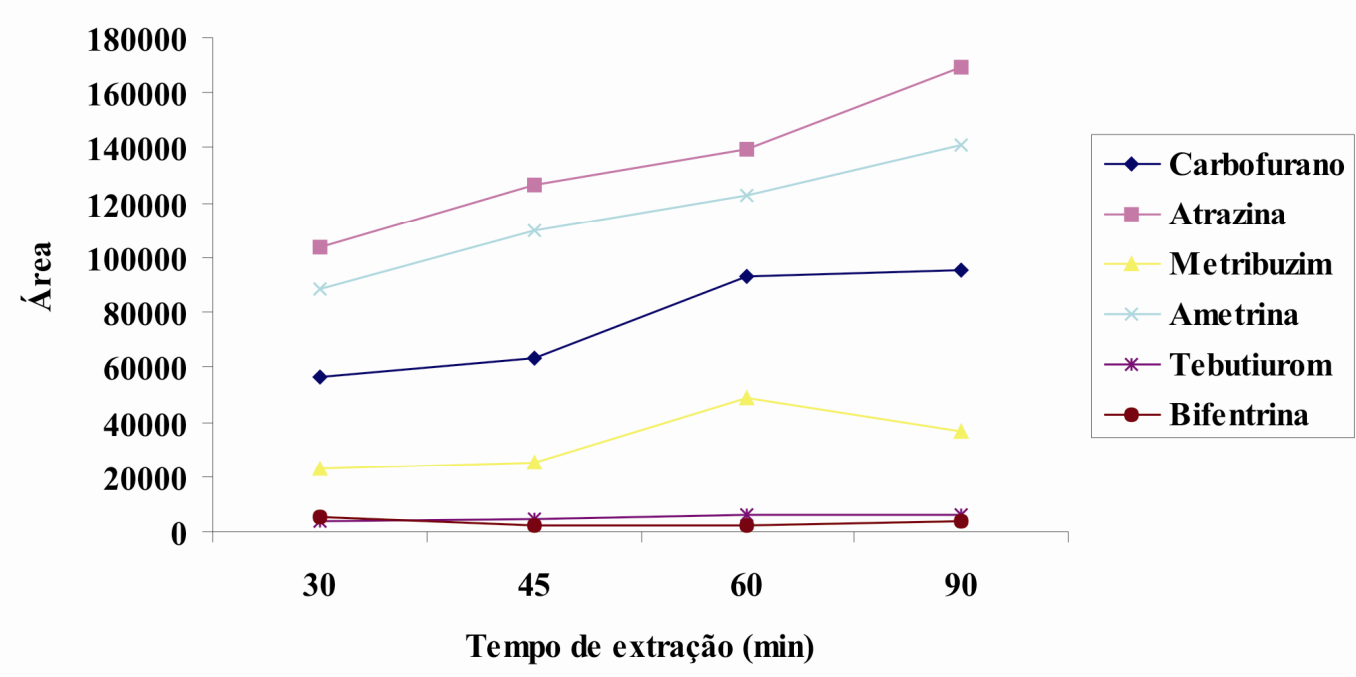

Figura 15. Curva cinética da extração por SBSE dos 6 pesticidas estudados.

A Figura 16 ilustra a curva cinética em relação à velocidade de agitação através da SBSE dos 6 pesticidas estudados nas condições otimizadas. Nota-se que utilizando a velocidade de agitação de 450 rpm o equilíbrio foi atingido para a maioria dos compostos. Deste modo, este valor foi escolhido para ser utilizado nos próximos ensaios.

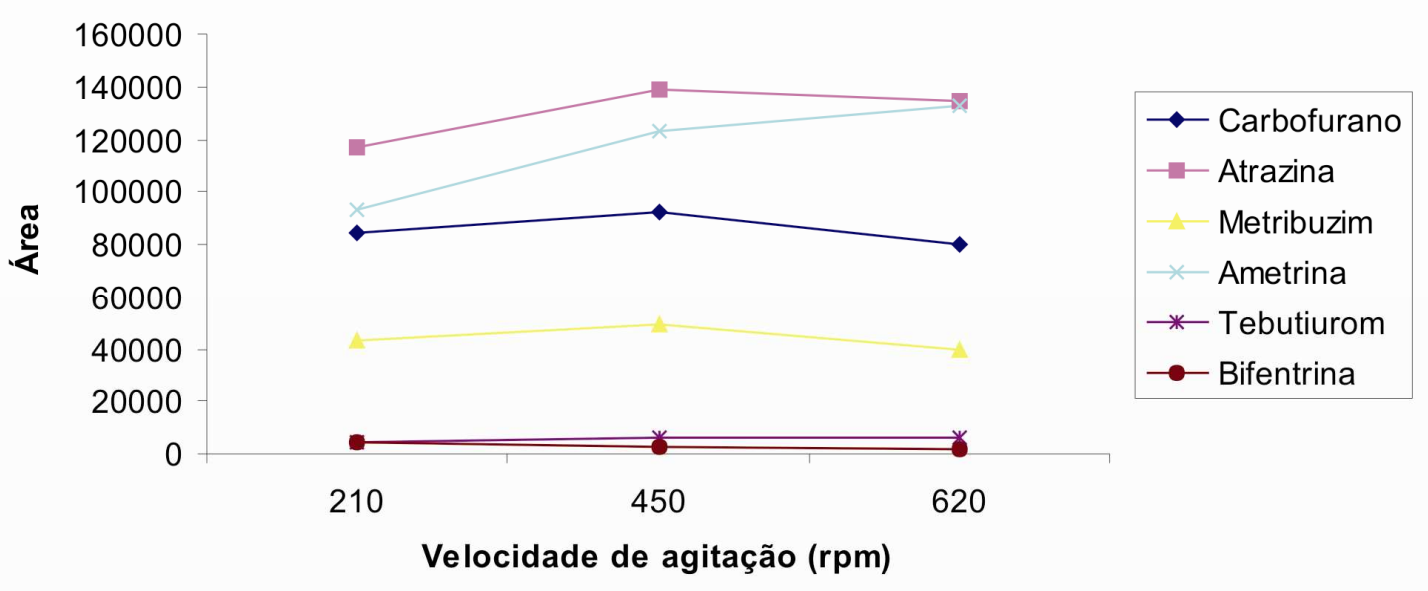

Figura 16. Curva de extração em relação à velocidade de agitação através da SBSE dos 6 pesticidas estudados. 


\subsection{Validação}

\subsubsection{Seletividade}

O método mostrou-se específico, pois quando as amostras de garapa livres de fortificação (branco) foram analisadas, nenhum pico eluiu no mesmo tempo de retenção dos analitos de interesse (Figura 17).

\subsubsection{Linearidade}

A linearidade foi verificada analisando-se os "brancos" das amostras fortificados nas concentrações determinadas, conforme descrito no item 3.3.7.2. Os resultados do estudo de linearidade, a faixa de linearidade avaliada, as equações da reta e os coeficientes de determinação $\left(r^{2}\right)$ e de correlação (r) obtidos estão apresentados na Tabela 15. Os coeficientes de determinação foram maiores que 0,99 para os analitos estudados mostrando a linearidade do método.

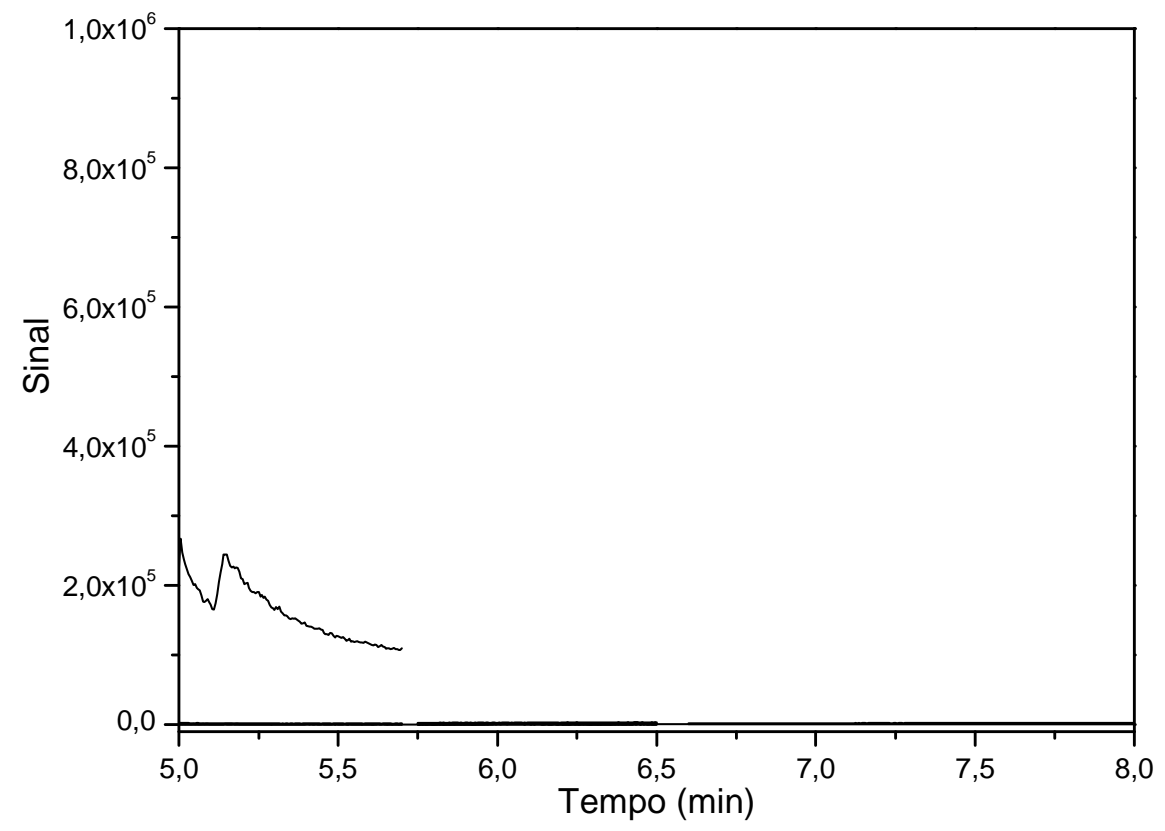

Figura 17. Cromatograma obtido através da injeção de uma extração de uma garapa livre de fortificação no modo SIM. 
Tabela 15. Resultados da linearidade para os 6 pesticidas estudados.

\begin{tabular}{ccccc}
\hline Compostos & Intervalo linear $\left(\mu \mathrm{g} \mathrm{L}^{-1}\right)$ & Equação da reta $(\mathrm{y}=\mathrm{ax}+\mathrm{b})$ & $\mathrm{r}^{2}$ & $\mathrm{r}$ \\
\hline Carbofurano & $0,5-150$ & $\mathrm{y}=1621,5 \mathrm{x}+8532,9$ & 0,9915 & 0,9957 \\
Atrazina & $0,5-200$ & $\mathrm{y}=3521,7 \mathrm{x}-7162,5$ & 0,9930 & 0,9965 \\
Metribuzim & $1-100$ & $\mathrm{y}=1005,6 \mathrm{x}+944,01$ & 0,9947 & 0,9973 \\
Ametrina & $1-50$ & $\mathrm{y}=3037,4 \mathrm{x}-5932,8$ & 0,9906 & 0,9953 \\
Tebutiurom & $40-1350$ & $\mathrm{y}=7,9325 \mathrm{x}+128,48$ & 0,9992 & 0,9996 \\
Bifentrina & $20-1350$ & $\mathrm{y}=2,7407 \mathrm{x}+882,61$ & 0,9962 & 0,9981 \\
\hline
\end{tabular}

A Figura 18 apresenta as curvas de calibração para cada analito e seu respectivo gráfico de resíduo. Através dos gráficos de resíduos e por ANOVA constatou-se que não houve falta de ajuste significativo para o modelo.
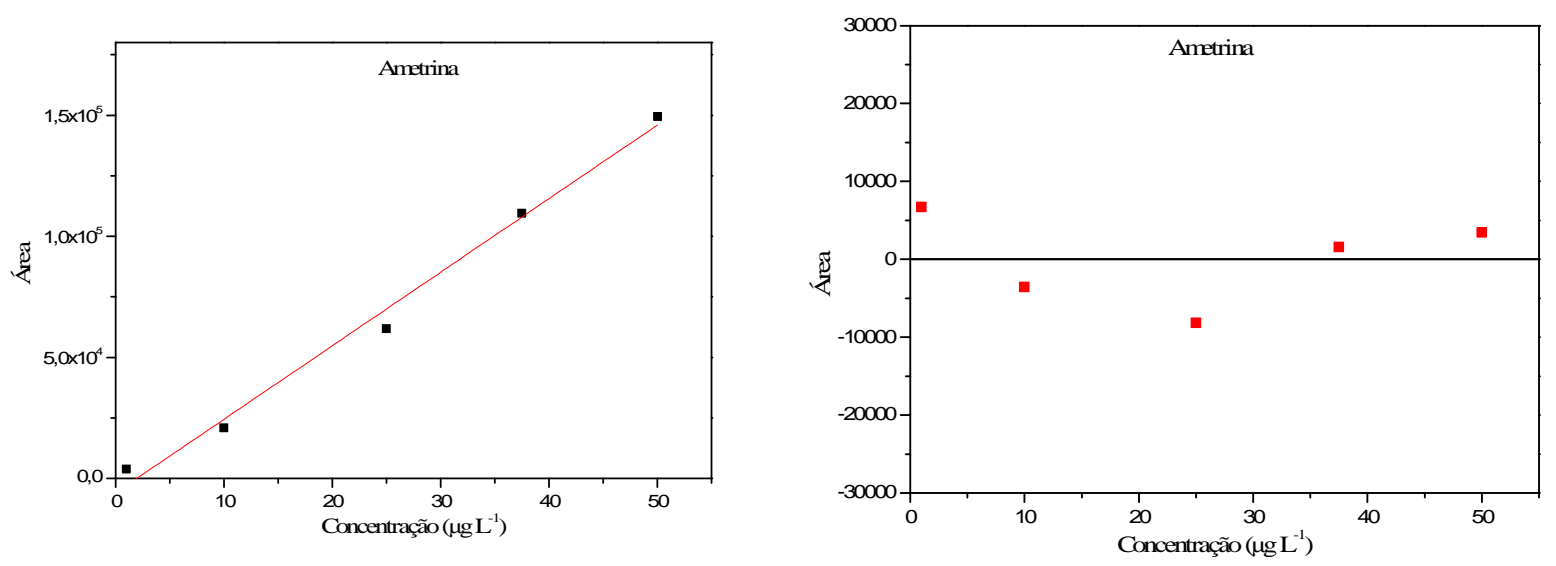

Figura 18. Curvas de calibração e seus respectivos gráfico de resíduos para os 6 pesticidas estudados. (continua) 

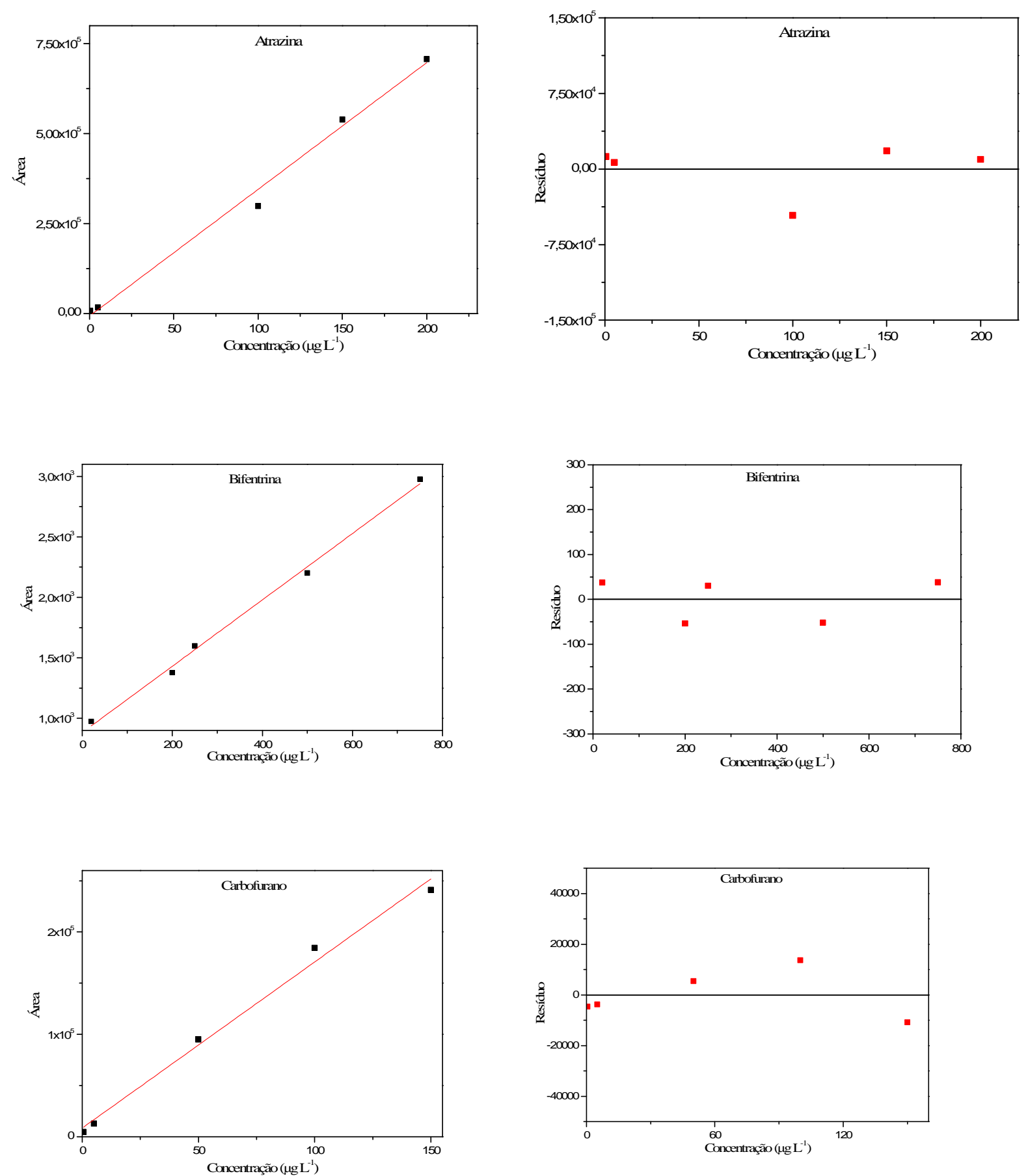

Figura 18. Curvas de calibração e seus respectivos gráfico de resíduos para os 6 pesticidas estudados. (continua) 

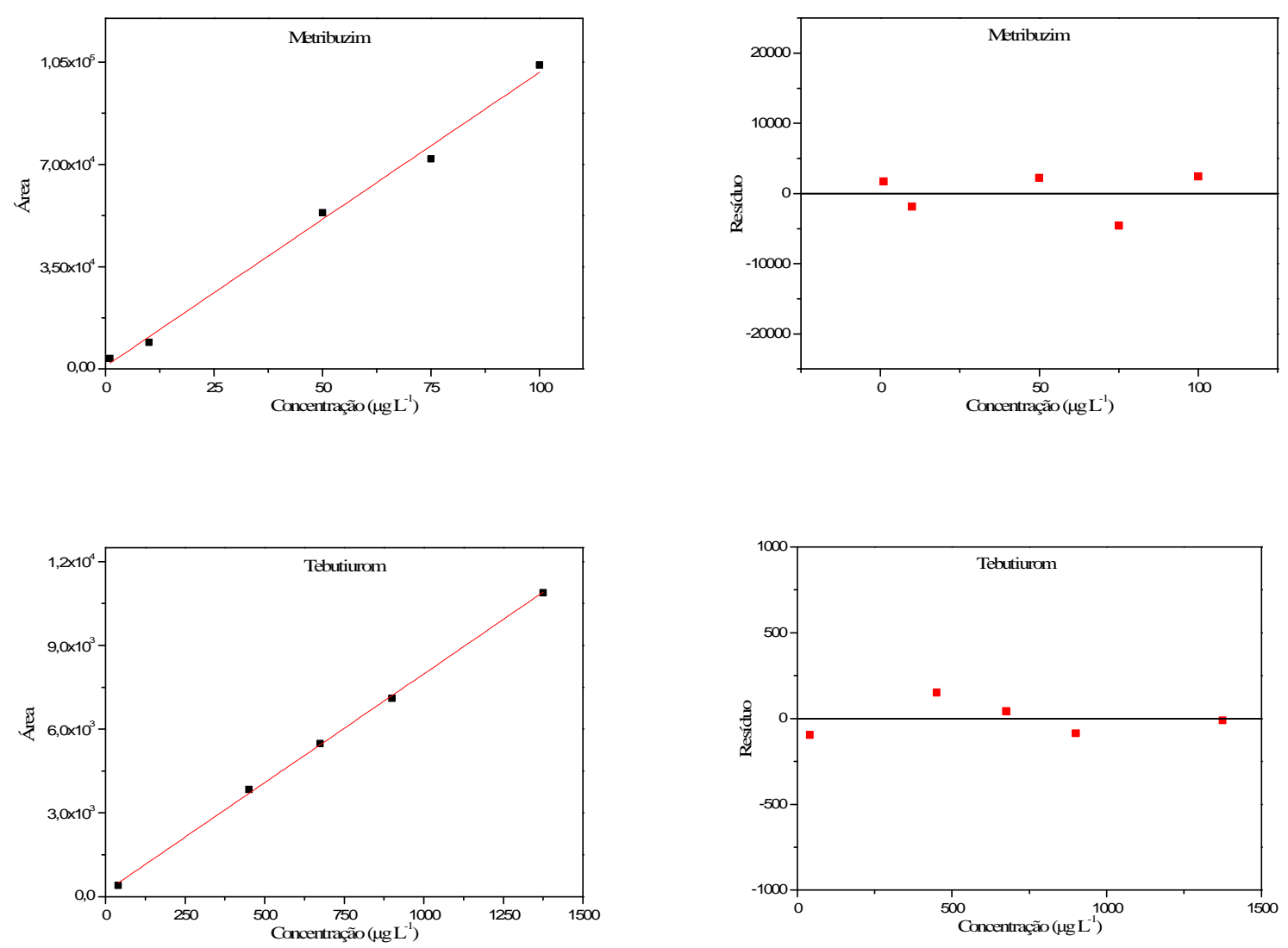

Figura 18. Curvas de calibração e seus respectivos gráfico de resíduos para os 6 pesticidas estudados. (conclusão).

\subsubsection{Precisão}

Os estudos de precisão intra-ensaio foram realizados em três níveis de concentração (baixa, média e alta) em triplicata, conforme descrito no item 3.3.7.3. A precisão foi expressa como Desvio Padrão Relativo (DPR, \%) e os valores obtidos foram menores que 8,4 \% em todas as concentrações avaliadas. Foi considerado como limite máximo o valor de $15 \%$ para DPR. Estes resultados demonstram que o método desenvolvido possui uma precisão adequada (Tabela 16). 
Tabela 16. Dados obtidos da Precisão intra-ensaio para os 6 pesticidas estudados.

\begin{tabular}{ccc}
\hline Compostos & Concentração $\left(\mu \mathrm{g} \mathrm{L}^{-1}\right)$ & Precisão intra-ensaio (DPR, \%) \\
\hline \multirow{3}{*}{ Carbofurano } & 5 & 1,19 \\
& 50 & 2,06 \\
Atrazina & 100 & 4,32 \\
& 5 & 4,99 \\
Metribuzim & 100 & 6,24 \\
& 150 & 6,72 \\
Ametrina & 10 & 2,39 \\
& 50 & 6,86 \\
& 75 & 0,072 \\
Tebutiurom & 10 & 0,87 \\
& 25 & 8,40 \\
& 37,5 & 4,49 \\
& 450 & 3,11 \\
& 675 & 8,40 \\
& 900 & 0,17 \\
& 200 & 0,33 \\
& 250 & 5,33 \\
& 500 & 2,74 \\
\hline
\end{tabular}

\subsubsection{Recuperação}

Os estudos de recuperação foram realizados, como descrito no item 3.3.7.4, em três níveis de concentração (baixa, média e alta) com injeção em triplicata. A Figura 19 ilustra um cromatograma obtido pela injeção de uma extração realizada no nível 3 de concentração.

A Figura 20 mostra os intervalos monitorados obtidos através da injeção de uma extração no nível 3 de concentração, no qual (a) Tempo: 5,2 - 5,7 minutos; (b) Tempo: 5,8 6,5 minutos e (c) Tempo: 6,6-8,0 minutos. 


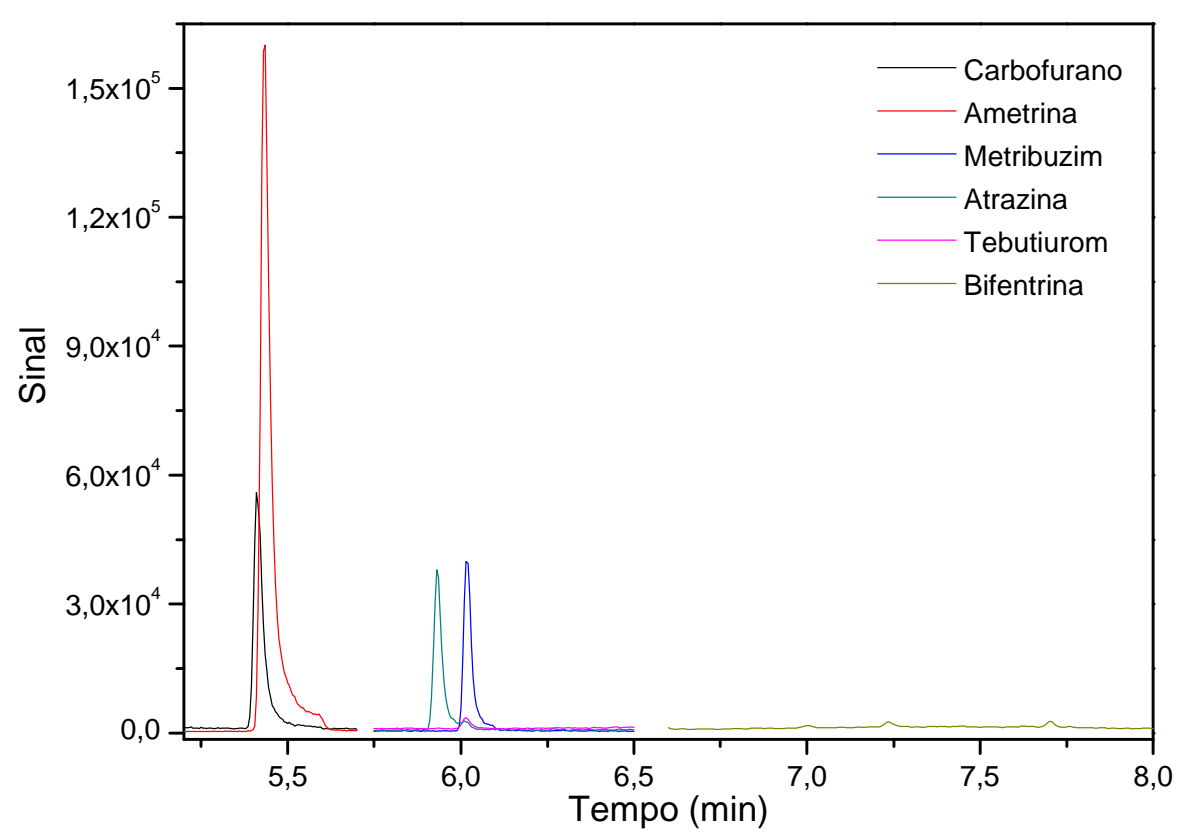

Figura 19. Cromatograma obtido através da injeção de uma extração no nível 3 de concentração.

(a)

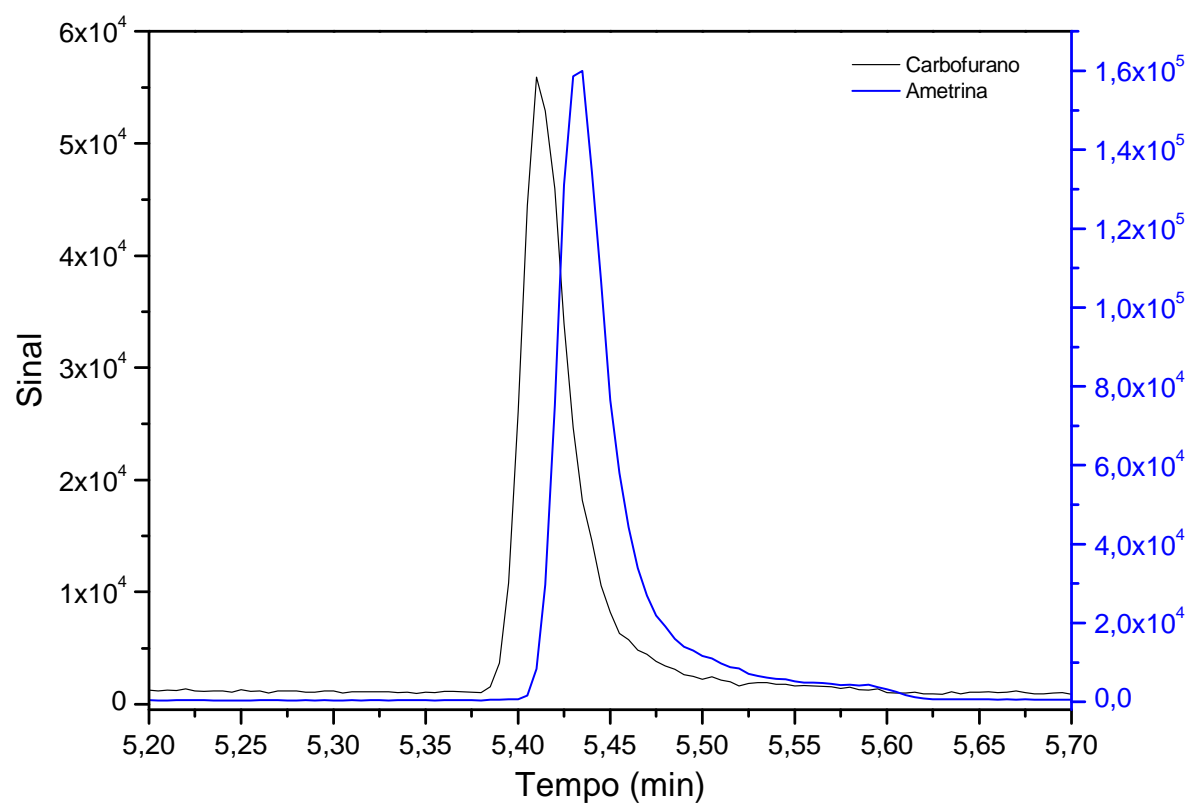

Figura 20. Intervalos monitorados obtidos através da injeção de uma extração no nível 3 de concentração. (a) Tempo: 5,2 - 5,7 minutos; (b) Tempo: 5,8 - 6,5 minutos e (c) Tempo: 6,6-8,0 minutos. (continua) 
(b)

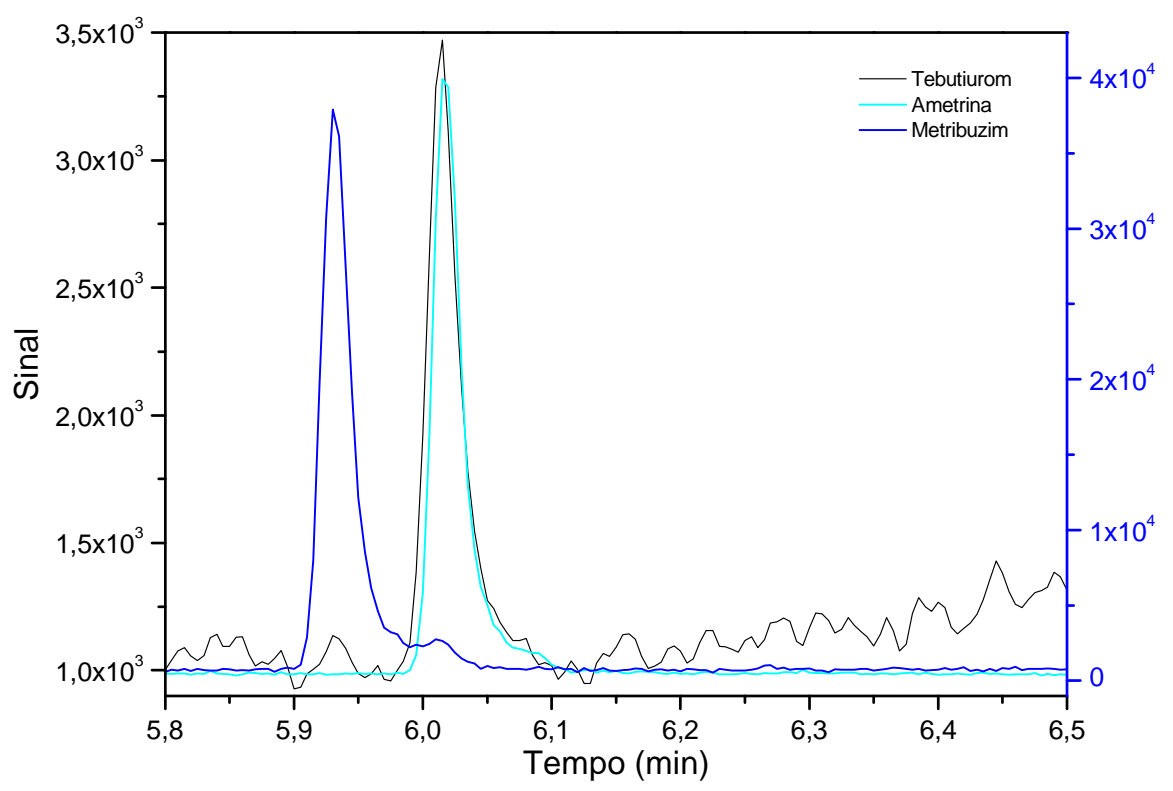

(c)

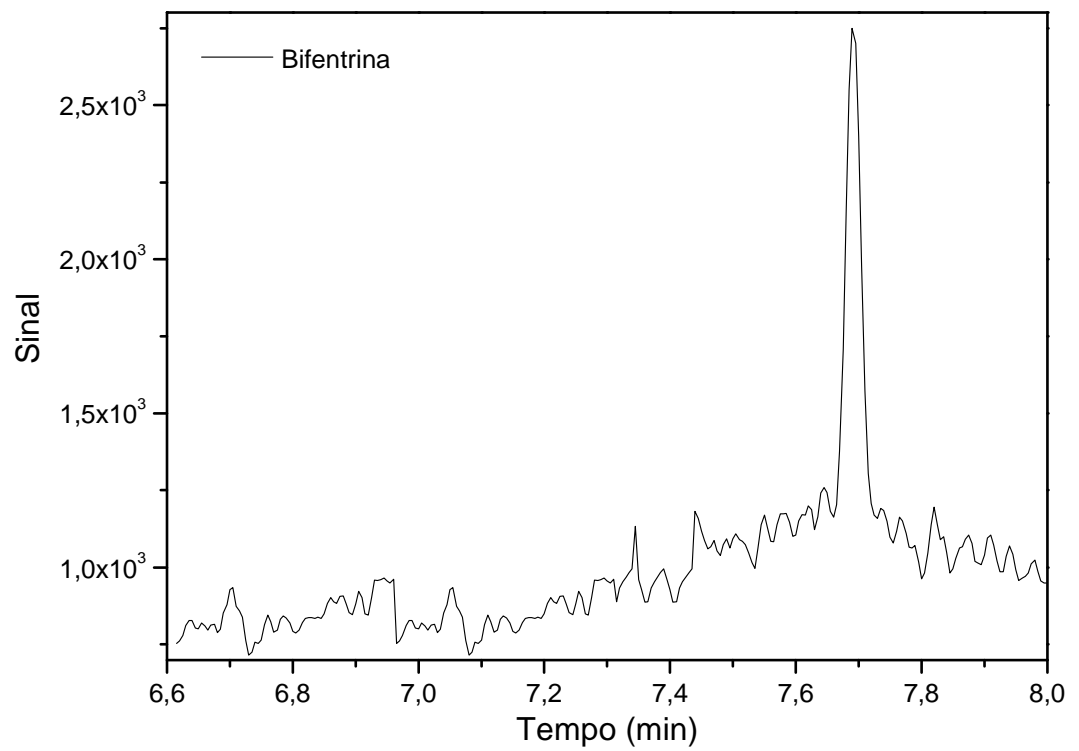

Figura 20. Intervalos monitorados obtidos através da injeção de uma extração no nível 3 de concentração. (a) Tempo: 5,2 - 5,7 minutos; (b) Tempo: 5,8-6,5 minutos e (c) Tempo: 6,6-8,0 minutos. (conclusão).

Os valores de recuperação obtidos estão apresentados na Tabela 17. Estes podem ser considerados baixos quando comparados com outras técnicas de extração, porém, deve-se considerar que a SBSE é uma técnica em microescala na qual a extração não é exaustiva, 
sendo assim, uma certa quantidade dos analitos permanece na solução. Além disso, o mecanismo de extração é baseado na sorção, até atingir o equilíbrio uma certa quantidade do analito é extraída. Após esse evento não é possível extrair mais os analitos ainda presentes na matriz. Dessa forma, é possível explicar a baixa recuperação ainda mais ao considerar que as análises foram realizadas em uma amostra complexa.

Os rendimentos de recuperação observados são bastante comuns em técnicas de sorção (SPME e SBSE), ou seja, onde a extração é regulada por um processo de equilíbrio, no qual o processo de extração não é exaustivo.

Tabela 17. Dados obtidos da Recuperação para os 6 pesticidas estudados.

\begin{tabular}{|c|c|c|}
\hline Compostos & Concentração $\left(\mu \mathrm{g} \mathrm{L}^{-1}\right)$ & Recuperação (\%) \\
\hline \multirow{3}{*}{ Carbofurano } & 5 & 40,09 \\
\hline & 50 & 38,20 \\
\hline & 100 & 34,61 \\
\hline \multirow{3}{*}{ Atrazina } & 5 & 43,83 \\
\hline & 100 & 33,44 \\
\hline & 150 & 34,86 \\
\hline \multirow{3}{*}{ Metribuzim } & 10 & 15,60 \\
\hline & 50 & 12,47 \\
\hline & 75 & 7,08 \\
\hline \multirow{3}{*}{ Ametrina } & 10 & 42,29 \\
\hline & 25 & 43,71 \\
\hline & 37,5 & 49,48 \\
\hline \multirow{3}{*}{ Tebutiurom } & 450 & 46,70 \\
\hline & 675 & 35,76 \\
\hline & 900 & 5,99 \\
\hline \multirow{3}{*}{ Bifentrina } & 200 & 0,18 \\
\hline & 250 & 0,22 \\
\hline & 500 & 0,24 \\
\hline
\end{tabular}


Acredita-se que a bifentrina apresentou valores baixos de recuperação devido a sua baixa polaridade $\left(\log \mathrm{K}_{\mathrm{o} / \mathrm{w}}>6\right.$ ) [90] e sua estrutura química ser volumosa. Em processos adsorptivos é comum acontecer competição pelos sítios extrativos. Em virtude de possuir uma cadeia muito grande, a bifentrina, migrava lentamente para os poros em relação aos demais analitos, dessa maneira grande parte dos poros já continham os analitos o que causava a baixa eficiência na extração desse composto.

\subsubsection{Limites de Detecção (LOD) e de Quantificação (LOQ)}

O limite de detecção (LOD) e de quantificação (LOQ) foram determinados como descrito no item 3.3.7.5.

Os valores do LOQ variaram de 0,5 - $40 \mu \mathrm{g} \mathrm{L}^{-1}$, dependendo do analito, proporcionando um pico cromatográfico em que foi possível observar claramente todos os íons monitorados sem qualquer dúvida, evitando assim o risco de falso positivo. Os valores de LOD e de LOQ estão apresentados na Tabela 18.

O método desenvolvido neste trabalho apresentou LOD menores do que alguns métodos publicados anteriormente, incluindo alguns que utilizam os mesmos compostos. Sampedro et al. [98] mostram resultados para a extração de pesticidas em água de rio utilizando SPME e GC-NPD. Os valores de LOD apresentados para o metribuzim foram de $1,2 \mu \mathrm{g} \mathrm{L} \mathrm{L}^{-1}$ para a fibra de poliacrilato e de $2,97 \mu \mathrm{g} \mathrm{L} \mathrm{L}^{-1}$ para a fibra de PDMS, valores acima do relatados neste trabalho. Portugual et al. [67] relataram um método de extração SBSE utilizando uma nova fase de poliuretana e HPLC-DAD, para herbicidas em matrizes aquosas. Dentre estes a atrazina e ametrina que apresentaram LOD de $0,5 \mu \mathrm{g} \mathrm{L^{-1 }}$ e $0,2 \mu \mathrm{g} \mathrm{L}^{-1}$, respectivamente, maiores do que os apresentados neste estudo. 
Tabela 18. Dados obtidos de Limites de Quantificação (LOQ) e Detecção (LOD) para os 6 pesticidas estudados. Compostos $\quad$ Limite de Quantificação (LOQ, $\mu g \mathrm{~L}^{-1}$ ) Limite de Detecção (LOD, $\mu g \mathrm{~L}^{-1}$ )

\begin{tabular}{ccc}
\hline Carbofurano & 0.5 & 0.145 \\
Atrazina & 0.5 & 0.0662 \\
Metribuzim & 1 & 0.213 \\
Ametrina & 1 & 0.0538 \\
Tebutiurom & 40 & 9.413 \\
Bifentrina & 20 & 6.811 \\
\hline
\end{tabular}

Somente um estudo que descreveu a determinação de pesticidas em garapa foi encontrado na literatura [8]. O método apresentado apresentou valores menores de LOD para

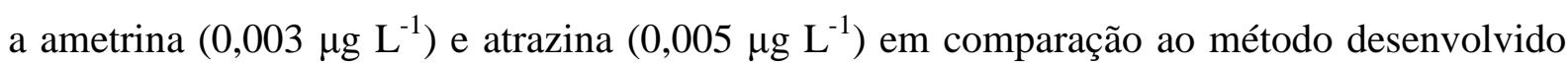
neste trabalho, no entanto, este fato pode ser atribuído ao uso de um sistema de dessorção térmica acoplado a um equipamento de GC-MS de mais nova geração e sensível.

\subsubsection{Amostras reais de garapa}

As amostras de garapa foram adquirida de 3 diferentes fornecedores em São Carlos-SP e tratadas previamente conforme descrito no item 3.3.5. A Tabela 19 mostra os resultados obtidos das análises das amostras de garapa disponíveis comercialmente. Ametrina e atrazina apareceram em todas as amostras em concentrações entre $2,15-3,65 \mu \mathrm{g} \mathrm{L}{ }^{-1}$. Os outros quatro compostos estavam abaixo do LOQ.

Devido a ausência de LMRs para a garapa adotou-se os LMRs recomendados para a cana-de-açúcar, pela ANVISA [10]. Os níveis encontrados de ametrina e atrazina estão abaixo dos LMRs recomendados. Estes resultados indicam que os pesticidas foram aplicados de acordo com as boas práticas agrícolas (BPA), significando que o consumo destas garapas analisadas não causariam riscos para a saúde humana. 
Tabela 19. Resíduos de pesticidas encontrados em garapas disponíveis comercialmente.

\begin{tabular}{cccc}
\hline Compostos & \multicolumn{3}{c}{ Amostras de $\operatorname{garapa}^{\mathrm{a}}\left(\mu \mathrm{g} \mathrm{L}^{-1}\right)$} \\
\cline { 2 - 4 } & 1 & 2 & 3 \\
\hline Carbofurano & - & - & 3.65 \\
Atrazina & 2.71 & 2.76 & $<\mathrm{LO}$ \\
Metribuzim & - & - & 2.42 \\
Ametrina & 2.22 & 2.19 & - \\
Tebutiurom & - & - & - \\
Bifentrina & - & - &
\end{tabular}

a(-): não detectado; <LOQ: abaixo do limite de quantificação. 
5

(Commicllursõones 


\section{CONCLUSÕES}

O estudo realizado apresenta duas das novas tendências da química analítica: a miniaturização de técnicas de extração e o desenvolvimento de novos materiais poliméricos para o recobrimento de barras de agitação para extração sortiva (SBSE).

Devido a algumas dificuldades apresentadas pelo molde anteriormente desenvolvido no Laboratório de Cromatografia, e com o intuito de produzir a fase extratora de SBSE desejada, um novo molde de teflon simplificado foi desenvolvido. Utilizando-se o novo molde foi possível produzir barras SBSE recobertas com um novo polímero sorptivo de extração, o polidimetilsiloxano com $18 \%$ de carbono ativado (PDMS-ACB), em apenas poucos minutos.

A partir dos resultados apresentados foi possível verificar que o PDMS-ACB demonstrou adequado para a extração de compostos polares presentes em uma matriz complexa. A barra SBSE apresentou boa estabilidade mecânica e química, já que foram realizadas cerca de 150 extrações sem danos a fase polimérica.

O delineamento experimental utilizado permitiu avaliar os efeitos das variáveis e da interação entre as variáveis envolvidas na extração SBSE. Além disso, na etapa de otimização foram realizados um número racional de experimentos economizando tempo e evitando o consumo exagerado de amostra e solvente orgânico.

O método desenvolvido demonstrou precisão, LOQ, LOD, linearidade e recuperação adequados para análise de ametrina, atrazina, bifentrina, carbofurano, metribuzim e tebutiurom em garapa usando de SBSE e GC-MS. Além disso, permitiu a separação, identificação e quantificação de resíduos de pesticidas em amostras reais de garapa disponíveis comercialmente na cidade de São Carlos-SP. 


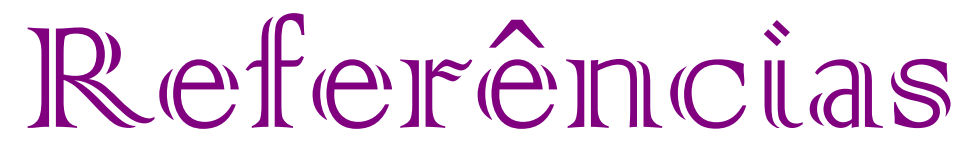

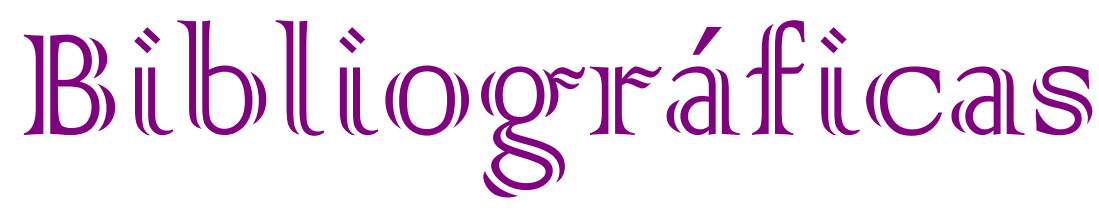




\section{REFERÊNCIAS BIBLIOGRÁFICAS}

\section{MINISTÉRIO DA AGRICULTURA, PECUÁRIA E ABASTECIMENTO (MAPA).} Cana-de-açúcar e agroenergia: estatísticas. Anuário Estatístico da Agroenergia-2009. Disponível em:

<http://www.agricultura.gov.br/images/MAPA/arquivos_portal/anuario_cana.pdf $>$. Acesso em: 17 ago. 2010.

2. UNIÃO DA INDÚSTRIA DE CANA-DE-AÇÚCAR (UNICA). Setor sucroenergético: histórico. Disponível em: <http://www.unica.com.br/content/show.asp?cntCode=9E97665F3A81-46F2-BF69-26E00C323988>. Acesso em: 16 ago. 2010.

\section{COMPANHIA NACIONAL DE ABASTECIMENTO (CONAB). Destaques: $2^{\circ}$} levantamento de cana-de-açúcar 2010. Disponível em: $<$ http://www.conab.gov.br/OlalaCMS/uploads/arquivos/344b55c90f6d37e3beca41418e5df0e 5..pdf $>$. Acesso em: 16 ago. 2010.

\section{SINDICATO NACIONAL DA INDÚSTRIA DE PRODUTOS PARA DEFESA} AGRÍCOLA (SINDAG). Sindag News. Brasil ganha destaque na indústria de defensivos. Disponível em: <http://www.sindag.com.br/noticia.php?News_ID=2019 > . Acesso em: 17 ago. 2010.

\section{COOPERATIVA DE PRODUTORES DE CANA-DE-AÇÚCAR E ÁLCOOL DO} ESTADO DE SÃO PAULO (COPERSUCAR). Institucional. Academia do açúcar e álcool. Cana-de-açúcar. Disponível em: $<$ http://www.copersucar.com.br/institucional/por/academia/cana_acucar.asp $>$. Acesso em: 16 ago. 2010.

6. UNIVERSIDADE ESTADUAL DE CAMPINAS (UNICAMP). Imprensa. Jornal da UNICAMP. Edições anteriores. Disponível em:

<http://www.unicamp.br/unicamp/unicamp_hoje/ju/maio2004/ju250pag8a.html >. Acesso em: 03 jul. 2009.

7. MCGHIE, T. K. Analysis of sugarcane flavonoids by capillary zone electrophoresis. Journal of Chromatography A, v. 634, p. 107-112, 1993.

8. ZUIN, V. G.; SCHELLIN, M.; MONTERO, L.; YARIWAKE, J. H.; AUGUSTO, F.; POPP, P. Comparison of stir bar sorptive extraction and membrane-assisted solvent extraction as enrichment techniques for the determination of pesticide and benzo[a]pyrene residues in Brazilian sugarcane juice. Journal of Chromatography A, v. 1114, p. 180-187, 2006. 
9. TFOUNI, S. A. V.; SOUZA, N. G.; NETO, M. B.; LOREDO, I. S. D.; LEME, F. M.; FURLANI, R. P. Z. Polycyclic aromatic hydrocarbons (PAHs) in sugarcane juice. Food Chemistry, v. 116, p. 391-394, 2009.

10. AGÊNCIA NACIONAL DE VIGILÂNCIA SANITÁRIA (ANVISA). Agrotóxicos e Toxicologia. Monografia. Disponível em:

$<$ http://portal.anvisa.gov.br/wps/portal/anvisa/home/agrotoxicotoxicologia?cat=Monografias + de+Agrotoxicos\&cat1=com.ibm.workplace.wcm.api.WCM_Category/Monografias+de+Agrot oxicos/1c4830004f5fe4aaad62af067ac26136/PUBLISHED\&con=com.ibm.workplace.wcm.a pi.WCM_Content/Monografias+Autorizadas/a7399f0040551d6c878faf89c90d54b4/PUBLIS HED\&showForm=no\&siteArea=Agrotoxicos+e+Toxicologia\&WCM_GLOBAL_CONTEXT =/wps/wcm/connect/Anvisa/Anvisa/Inicio/Agrotoxicos+e+Toxicologia/Publicacao+Agrotoxi cos+e+Toxicologia/Monografias+Autorizadas>. Acesso em: 01 jun. 2009.

\section{SINDICATO NACIONAL DA INDÚSTRIA DE PRODUTOS PARA A DEFESA} AGRÍCOLA (SINDAG). Sindag News. O setor de defensivos agrícolas no Brasil. Disponível em: <http://www.sindag.com.br/noticia.php?News_ID=2065>. Acesso em: 17 ago. 2010.

12. MAJORS, R. E. New approaches to sample preparation. LC-GC, v. 13, p. 82-94, 1995.

13. LANÇAS, F. M. Extração em fase sólida (SPE). São Carlos: RiMa, 2004. 96 p.

14. ARTHUR, C.; PAWLISZYN, J. Solid Phase Microextraction with thermal desorption using fused silica optical fibers. Analytical Chemistry, v. 62, p. 2145-2148, 1990.

15. ALPENDURADA, M. F. Solid-phase microextraction: a promising technique for sample preparation in environmental analysis. Journal of Chromatography A, v. 889, p. 3-14, 2000.

16. LORD, H.; PAWLISZYN, J. Microextraction of drugs. Journal of Chromatography A, v. 902, p. 17-63, 2000.

17. SIGMA-ALDRICH. Products. Solid phase microextraction. SPME fibers assemblies. Disponível em: <http://www.sigmaaldrich.com/analytical-chromatography/analyticalproducts.html?TablePage=9645337> . Acesso em: 18 ago. 2010.

18. BURLESON, G. L.; GONZALEZ, B.; SIMONS, K.; YU, J. C. C. Forensic analysis of a single particle of partially burnt gunpowder by solid phase micro-extraction-gas chromatography-nitrogen phosphorus detector. Journal of Chromatography A, v. 1216, p. 4679-4683, 2009. 
19. MOLLER, M.; ALEKSA, K.; WALASEK, P.; KARASKOV, T.; KOREN, G. Solid-phase microextraction for the detection of codeine, morphine and 6-monoacetylmorphine in human hair by gas chromatography-mass spectrometry. Forensic Science International, v. 196, p. 64-69, 2010.

20. CAMPILLO, N.; PEÑALVER, R.; LÓPEZ-GARCÍA, I.; HERNÁNDEZ-CÓRDOBA, M. Headspace solid-phase microextraction for the determination of volatile organic sulphur and selenium compounds in beers, wines and spirits using gas chromatography and atomic emission detection. Journal of Chromatography A, v. 1216, p. 6735-6740, 2009.

21. CHAI, X. L.; JIA, J. P.; SUN, T. H.; WANG, Y. L. Suitability of a novel circulating cooling SPME for analysis of organophosphorous pesticides in tomatoes. Chromatographia, v. 67, p. $309-313,2008$.

22. LLORENTE, D. D.; ABRODO, P. A.; DE LA FUENTE, E. D.; ALONSO, J. J. M.; ÁLVAREZ, M. D. G.; GOMIS, D. B. A novel method for the determination of total 1,3octanediols in apple juice via 1,3-dioxanes by solid-phase microextraction and high-speed gas chromatography. Journal of Chromatography A, v. 1217, p. 2993-2999, 2010.

23. MENEZES FILHO, A.; DOS SANTOS, F. N.; DE PAULA PEREIRA, P. A. Development, validation and application of a methodology based on solid-phase micro extraction followed by gas chromatography coupled to mass spectrometry (SPME/GC-MS) for the determination of pesticide residues in mangoes. Talanta, v. 81, p. 346-354, 2010.

24. SAISON, D.; DE SCHUTTER, D. P.; DELVAUX, F.; DELVAUX, F. R. Determination of carbonyl compounds in beer by derivatisation and headspace solid-phase microextraction in combination with gas chromatography and mass spectrometry. Journal of

Chromatography A, v. 1216, p. 5061-5068, 2009.

25. VÁZQUEZ, P. P.; MUGHARI, A. R.; GALERA, M. M. Solid-phase microextraction (SPME) for the determination of pyrethroids in cucumber and watermelon using liquid chromatography combined with post-column photochemically induced fluorimetry derivatization and fluorescence detection. Analytica Chimica Acta, v. 607, p. 74-82, 2008.

26. VIÑAS, P.; CAMPILLO, N.; MARTÍNEZ-CASTILLO, N.; HERNÁNDEZ-CÓRDOBA, M. Solid-phase microextraction on-fiber derivatization for the analysis of some polyphenols in wine and grapes using gas chromatography-mass spectrometry. Journal of Chromatography A, v. 1216, p. 1279-1284, 2009. 
27. VIÑAS, P.; CAMPILLO, N.; MARTÍNEZ-CASTILLO, N.; HERNÁNDEZ-CÓRDOBA, M. Method development and validation for strobilurin fungicides in baby foods by solidphase microextraction gas chromatography-mass spectrometry. Journal of Chromatography A, v. 1216, p. 140-146, 2009.

28. FERNANDES, C.; NETO, A. J. D. S.; RODRIGUES, J. C.; ALVES, C.; LANÇAS, F. M. Solid-phase microextraction-liquid chromatography (SPME-LC) determination of fluoxetine and norfluoxetine in plasma using a heated liquid flow through interface. Journal of Chromatography B, v. 847, p. 217-223, 2007.

29. OLSZOWY, P.; SZULTKA, M.; LIGOR, T.; NOWACZYK, J.; BUSZEWSKI, B. Fibers with polypyrrole and polythiophene phases for isolation and determination of adrenolytic drugs from human plasma by SPME-HPLC. Journal of Chromatography B, v. 878, p. 2226-2234, 2010.

30. LIU, H.; LIU, L.; XIONG, Y.; YANG, X.; LUAN, T. Simultaneous determination of UV filters and polycyclic musks in aqueous samples by solid-phase microextraction and gas chromatography-mass spectrometry. Journal of Chromatography A, v. 1217, p. 6747-6753, 2010.

31. LLOP, A.; POCURULL, E.; BORRULL, F. Automated determination of aliphatic primary amines in wastewater by simultaneous derivatization and headspace solid-phase microextraction followed by gas chromatography-tandem mass spectrometry. Journal of Chromatography A, v. 1217, p. 575-581, 2010.

32. PASSEPORT, E.; GUENNE, A.; CULHAOGLU, T.; MOREAU, S.; BOUYÉ, J.-M.; TOURNEBIZE, J. Design of experiments and detailed uncertainty analysis to develop and validate a solid-phase microextraction/gas chromatography-mass spectrometry method for the simultaneous analysis of 16 pesticides in water. Journal of Chromatography A, v. 1217, p. 5317-5327, 2010.

33. REGUEIRO, J.; LLOMPART, M.; GARCIA-JARES, C.; CELA, R. Development of a solid-phase microextraction-gas chromatography-tandem mass spectrometry method for the analysis of chlorinated toluenes in environmental waters. Journal of Chromatography A, v. 1216, p. 2816-2824, 2009.

34. MMUALEFE, L. C.; TORTO, N.; HUNTSMAN-MAPILA, P.; MBONGWE, B. Headspace solid phase microextraction in the determination of pesticides in water samples from the Okavango Delta with gas chromatography-electron capture detection and time-offlight mass spectrometry. Microchemical Journal, v. 91, p. 239-244, 2009. 
35. BALTUSSEN, E.; SANDRA, P.; DAVID, F.; CRAMERS, C. Stir bar sorptive extraction (SBSE), a novel extraction technique for aqueous samples: Theory and principles. Journal of Microcolumn Separations, v. 11, p. 737-747, 1999.

36. CAMPILLO, N.; VIÑAS, P.; AGUINAGA, N.; FÉREZ, G.; HERNÁNDEZ-CÓRDOBA, M. Stir bar sorptive extraction coupled to liquid chromatography for the analysis of strobilurin fungicides in fruit samples. Journal of Chromatography A, v. 1217, p. 4529-4534, 2010.

37. COELHO, E.; COIMBRA, M. A.; NOGUEIRA, J. M. F.; ROCHA, S. M. Quantification approach for assessment of sparkling wine volatiles from different soils, ripening stages, and varieties by stir bar sorptive extraction with liquid desorption. Analytica Chimica Acta, v. 635, p. 214-221, 2009.

38. FRANC, C.; DAVID, F.; DE REVEL, G. Multi-residue off-flavour profiling in wine using stir bar sorptive extraction-thermal desorption-gas chromatography-mass spectrometry. Journal of Chromatography A, v. 1216, p. 3318-3327, 2009.

39. RIDGWAY, K.; LALLJIE, S. P. D.; SMITH, R. M. The use of stir bar sorptive extraction--A potential alternative method for the determination of furan, evaluated using two example food matrices. Analytica Chimica Acta, v. 657, p. 169-174, 2010.

40. BARRIADA-PEREIRA, M.; SERÔDIO, P.; GONZÁLEZ-CASTRO, M. J.; NOGUEIRA, J. M. F. Determination of organochlorine pesticides in vegetable matrices by stir bar sorptive extraction with liquid desorption and large volume injection-gas chromatography-mass spectrometry towards compliance with European Union directives. Journal of Chromatography A, v. 1217, p. 119-126, 2010.

41. GIORDANO, A.; FERNANDEZ-FRANZON, M.; RUIZ, M. J.; FONT, G.; PICO, Y. Pesticide residue determination in surface waters by stir bar sorptive extraction and liquid chromatography/tandem mass spectrometry. Analytical and Bioanalytical Chemistry, v. 393, p. 1733-1743, 2009.

42. GROSSI, P.; OLIVARES, I. R. B.; DE FREITAS, D. R.; LANCAS, F. M. A novel HSSBSE system coupled with gas chromatography and mass spectrometry for the analysis of organochlorine pesticides in water samples. Journal of Separation Science, v. 31, p. 36303637, 2008.

43. VAN HOECK, E.; CANALE, F.; CORDERO, C.; COMPERNOLLE, S.; BICCHI, C.; SANDRA, P. Multiresidue screening of endocrine-disrupting chemicals and pharmaceuticals in aqueous samples by multi-stir bar sorptive extraction-single desorption-capillary gas chromatography/mass spectrometry. Analytical and Bioanalytical Chemistry, v. 393, p. 907-919, 2009. 
44. ITO, R.; KAWAGUCHI, M.; SAKUI, N.; OKANOUCHI, N.; SAITO, K.; SETO, Y.; NAKAZAWA, H. Stir bar sorptive extraction with in situ derivatization and thermal desorption-gas chromatography-mass spectrometry for trace analysis of methylmercury and mercury(II) in water sample. Talanta, v. 77, p. 1295-1298, 2009.

45. KLEIN, D. R.; FLANNELLY, D. F.; SCHULTZ, M. M. Quantitative determination of triclocarban in wastewater effluent by stir bar sorptive extraction and liquid desorption-liquid chromatography-tandem mass spectrometry. Journal of Chromatography A, v. 1217, p. 1742-1747, 2010.

46. LLORCA-PÓRCEL, J.; MARTÍNEZ-PARREÑO, M.; MARTÍNEZ-SORIANO, E.; VALOR, I. Analysis of chlorophenols, bisphenol-A, 4-tert-octylphenol and 4-nonylphenols in soil by means of ultrasonic solvent extraction and stir bar sorptive extraction with in situ derivatisation. Journal of Chromatography A, v. 1216, p. 5955-5961, 2009.

47. MACNAMARA, K.; LEARDI, R.; MCGUIGAN, F. Comprehensive investigation and optimisation of the main experimental variables in stir-bar sorptive extraction (SBSE)-thermal desorption-capillary gas chromatography (TD-CGC). Analytica Chimica Acta, v. 636, p. 190-197, 2009.

48. SÁNCHEZ-AVILA, J.; QUINTANA, J.; VENTURA, F.; TAULER, R.; DUARTE, C. M.; LACORTE, S. Stir bar sorptive extraction-thermal desorption-gas chromatography-mass spectrometry: An effective tool for determining persistent organic pollutants and nonylphenol in coastal waters in compliance with existing Directives. Marine Pollution Bulletin, v. 60, p. 103-112, 2010.

49. SANCHEZ-ORTEGA, A.; UNCETA, N.; GÓMEZ-CABALLERO, A.; SAMPEDRO, M. C.; AKESOLO, U.; GOICOLEA, M. A.; BARRIO, R. J. Sensitive determination of triazines in underground waters using stir bar sorptive extraction directly coupled to automated thermal desorption and gas chromatography-mass spectrometry. Analytica Chimica Acta, v. 641, p. 110-116, 2009.

50. SILVA, A. R. M.; NOGUEIRA, J. M. F. Stir-bar-sorptive extraction and liquid desorption combined with large-volume injection gas chromatography-mass spectrometry for ultra-trace analysis of musk compounds in environmental water matrices. Analytical and Bioanalytical Chemistry, v. 396, p. 1853-1862, 2010.

51. BALBÃO, M. S.; BERTUCCI, C.; BERGAMASCHI, M. M.; QUEIROZ, R. H. C.; MALFARÁ, W. R.; DREOSSI, S. A. C.; DE PAULA MELLO, L.; QUEIROZ, M. E. C. Rifampicin determination in plasma by stir bar-sorptive extraction and liquid chromatography. Journal of Pharmaceutical and Biomedical Analysis, v. 51, p. 1078-1083, 2010. 
52. UNCETA, N.; UGARTE, A.; SÁNCHEZ, A.; GÓMEZ-CABALLERO, A.; GOICOLEA, M. A.; BARRIO, R. J. Development of a stir bar sorptive extraction based HPLC-FLD method for the quantification of serotonin reuptake inhibitors in plasma, urine and brain tissue samples. Journal of Pharmaceutical and Biomedical Analysis, v. 51, p. 178-185, 2010.

53. QUEIROZ, M. E. C. Extração sortiva em barra de agitação (SBSE): Fundamentos teóricos e fases seletivas. Scientia Chromatographica, v. 1, p. 21-29, 2009.

54. ALMEIDA, C., ROSÁRIO, P., SERÔDIO, P., NOGUEIRA, J. M. F. Novas perspectivas na preparação de amostras para análise cromatográfica. Química, v. 95, p. 69-77, 2004.

55. BLASCO, C.; FERNÁNDEZ, M.; PICÓ, Y.; FONT, G. Comparison of solid-phase microextraction and stir bar sorptive extraction for determining six organophosphorus insecticides in honey by liquid chromatography-mass spectrometry. Journal of Chromatography, v. 1030, p. 77-85, 2004.

56. DE JAGER, L. S.; PERFETTI, G. A.; DIACHENKO, G. W. Stir bar sorptive extractiongas chromatography-mass spectrometry analysis of tetramethylene disulfotetramine in food: Method development and comparison to solid-phase microextraction. Analytica Chimica Acta, v. 635, p. 162-166, 2009.

57. MAGGI, L.; ZALACAIN, A.; MAZZOLENI, V.; ALONSO, G. L.; SALINAS, M. R. Comparison of stir bar sorptive extraction and solid-phase microextraction to determine halophenols and haloanisoles by gas chromatography-ion trap tandem mass spectrometry. Talanta, v. 75, p. 753-759, 2008.

58. LIU, W.; WANG, H.; GUAN, Y. Preparation of stir bars for sorptive extraction using solgel technology. Journal of Chromatography A, v. 1045, p. 15-22, 2004.

59. LAMBERT, J.-P.; MULLETT, W. M.; KWONG, E.; LUBDA, D. Stir bar sorptive extraction based on restricted access material for the direct extraction of caffeine and metabolites in biological fluids. Journal of Chromatography A, v. 1075, p. 43-49, 2005.

60. BICCHI, C.; CORDERO, C.; LIBERTO, E.; RUBIOLO, P.; SGORBINI, B.; DAVID, F.; SANDRA, P. Dual-phase twisters: A new approach to headspace sorptive extraction and stir bar sorptive extraction. Journal of Chromatography A, v. 1094, p. 9-16, 2005.

61. ZHU, X.; CAI, J.; YANG, J.; SU, Q.; GAO, Y. Films coated with molecular imprinted polymers for the selective stir bar sorption extraction of monocrotophos. Journal of Chromatography A, v. 1131, p. 37-44, 2006. 
62. HUANG, X.; YUAN, D. Preparation of stir bars for sorptive extraction based on monolithic material. Journal of Chromatography A, v. 1154, p. 152-157, 2007.

63. HU, Y.; ZHENG, Y.; ZHU, F.; LI, G. Sol-gel coated polydimethylsiloxane/[beta]cyclodextrin as novel stationary phase for stir bar sorptive extraction and its application to analysis of estrogens and bisphenol A. Journal of Chromatography A, v. 1148, p. 16-22, 2007.

64. YU, C.; HU, B. Novel combined stir bar sorptive extraction coupled with ultrasonic assisted extraction for the determination of brominated flame retardants in environmental samples using high performance liquid chromatography. Journal of Chromatography A, v. 1160, p. 71-80, 2007.

65. NENG, N. R.; PINTO, M. L.; PIRES, J.; MARCOS, P. M.; NOGUEIRA, J. M. F. Development, optimisation and application of polyurethane foams as new polymeric phases for stir bar sorptive extraction. Journal of Chromatography A, v. 1171, p. 8-14, 2007.

66. BICCHI, C.; CORDERO, C.; LIBERTO, E.; SGORBINI, B.; DAVID, F.; SANDRA, P.; RUBIOLO, P. Influence of polydimethylsiloxane outer coating and packing material on analyte recovery in dual-phase headspace sorptive extraction. Journal of Chromatography A, v. 1164, p. 33-39, 2007.

67. PORTUGAL, F. C. M.; PINTO, M. L.; NOGUEIRA, J. M. F. Optimization of Polyurethane Foams for Enhanced Stir Bar Sorptive Extraction of Triazinic Herbicides in Water Matrices. Talanta, v. 77, p. 765-773, 2008.

68. SILVA, A. R. M.; PORTUGAL, F. C. M.; NOGUEIRA, J. M. F. Advances in stir bar sorptive extraction for the determination of acidic pharmaceuticals in environmental water matrices: Comparison between polyurethane and polydimethylsiloxane polymeric phases. Journal of Chromatography A, v. 1209, p. 10-16, 2008.

69. HUANG, X.; QIU, N.; YUAN, D. Direct enrichment of phenols in lake and sea water by stir bar sorptive extraction based on poly (vinylpyridine-ethylene dimethacrylate) monolithic material and liquid chromatographic analysis. Journal of Chromatography A, v. 1194, p. 134-138, 2008.

70. HUANG, X.; YUAN, D.; HUANG, B. Determination of steroid sex hormones in urine matrix by stir bar sorptive extraction based on monolithic material and liquid chromatography with diode array detection. Talanta, v. 75, p. 172-177, 2008. 
71. GUAN, W.; WANG, Y.; XU, F.; GUAN, Y. Poly(phthalazine ether sulfone ketone) as novel stationary phase for stir bar sorptive extraction of organochlorine compounds and organophosphorus pesticides. Journal of Chromatography A, v. 1177, p. 28-35, 2008.

72. MELO, L. P.; NOGUEIRA, A. M.; LANÇAS, F. M.; QUEIROZ, M. E. C. Polydimethylsiloxane/polypyrrole stir bar sorptive extraction and liquid chromatography (SBSE/LC-UV) analysis of antidepressants in plasma samples. Analytica Chimica Acta, v. 633, p. 57-64, 2009.

73. YU, C. H.; HU, B. Sol-gel polydimethylsiloxane/poly(vinylalcohol)-coated stir bar sorptive extraction of organophosphorus pesticides in honey and their determination by large volume injection GC. Journal of Separation Science, v. 32, p. 147-153, 2009.

74. YU, C.; YAO, Z.; HU, B. Preparation of polydimethylsiloxane/[beta]cyclodextrin/divinylbenzene coated "dumbbell-shaped" stir bar and its application to the analysis of polycyclic aromatic hydrocarbons and polycyclic aromatic sulfur heterocycles compounds in lake water and soil by high performance liquid chromatography. Analytica Chimica Acta, v. 641, p. 75-82, 2009.

75. HUANG, X. J.; QIU, N. N.; YUAN, D. X. Development and validation of stir bar sorptive extraction of polar phenols in water followed by HPLC separation in poly(vinylpyrrolididonedivinylbenzene) monolith. Journal of Separation Science, v. 32, p. 1407-1414, 2009.

76. HUANG, X.; QIU, N.; YUAN, D.; HUANG, B. A novel stir bar sorptive extraction coating based on monolithic material for apolar, polar organic compounds and heavy metal ions. Talanta, v. 78, p. 101-106, 2009.

77. HUANG, X.; QIU, N.; YUAN, D. Simple and sensitive monitoring of sulfonamide veterinary residues in milk by stir bar sorptive extraction based on monolithic material and high performance liquid chromatography analysis. Journal of Chromatography A, v. 1216, p. 8240-8245, 2009.

78. HUANG, X.; LIN, J.; YUAN, D.; HU, R. Determination of steroid sex hormones in wastewater by stir bar sorptive extraction based on poly(vinylpyridine-ethylene dimethacrylate) monolithic material and liquid chromatographic analysis. Journal of Chromatography A, v. 1216, p. 3508-3511, 2009.

79. HUANG, X.; QIU, N.; YUAN, D.; LIN, Q. Sensitive determination of strongly polar aromatic amines in water samples by stir bar sorptive extraction based on poly(vinylimidazole-divinylbenzene) monolithic material and liquid chromatographic analysis. Journal of Chromatography A, v. 1216, p. 4354-4360, 2009. 
80. HUANG, X.; QIU, N.; YUAN, D.; LIN, Q. Preparation of a mixed stir bar for sorptive extraction based on monolithic material for the extraction of quinolones from wastewater. Journal of Chromatography A, v. 1217, p. 2667-2673, 2010.

81. HUANG, X.; LIN, J.; YUAN, D. A new anionic exchange stir bar sorptive extraction coating based on monolithic material for the extraction of inorganic anion. Journal of Chromatography A, v. 1217, p. 4898-4903, 2010.

82. HU, Y.; LI, J.; HU, Y.; LI, G. Development of selective and chemically stable coating for stir bar sorptive extraction by molecularly imprinted technique. Talanta, v. 82, p. 464-470, 2010.

83. YANG, L.; ZHAO, X.; ZHOU, J. Selective enrichment and determination of nicosulfuron in water and soil by a stir bar based on molecularly imprinted polymer coatings. Analytica Chimica Acta, v. 670, p. 72-77, 2010.

84. XU, Z.; HU, Y.; HU, Y.; LI, G. Investigation of ractopamine molecularly imprinted stir bar sorptive extraction and its application for trace analysis of [beta]2-agonists in complex samples. Journal of Chromatography A, v. 1217, p. 3612-3618, 2010.

85. PORTUGAL, F. C. M.; PINTO, M. L.; PIRES, J.; NOGUEIRA, J. M. F. Potentialities of polyurethane foams for trace level analysis of triazinic metabolites in water matrices by stir bar sorptive extraction. Journal of Chromatography A, v. 1217, p. 3707-3710, 2010.

86. BARROS NETO, B.; SCARMÍNIO, I. S.; BRUNS, R. E. Planejamento e otimização de experimentos. Campinas: Editora da Unicamp, 1995. 299 p.

87. TEÓFILO, R. F.; FERREIRA, M. M. C. Quimiometria II: Planilhas eletrônicas para cálculos de planejamentos experimentais, um tutorial. Química Nova, v. 29, p. 338-350, 206.

88. BEZERRA, M. D. A. Aplicação de matriz de Doehlert na otimização de um sistema de pré-concentração em linha para determinação de cobre usando Espectrometria de absorção atômica com chama. 2007. 95 f. Dissertação (Mestrado em Ciências) - Instituto de Química, Universidade Federal da Bahia, Salvador, 2007.

89. TOMIN, C. D. S. The pesticide manual. Hampshire: British Crop Production Council, 2006. $1480 \mathrm{p}$. 
90. NOGUEIRA, A. M. Desenvolvimento, análise, aplicação de novas fases para extração por sorção em barra de agitação (SBSE). 2007. 118 f. Dissertação (Mestrado em ciências) Instituto de Química de São Carlos, Universidade de São Paulo, São Carlos, 2007.

91. PAGE, B. D.; LACROIX, G. Analysis of volatile contaminants in vegetable oils by headspace solid-phase microextraction with Carboxen-based fibres. Journal of Chromatography A, v. 873, p. 79-94, 2000.

92. ANTALICK, G.; PERELLO, M.-C.; DE REVEL, G. Development, validation and application of a specific method for the quantitative determination of wine esters by headspace-solid-phase microextraction-gas chromatography-mass spectrometry. Food Chemistry, v. 121, p. 1236-1245, 2010.

93. CAMPILLO, N.; PEÑALVER, R.; HERNÁNDEZ-CÓRDOBA, M. Determination of dimethylselenide and dimethyldiselenide in milk and milk by-products by solid-phase microextraction and gas chromatography with atomic emission detection. Talanta, v. 80, p. 1856-1861, 2010.

94. CODEX alimentarius. Submission and evaluation of pesticide residues data for the estimation of maximum residue levels in food and feed. 2002. p. 1-16. Disponível em: < http://www.mhlw.go.jp/shingi/2008/09/dl/s0919-5h.pdf>. Acesso em: 14 jun. 2009.

95. U.S. FOOD AND DRUG ADMINISTRATION. Guidance for Industry: bioanalytical method validation. 2001. p. 1-22. Disponível em:

$<$ http://www.fda.gov/downloads/Drugs/GuidanceComplianceRegulatoryInformation/Guidanc es/ucm070107.pdf>. Acesso em: 14 jun. 2009.

96. GOMES, P. C. F. L.; D'ANDRÉA, É. D.; MENDES, C. B.; SIQUEIRA, M. E. P. B. Determination of benzene, toluene and n-hexane in urine and blood by headspace Solid-Phase Microextration/Gas-Chromatography for the biomonitoring of occupational exposure.

Journal of Brazilian Chemical Society, v. 21, p. 119-126, 2010.

97. SAMPEDRO, M. C.; MARTÍN, O.; LÓPEZ DE ARMENTIA, C.; GOICOLEA, M. A.; RODRÍGUEZ, E.; GÓMEZ DE BALUGERA, Z.; COSTA-MOREIRA, J.; BARRIO, R. J. Solid-phase microextraction for the determination of systemic and non-volatile pesticides in river water using gas chromatography with nitrogen-phosphorous and electron-capture detection. Journal of Chromatography A, v. 893, p. 347-358, 2000. 


\section{PRODUÇÃO CIENTÍFICA DURANTE O MESTRADO}

\section{Artigos submetidos}

Analytica Chimica Acta (Outubro de 2010)

BARLETTA, J. Y., GOMES, P. C. F. L., SANTOS-NETO, A. J., LANÇAS, F. M. Development a new coating of stir bar sorptive extraction, optimization and validation of a method to determine of six pesticides in sugarcane juice.

Journal of Separation Science (Outubro de 2010)

GOMES, P. C. F. L., BARLETTA, J. Y., NAZARIO C. E. D., SANTOS-NETO, A. J., WOlfF, M. A. V., CONEGliAN, C. M. R., UMBUZEIRO, G. A., LANÇAS, F. M. Experimental design optimization of SPME extraction with in situ derivatization for multiresidue analysis of pharmaceuticals in water by GC-MS. 


\section{Resumos publicados em anais de congressos}

BARLETTA, J. Y., GOMES, P. C. F. L., SANTOS-NETO, A. J., LANÇAS, F. M. Desenvolvimento de nova fase para extração por sorção em barra de agitação (SBSE); otimização e validação de um método para a determinação de 6 pesticidas em garapa. In: $4^{\circ}$ Simpósio Brasileiro de Cromatografia e Técnicas Afins (SIMCRO), Campos do Jordão, Brasil, 2010.

GOMES, P. C. F. L., BARLETTA, J. Y., NAZARIO C. E. D., WOLF, A., SANTOS-NETO, A. J., UMBUZEIRO, G. A., LANÇAS, F. M. Planejamento experimental aplicado na otimização da extração por SPME e derivatização in situ na determinação de resíduos de fármacos em água por GC-MS. In: $4^{\circ}$ Simpósio Brasileiro de Cromatografia e Técnicas Afins (SIMCRO), Campos do Jordão, Brasil, 2010.

NAZARIO C. E. D., GOMES, P. C. F. L., BARLETTA, J. Y., SANTOS-NETO, A. J., LANÇAS, F. M. Validação de metodologia na determinação de Nor e Fluoxetina em plasma humano por SPE e HPLC-UV. In: 4 Simpósio Brasileiro de Cromatografia e Técnicas Afins (SIMCRO), Campos do Jordão, Brasil, 2010.

BARLETTA, J. Y., GOMES, P. C. F. L., SANTOS-NETO, A. J., LANÇAS, F. M. Desenvolvimento de uma barra SBSE (stir bar sorptive extraction) lab-made de PDMS/carbono ativado para determinação de resíduo de pesticidas na água. In: X Workshop de Pós-Graduação IQSC/USP, São Carlos, Brasil, 2010. 
BARLETTA, J. Y., GOMES, P. C. F. L., LANÇAS, F. M. Study of pesticide residues and contaminants in sugarcane crops using gas chromatography and mass spectrometry (GCMS). In: $34^{\text {th }}$ International Symposium on Capillary Chromatography (ISCC), Riva Del Garda, Itália, 2010.

BARLETTA, J. Y., GOMES, P. C. F. L., LANÇAS, F. M. Development of new stir bar sorptive extraction (SBSE) coated with polydimethylsiloxane (PDMS) modified with activated carbon to determination of pesticide residues in water. In: III Congresso da Sociedade Brasileira de Espectrometria de Massas, Campinas, Brasil, 2009. 


\section{Participação em cursos}

is Curso - Determinação de Resíduos e Contaminantes em alimentos e fluidos biológicos. Promovido pelo $4^{\mathrm{o}}$ Simpósio Brasileiro de Cromatografia e Técnicas Afins (SIMCRO), Campos do Jordão, 2010.

¿s Curso - Normas de segurança em laboratório químico. Promovido pelo Instituto de Química de São Carlos (IQSC), São Carlos, 2010.

¿ Curso - Técnicas de análise ambiental e segurança alimentar por espectrometria de massas. Promovido pelo III Congresso da Sociedade Brasileira de Espectrometria de Massas, Campinas, 2009. 